\title{
Caracterização do Último Interglacial sensu lato com base em geoquímica e foraminíferos planctônicos na margem continental sudeste brasileira
}

\author{
Dissertação apresentada ao Instituto \\ Oceanográfico da Universidade de São \\ Paulo, como parte dos requisitos para \\ obtenção do título de Mestre em Ciências, \\ Programa de Oceanografia, área de \\ Oceanografia Geológica
}

Orientadora: Prof ${ }^{a}$ Dr $^{a}$ Karen B. Costa

São Paulo 
Universidade de São Paulo

Instituto Oceanográfico

\title{
Caracterização do Último Interglacial sensu lato com base em geoquímica e foraminíferos planctônicos na margem continental sudeste brasileira
}

\author{
Carla Nishizaki
}

Dissertação apresentada ao Instituto Oceanográfico da Universidade de São Paulo, como parte dos requisitos para obtenção do título de Mestre em Ciências, Programa de Oceanografia, área de Oceanografia Geológica

Julgada em ________ por 


\section{Sumário}

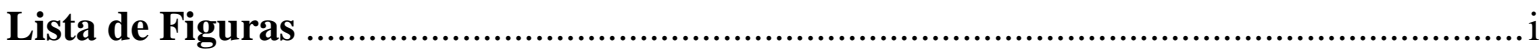

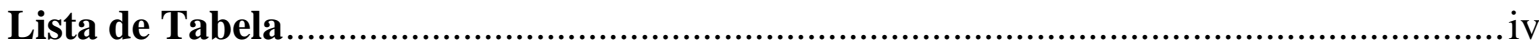

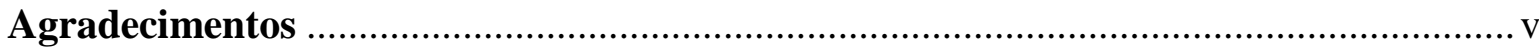

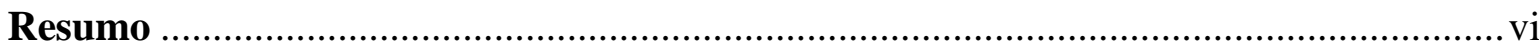

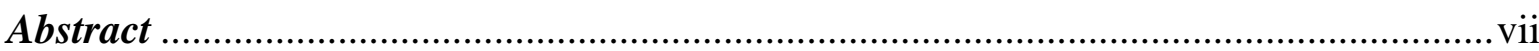

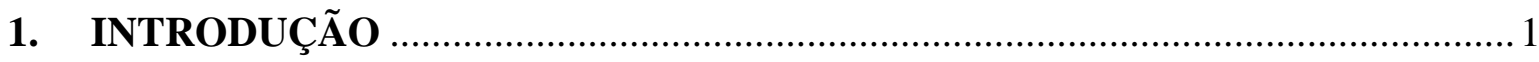

1.1 Panorama do Último Interglacial ...................................................... 1

1.2 Biozoneamento climático e estratigrafia isotópica .................................... 4

1.3 Espécies de foraminíferos planctônicos ................................................. 6

1.4 Histórico dos intervalos MIS 5 e Eemiano............................................ 8

1.5 O Último Interglacial no Hemisfério Norte .............................................. 9

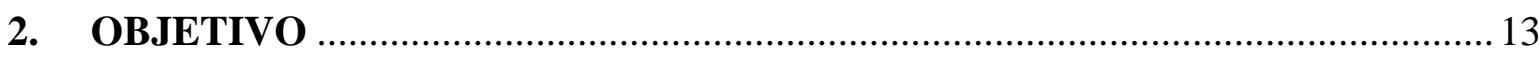

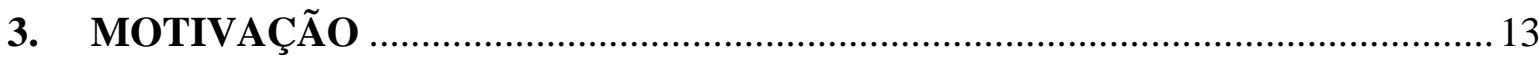

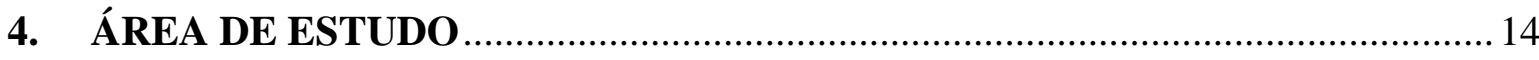

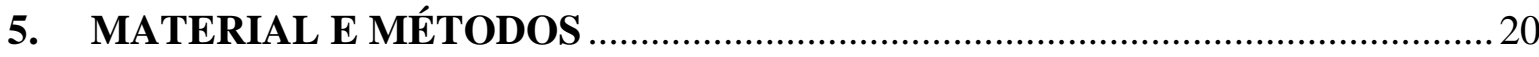

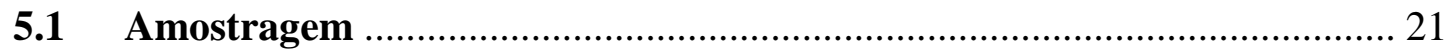

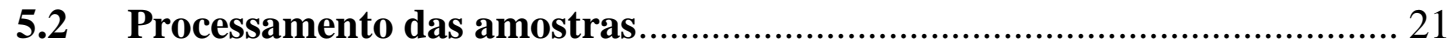

5.3 Identificação dos foraminíferos (KF-12 e KF-18) ................................... 22

5.4 Análise isotópica de oxigênio $\left(\delta^{18} \mathrm{O}\right)(\mathrm{KF}-12$ e KF-18) ................................ 22

5.5 Modelo de Idade (KF-12 e KF-18) ....................................................... 24

5.6 Estimativas de paleotemperatura obtidas pela rede neural artificial (ANN)

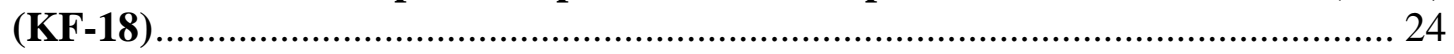

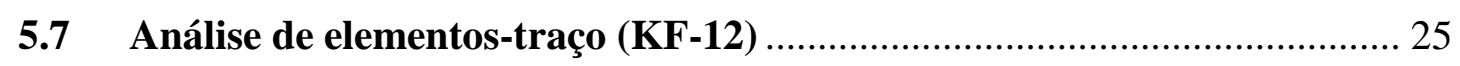

5.8 Teor de carbonato (KF-12 e KF-18) ....................................................... 26

5.9 Aplicação da relação de Rögl e Bolli (1973), adaptada por Vicalvi (1997), em estudos paleoclimáticos e paleoceanográficos............................................... 27

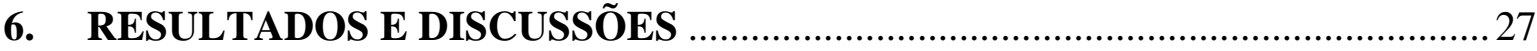

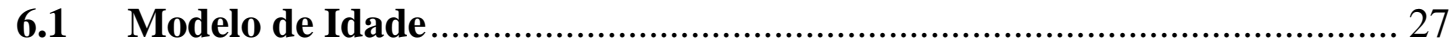

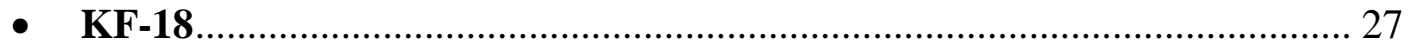

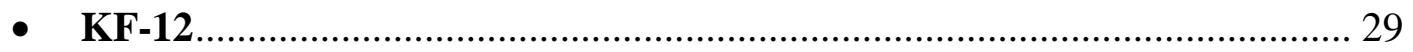

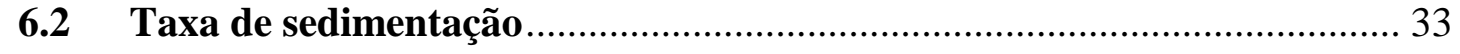

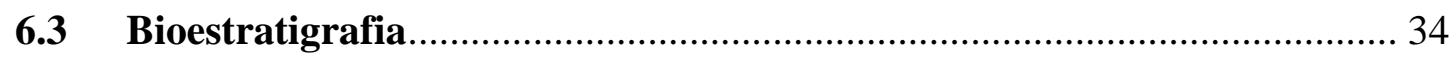




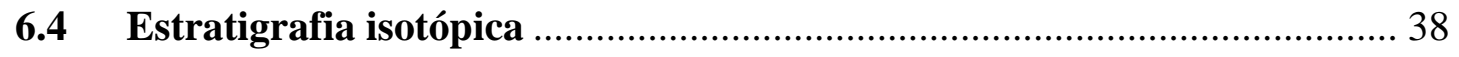

6.5 Isótopos de oxigênio em foraminíferos planctônicos (KF-12 e KF-18) ..... 40

6.6 Curvas climáticas com base na fauna de foraminíferos planctônicos (KF12 e KF-18)

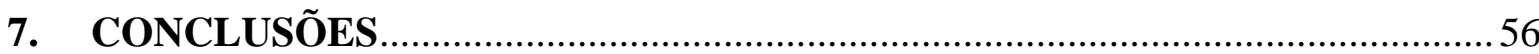

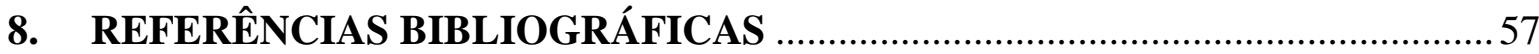




\section{Lista de Figuras}

Figura 1: Estágios isotópicos marinhos (MIS) 6 a 1, seus limites, subdivisões e denominações, de acordo com os dados de Lisiecki e Raymo (2005) e biozoneamento de foraminíferos planctônicos (W a Z) de acordo com Ericson e Wollin (1968). O quadrado vermelho delimita o período estudado neste trabalho.

Figura 2: Registros de fauna e IRD do Atlântico Subpolar comparados ao registro de SST - MD 95-2036 - do MIS 5: (A) Abundância relativa de N. Pachyderma (linha vermelha) e porcentagem de IRD - V29-191 (linha azul) (McManus et al., 1994); (B) SST - MD 95-2036 (linha vermelha) e IRD -NEAP18K (linha azul) (Chapman and Shackleton, 1999). Os eventos frios indicados por C19 a C24 foram originariamente descritos por (McManus et al., 1994) e o C25 e C26 foram identificados mais tarde NEAP18K por Chapman and Shackleton, op. cit) (modificada de Lehman, 2002)....... 11

Figura 3: Topografia de fundo da costa sudeste brasileira (modificada de Mattos, 2006).

Figura 4: Representação esquemática da circulação superficial do Atlântico Sul. SESC: Corrente Sul-Equatorial; NBC: Corrente do Norte do Brasil; BC: Corrente do Brasil; MC: Corrente das Malvinas; AC: Corrente das Agulhas; Angola Gyre: Giro de Angola; Benguela Current: Corrente de Benguela; Antarctic Circumpolar Current: Corrente Circumpolar Antártica. (modificada de Peterson e Stramma, 1991; Signorelli, 2013).. 16

Figura 5: Esquema das principais feições na região ao largo da costa leste-sudeste brasileira. VE: Vórtice de Vitória; CSTE: Vórtice de Cabo de São Tomé; CFE: Vórtice de Cabo Frio; SEC: Corrente Sul Equatorial; IWBC: Corrente de Contorno Oeste Intermediária; TW: Água Tropical; SACW: Água Central do Atlântico Sul; AAIW: Água Intermediária Antártica; NADW: Água Profunda do Atlântico Norte (modificado de Projeto SPOC I-2004).

Figura 6: Circulação atmosférica padrão mundial associada aos centros de baixa e alta pressão, e a Zona de Convergência Intertropical (ITCZ) indicada pela linha espessa roxa: (a) verão austral e (b) verão boreal (extraída de The Atmosphere, 8th edition, Lutgens and Tarbuck, 2001)

Figura 7: Localização dos testemunhos KF-12 e KF-18 na margem continental sudeste brasileira, porção oeste do Atlântico Sul.

Figura 8: Configuração do modelo de idade: a) Curvas isotópicas de oxigênio (LR04 e KF-18) com os pontos de controle utilizados, b) correlação entre as respectivas curvas ilustrando as terminações glaciais e, c) modelo de idade final do KF-18.

Figura 9: Correlação entre as curvas isotópicas LR04, linha vermelha, e a fornecida por Oppo, linha verde. Os pontos de controle das duas curvas estão interligados pelas linhas azuis.

Figura 10: Correlação entre as curvas isotópicas de Oppo, linha vermelha, e do testemunho KF-12, linha verde. Os pontos de controle das duas curvas estão interligados pelas linhas azuis. 
Figura 11: Correlação entre as curvas isotópicas LR04, linha vermelha, e do testemunho KF-12, linha verde. Os pontos de controle das duas curvas estão interligados pelas linhas azuis.

Figura 12: Correlação entre as curvas isotópicas VOSTOK $(\delta \mathrm{D})$, linha vermelha, e do testemunho KF-12 $\left(\delta^{18} \mathrm{O}\right)$, linha verde. Os pontos de controle das duas curvas estão interligados pelas linhas azuis.

Figura 13: Correlação entre as curvas isotópicas NGRIP, linha vermelha, e do testemunho KF-12, linha verde. Os pontos de controle das duas curvas estão interligados pelas linhas azuis.

Figura 14: Correlação entre as curvas isotópicas dos testemunhos KF-18, linha vermelha, e KF-12, linha verde. Os pontos de controle das duas curvas estão interligados pelas linhas azuis.

Figura 15: Modelos de idade para o testemunho KF-12 elaborados com diferentes curvas de referência e seus respectivos valores de regressão.

Figura 16: Taxa de sedimentação dos testemunhos KF-12, linha azul, e KF-18, linha vermelha. Nestas estimativas, a taxa é considerada constante dentro de um mesmo intervalo.

Figura 17: Biozonas $\mathrm{X}$ e seus limites com as biozonas $\mathrm{W}$ e $\mathrm{Y}$ no intervalo estudado... 35

Figura 18: Abundância relativa das espécies que compõem o plexo menardii, do testemunho KF-18.

Figura 19: Biozonas X e seus limites com as biozonas W e Y no intervalo estudado... 37

Figura 20: Abundância relativa das espécies que compõem, em parte, o plexo menardii, do testemunho KF-12.

Figura 21: Curva isotópica de oxigênio em foraminíferos bentônicos ao longo dos testemunhos KF-18 (linha vermelha) e KF-12 (linha azul). Os estágios isotópicos marinhos glaciais, MIS 4 e 6 estão indicados pela área sombreada. As linhas verticais cinzas indicam os limites MIS 4-5 e MIS 5-6. Os subestágios do período interglacial, MIS 5, estão indicados por 5a, 5b, 5c, 5d e 5e.

Figura 22: Curva isotópica de oxigênio em foraminíferos planctônicos ao longo dos testemunhos KF-18, linha vermelha, e KF-12, linha azul. Os estágios isotópicos marinhos glaciais, MIS 4 e 6 estão indicados pelas áreas sombreadas. As linhas verticais cinza indicam os limites MIS 4-5 e MIS 5-6. Os subestágios do período interglacial, MIS 5, estão indicados por 5a, 5b, 5c, 5d e 5e.

Figura 23: Paleotemperaturas obtidas através da rede neural artifical. São temperaturas de verão (linha vermelha), inverno (linha azul) e anual (linha verde) ao longo do testemunho KF-18. Os estágios isotópicos marinhos glaciais, MIS 4 e 6 estão indicados pelas áreas sombreadas. As linhas verticais cinza indicam os limites MIS 4-5 e MIS 5-6. 
Figura 24: Análise comparativa da curva de paleotemperatura anual com a abundância relativa da espécie de foraminífero planctônico Globorotalia inflata dos dois testemunhos. Os estágios isotópicos marinhos glaciais, MIS 4 e 6 estão indicados pelas áreas sombreadas. As linhas verticais cinza indicam os limites MIS 4-5 e MIS 5-6..... 44

Figura 25: Curva paleoclimática do período estudado obtida pela relação de Rögl e Bolli (1973) adaptada por Vicalvi (1997). 45

Figura 26: Estimativas da variação do nível do mar ao longo do intervalo de 60 a $130 \mathrm{ka}$ no testemunho KF-18. Os estágios isotópicos marinhos glaciais, MIS 4 e 6 estão indicados pela área sombreada. As linhas verticais cinzas indicam os limites MIS 4-5 e MIS 5-6

Figura 27: Variação do nível do mar e razão Fe/Ca no testemunho KF-18. Os estágios isotópicos marinhos glaciais, MIS 4 e 6 estão indicados pela área sombreada. As linhas verticais cinzas indicam os limites MIS 4-5 e MIS 5-6.

Figura 28: O teor de carbonato (\%) ao longo dos testemunhos KF-18 (linha vermelha) e KF-12 (linha azul). Os estágios isotópicos marinhos glaciais, MIS 4 e 6 estão separados pelo fundo cinza claro. A linha vertical cinza indica os limites MIS 4-5 e MIS 5-6.... 49

Figura 29: Dados obtidos do testemunho KF-12 e insolação de verão. De cima para baixo: Razão isotópica de oxigênio em foraminíferos bentônicos $\left(\delta^{18} 0\right)$ (linha azul); $\mathrm{CaCO}_{3}(\%)$ (linha verde); razão Fe/Ca (linha vinho); razão Ti/Ca (linha laranja) e insolação de verão $25^{\circ} \mathrm{S}\left(\mathrm{W} / \mathrm{m}^{2}\right)$ (linha roxa).

Figura 30: Análise espectral dos registros de Ti/Ca do KF-12 . O único pico que ultrapassa o nível de $99 \%$ de confiância representa o período (inverso da frequência) de $22 \mathrm{ka}$, similar ao período de precessão.

Figura 31: Curvas paleoclimáticas obtidas por diferentes proxies. De cima para baixo: $\delta^{18} \mathrm{O}$ (planctônico) (\%o), Razão Rögl e Bolli, SST $\left({ }^{\circ} \mathrm{C}\right)$, G. ruber $(\%)$, N. incompta $(\%)$, G. Inflata $(\%)$.....

Figura 32: Eventos frios $(C s)$ indicados por setas nas curvas paleoclimáticas do testemunho KF-18. De cima para baixo: G. inflata, $N$, incompta, G. ruber (TT) (lado esquerdo) e $\operatorname{SST}\left({ }^{\circ} \mathrm{C}\right)$ (lado direito).

Figura 33: Comparação do proxy de volume de gelo $\left(\delta^{18} \mathrm{O}\right)$ nos testemunhos KF-12 e KF-18 com os testemunhos de gelo NGRIP $\left(\delta^{18} \mathrm{O}\right)$ e VOSTOK $(\delta \mathrm{D})$. As marcações "GIS" referem-se aos subestágios interestadias deste testemunho. 


\section{Lista de Tabela}

Tabela 1: Alguns testemunhos com dados do Último Interglacial (s.s.) nos oceanos

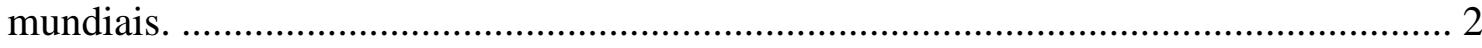

Tabela 2: Lista das espécies utilizadas para estimar paleotemperaturas através das redes

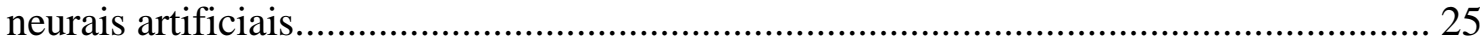




\section{Agradecimentos}

À minha orientadora $\operatorname{prof}^{a}$. Dr ${ }^{\mathrm{a}}$. Karen Badaraco Costa e ao prof $^{\mathrm{o}}$. Dro . Felipe Antônio de Lima Toledo por seus ensinamentos e pela imensa paciência.

À equipe do LaPAS, pela ajuda e companheirismo. Obrigada Ana Cláudia, Juliana, Sayuri, Louise, Fabiana, Fabian (Chileno), Mariane, Mariana, Sarah, Larissa, Heliane, Renan, Guilherme (Chapolin), Everton (Kotarski), Marcus e Edmundo.

Às meninas da Secretaria de Pós-graduação por aguentarem minhas atrapalhadas,

Às meninas da sala da pós: Núria, Naira, Thaisa, Cíntia, Renata e Daniele.

Aos amigos da Turma V, a melhor turma do mundo: às Dad's (Ju, Carine, Mari, Nati, Tathi e Patty), ao Danilo, Maca, Cunhado, César, Bixão, Barbie, Betinho, Pinguim, Escadinha, Beraba, Bahia, Sushi e Camila.

A todos meus veteranos e bixos, aos meus professores e aos funcionários do IOUSP que fizeram parte do meu caminho, e à Didi e ao Betão por terem sempre um pão de queijo quentinho pra mim no momento da fome.

A todos os funcionários e parceiros da FUNDESPA, principalemente ao Raul, Tiago (Kalango), Chiquinho e Prof. Ilson.

Às Lesmas Aquáticas Futsal Arte e aos técnicos que aperfeiçoaram nosso time.

À Locus Danças - Ju, Carlos, Erika, Maçã, Forró 5 e todos os dançarinos.

Aos Angels, minha mais nova família e ao Centro de Dança Jaime Arôxa e todos seus frequentadores e professores.

Aos meus amigos do Centro de Línguas e do Kumon, principalmente às senseis.

À minha família a quem devo minha vida: Erica, mãe, Sidney, vó Lolita, e a todos meus parentes de Guararema, São Paulo, Minas Gerais, Bahia e Japão.

Aos amigos Alexandre Salaroli, Tom, Fabrício, Adriano que também me ajudaram de alguma forma.

À $\mathrm{CNPq}$ e à Petrobras pelo suporte financeiro e logístico que permitiu a realização desse trabalho.

Saibam que meu amor e gratidão por todos vocês é imensurável! 


\section{Resumo}

A partir de registros de dois testemunhos, KF-12 localizado na Bacia de Campos e KF18 na Bacia de Santos, ambos na margem continental sudeste brasileira, realizou-se a caracterização do Último Interglacial s.l, de 60 a 130 ka atrás. Primeiramente, estabeleceu-se um Modelo de Idade para o KF-12 tendo como referência a curva do KF18 que já possuía uma boa cronologia. Com a curva do plexo Menardii, determinou-se as biozonas de Ericson e Wollin (1968) e constatou-se a diferença existente entre os limites da Zona $\mathrm{X}$ e do estágio isotópico marinho 5. Os limites inferidos para a biozona $\mathrm{X}$ foram 135,6 ka AP (limite inferior), e 82,3 ka AP (limite superior) para o testemunho KF-18 e; para o KF-12, 133,5 ka AP (limite inferior) a 88,4 ka AP (limite superior). O estágio isotópico marinho (MIS) 5, na região de estudo, compreende o intervalo entre 129,5 e 71,1 ka AP, em ambos os testemunhos. Também foram utilizados outros dados, tais como, razão isotópica em foraminífero planctônico, fauna, teor de carbonato, razão Ti/Ca e Fe/Ca através dos quais pôde-se estimar paleotemperaturas da superfície do mar, aporte de material terrígeno de acordo com as condições de umidade/seca na região de estudo durante o intervalo de interesse. Por fim, verificou-se que tanto os dados isotópicos de oxigênio $\left(\delta^{18} \mathrm{O}\right)$ do testemunho de gelo da Groenlândia (NGRIP) quanto os da razão de deutério da Antártica variaram de forma semelhante aos $\delta^{18} \mathrm{O}$ de foraminíferos bentônicos do KF-12 e KF-18, confirmando o sincronismo de tais registros.

Palavras chave: isótopo de oxigênio, testemunho à pistão, paleoclima. 


\section{Abstract}

The Last Interglacial Cycle s.l. (between 60 and $130 \mathrm{ky}$ ago) was characterized through registers of two diferent cores in the brazilian continental shelf, KF-12, located in Campos Basin and KF-18, located in Santos Basin. First an "age model" was established for KF-12, from the KF-18 curve that already had a good cronology. Using Menardii group curve, the biozones from Ericson e Wollin (1968) were established and a diference between the $\mathrm{X}$ Zone and the marine isotope stage 5 edges was noticed.The infered limits for X biozone were 35,6 ky BP (inferior limit) and 82,3 ky BP (superior limit) for KF-18 core and 133,5 and 88,4 ky BP for KF-12 core. In both cores the marine isotope stage (MIS) 5 was between 129,5 and 71,1 ky BP. Other data were also used in the study, such as isotope ratio in planktonic foraminifera, fauna, carbonate content, $\mathrm{Ti} / \mathrm{Ca}$ and $\mathrm{Fe} / \mathrm{Ca}$ ratios whereby humidity/dry conditions and continental runoff were infered. Finally, the correlation between $\delta^{18} \mathrm{O}$ ice core (NGRIP) and $\delta \mathrm{D}$ ice core (VOSTOK) and $\delta 180$ benthic from KF-12 and KF-18 core were synchronous.

Key words: oxygen isotope, piston core, paleoclimate. 


\section{INTRODUÇÃO}

A grande maioria das previsões modernas para o clima futuro e dos possíveis impactos ambientais tem sido efetuada com base em modelos computacionais que simulam sistemas complexos da Terra (por exemplo: Manabe e Stouffer, 1994; Kutzbach apud Ruddiman e Wright Jr, 1987). Embora tais modelos tenham sido bem sucedidos em diversas áreas, e estão melhorando na precisão e confiabilidade, ainda possuem grandes incertezas e margens de erro, especialmente quando utilizados para previsões futuras. Estas incertezas podem ser reduzidas com a utilização de dados obtidos através da análise do registro sedimentar marinho do Quaternário. A assembleia de foraminíferos encontrada nos sedimentos marinhos reflete as variações ambientais e pode indicar períodos da história da Terra mais quentes do que hoje, como o Último Interglacial sensu stricto. Assim, o estudo do passado permite-nos uma melhor avaliação dos efeitos ambientais associados às mudanças climáticas que podem ocorrer no futuro.

\subsection{Panorama do Último Interglacial}

O período abrangido no presente estudo, considerado o Último Interglacial antes do presente, é chamado também de estágio isotópico marinho 5 (MIS 5 - Marine Isotope Stage 5). O MIS 5, por sua vez, foi dividido em 5 subestágios que podem ser representados por números (1 - 5) ou letras (a - e) (Lisiecki e Raymo, 2005) (Figura 1). O subestágio onde foram registradas as mais altas temperaturas é o MIS 5e que ocorreu no início do MIS 5, e este subestágio é comumente descrito como Último Interglacial sensu strictu ou Último Máximo Interglacial. Através de datações U/Th em recifes de corais constatou-se que o MIS 5e compreende o intervalo entre 116 e 130 mil anos (ka). O testemunho de gelo Vostok (Antártica) detalha bem o Último Interglacial. A temperatura alcançou níveis atuais há 132 ka e continuou aumentando nos seguintes 2 ka. Em registros com menor resolução, o Último Interglacial é comumente tratado como o MIS 5 inteiro.

O representante do MIS 5e em áreas continentais é chamado Eemiano. Este evento iniciou-se há 127 ka com sucessão das ervas por Betula, Pinus, Ulmus e Quercus após o desaparecimento do permafrost, caracterizando as florestas mistas da época na Europa. Em 115 ka antes do presente (AP), a vegetação aberta substituiu as florestas no noroeste da Europa e a proporção de coníferas aumentou amplamente no Sul. Ao 
mesmo tempo, a temperatura do ar deste período, inferida através das bolhas de ar no testemunho de gelo Vostok, caiu bruscamente (Aaby e Tauber, 1995; Field et al., 1994; Guiot et al., 1989; Woillard, 1978).

Tabela 1: Alguns testemunhos com dados do Último Interglacial (s.s.) nos oceanos mundiais.

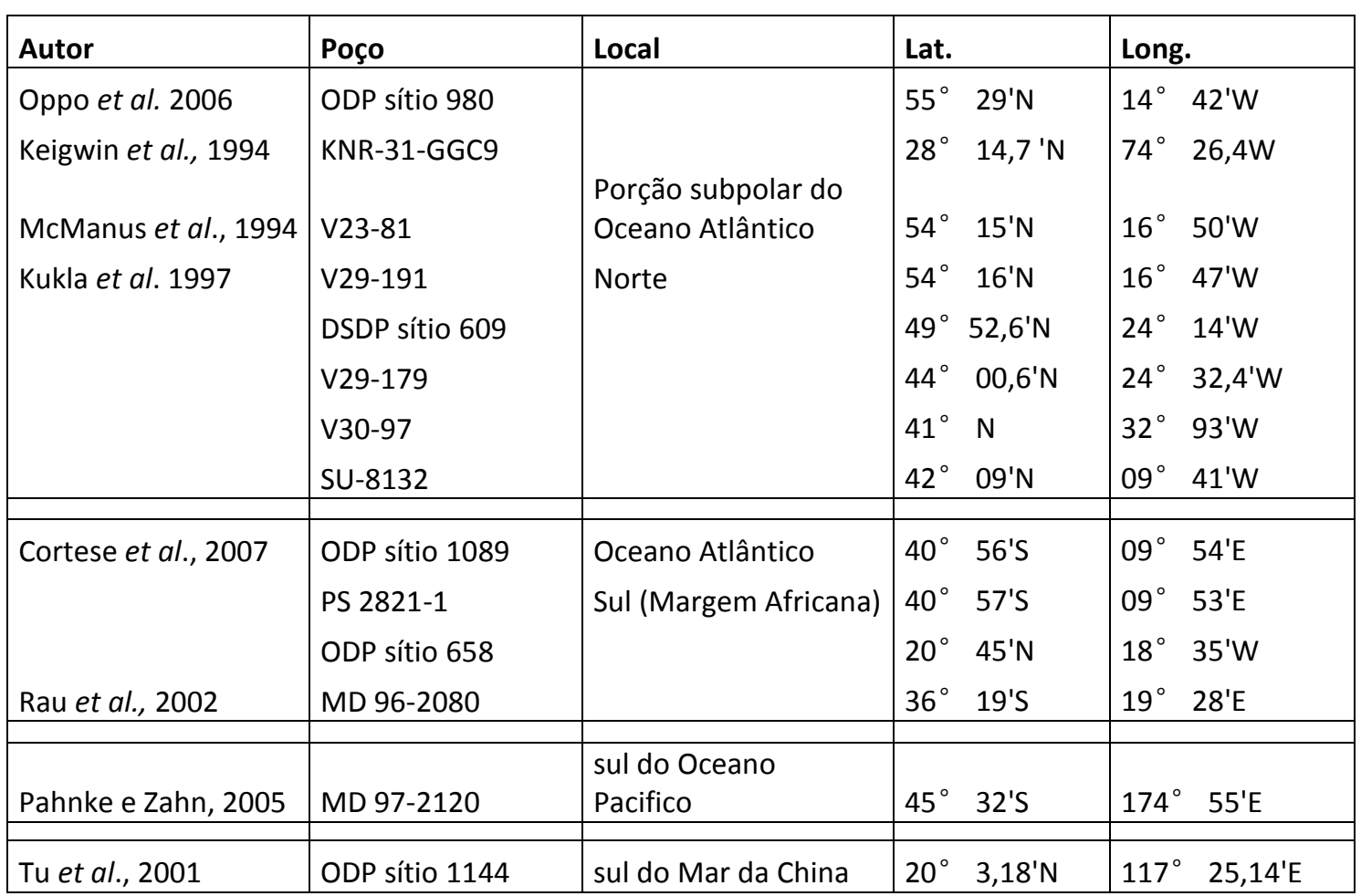

Dentre os trabalhos citados na tabela 1, alguns fornecem um cenário amplo do registro do MIS 5e em diferentes oceanos. Cortese et al. (2007) registraram variações de temperatura superficial da água do mar (SST) em escala milenar com base em radiolários e verificaram que as variações de SST observadas no testemunho ODP 1089 são similares ao registro de temperatura atmosférica do testemunho de gelo Vostok (Antártica), de testemunhos marinhos do Oceano Austral (MD97-2120 e MD96-2080) e do Atlântico Norte (ODP 980); indicando que a variabilidade climática que separam estas áreas tão distantes (continente antártico, Atlântico Norte temperado e Atlântico Sul e Pacífico Sul subantártico) parece estar fortemente relacionada e covaria em escalas milenares. Tu et al., (2001) realizaram análises quantitativas em foraminíferos planctônicos e isótopos de oxigênio em sedimentos de alta resolução no nordeste do Mar da China (ODP 184), observaram um evento abrupto de resfriamento da SST de $\sim 7^{\circ} \mathrm{C}$ e verificaram que este evento é comparável com outros do oeste da Europa e do norte do Atlântico Norte, porém, com maior intensidade. Oppo et al. (2006) efetuaram 
análise detalhadas de assembleias de foraminíferos planctônicos, isótopos de oxigênio em foraminíferos bentônicos e em sedimentos litogênicos para avaliar a estabilidade e progressão climática do MIS 5 no Atlântico Norte subpolar (ODP 980). Estes autores verificaram que uma instabilidade climática seguiu o pico do MIS 5e com seis eventos de resfriamento abruptos bem documentados (C24 a C19).

Há 107 ka, as condições interglaciais no Sudoeste da Europa permaneceram inalteradas por crescimento de gelo até o fim do MIS $5 \mathrm{~d}$ quando as florestas desapereceram abruptamente e águas frias invadiram o Atlântico Norte Central. Kukla et al. (2002a) através de resultados de modelo (Clement et al., 1999) mostraram que o crescimento de gelo global no MIS 5d foi contemporâneo com o aumento da frequência de anomalias quentes do El Niño no Pacífico Tropical Oeste.

Nos trópicos, as temperaturas da superfície do mar eram relativamente altas durante os períodos de aumento de gelo (Kukla et al., 2002a). A mudança no volume de gelo global ocorreu após o aumento da temperatura média do planeta. É importante salientar que a ligação entre MIS e SST local ou outras mudanças paleoambientais na Terra não são diretas e nem necessariamente sincrônicas.

Uma sequência contínua dos últimos 420 ka está presente no testemunho de gelo Vostok da Antártica, permitindo comparações do intervalo Holoceno com outros quatro intervalos interglaciais anteriores. Este testemunho fornece um registro detalhado e confiável das temperaturas locais para o Último Interglacial s.s.. As paleotemperaturas, reconstruídas a partir de dados de deutério, aumentaram gradualmente cerca de $12^{\circ} \mathrm{C}$ depois do máximo glacial a 138 ka atrás. Os valores atuais de temperatura foram atingidos em $\sim 132 \mathrm{ka}$ e a temperatura permaneceu alta ou mais alta pelos próximos $13 \mathrm{ka}$. No início do interglacial subsequente, entre 130 e $127 \mathrm{ka}$ atrás, a temperatura era $3^{\circ} \mathrm{C}$ mais elevada do que hoje. Então, houve uma lenta diminuição da temperatura até 115-117 ka, quando ocorreu um declínio abrupto. Nos 10 ka seguintes, a temperatura diminuiu $7^{\circ} \mathrm{C}$ (Petit et al. 1999).

O testemunho KF-12 utilizado neste trabalho foi estudado previamente por Tokutake (2005) para a análise de nanofósseis calcários e da razão isotópica de oxigênio $\left(\delta^{18} \mathrm{O}\right)$ em foraminíferos planctônicos e, por Santarosa (2007) e Marins (2009) para a quantificação de algumas espécies de foraminíferos planctônicos relevantes ao estudo paleoclimático e bioestratigráfico. Tokutake (2005) e Santarosa (2007) utilizaram amostras em intervalos de $50 \mathrm{~cm}$, Marins (2009) utilizou amostras a cada $30 \mathrm{~cm} \mathrm{em}$ 
média. Santarosa (2007) estabeleceu o zoneamento bioestratigráfico do testemunho e identificou os limites das biozonas W, X, Y e Z; Marins (2009) ainda subdividiu as biozonas quando possível.

\subsection{Biozoneamento climático e estratigrafia isotópica}

Um dos critérios mais utilizados para subdividir o Quaternário superior é o baseado na presença ou ausência de determinadas espécies de foraminíferos planctônicos, como reflexo das variações climáticas. O zoneamento mais comumente utilizado é fundamentado no foraminífero planctônico Globorotalia menardii e foi estabelecido por Ericson e Wollin (1968). Este biozoneamento, para os últimos 150 mil anos, constitui-se de quatro biozonas identificadas com letras do alfabeto no sentido inverso - de W a Z - onde Z é a biozona mais nova e corresponde ao Holoceno e W a mais antiga, correspondendo ao Penúltimo Glacial (Figura 1).

A estratigrafia do Quaternário é baseada no registro de isótopos de oxigênio em foraminíferos bentônicos (Shackleton, 1967; Pisias et al.,1984), os quais estão associados às variações sucessivas no volume de gelo global e, consequentemente, à oscilação do nível do mar. Um intervalo interglacial é normalmente considerado como um intervalo de tempo geológico onde as principais feições da circulação atmosférica e oceânica podem ser comparáveis com o período interglacial (quente) atual, denominado Holoceno (Fairbridge, 1972).

A abundância relativa do foraminífero planctônico Globorotalia menardii sofre oscilações no Oceano Atlântico em sincronia com os ciclos glaciais (Schott (1935) apud Ericson e Wollin (1968)). Outros autores também reportaram que esta espécie é rara ou ausente no Atlântico durante os períodos glaciais, reaparecendo durante os intervalos interglaciais (Martinez et al., 2007; Berger \& Vincent, 1986; Ericson e Wollin 1956, 1968). As flutuações na abundância relativa de G. menardii fornecem um valioso instrumento para o estabelecimento estratigráfico do Pleistoceno em um primeiro momento (Martinez et al., op cit; Hall \& Chan, 2004). Entretanto, estudos mais recentes têm evidenciado outros mecanismos, especialmente de caráter oceanográfico, que parecem controlar as populações de G. menardii no oceano Atlântico.

A partir do início da década de 80 , a estratigrafia isotópica consolidou-se com estudos de Shackleton e Hall (1984), Curry e Lohmann (1982) e Ruddiman e McIntyre, (1979). Com o estabelecimento de uma estratigrafia isotópica de alta resolução e a 
consequente identificação dos Estágios Isotópicos Marinhos (MIS) (Figura 1) nota-se que a simples ausência (ou a diminuição abrupta da abundância) deste grupo de organismos não indica, efetivamente, os períodos glaciais. Uma das hipóteses propõe que a diminuição do transporte de águas superficiais provenientes do Oceano Índico através do desprendimento de vórtices na Retroflexão das Agulhas, ou Transporte das Agulhas (Agulhas Leakage), para o Atlântico mediado atualmente pela corrente das Agulhas impede a proliferação das populações de G. menardii neste oceano. (Caley et al, 2012; Berger e Wefer, 1996). Esta proliferação ocorre durante os intervalos interglaciais através do transporte das águas superficiais quentes e salinas do oceano Índico para o Atlântico. Durante os períodos glaciais, com a diminuição do Transporte das Agulhas, o oceano Atlântico sofre uma queda significativa nas populações de $G$. menardii, diminuindo assim, sua aparição no registro sedimentar nestes intervalos. Ultimamente, uma grande variedade de modelos da circulação oceânica e dados geológicos tem demonstrado que as características oceanográficas nas altas latitudes exercem controle substancial sobre a hidrografia (Harper, 2000; Kiefer et al., 2006) e na formação da termoclina em baixas latitudes (Marinov et al., 2006; Pena et al., 2008; Sarmiento et al., 2004; Spero e Lea, 2002; Toggweiler et al., 1991). Nos oceanos atuais, a maioria da produção biológica em baixas e médias latitudes é controlada pelas propriedades das águas superficiais da zona sub-Antártica do Oceano Austral devido ao alcance global da AAIW e da SAMW (sub-Antarctic Mode Water) que são formadas nesta região (Marinov et al., 2006; Palter et al., 2010; Sarmiento et al., 2004).

A ventilação da termoclina em baixas latitudes é amplamente governada pela concentração de gases dissolvidos destas águas durante sua formação, nas altas latitudes (Sarmiento et al., 2004; Toggweiler et al., 1991). Segundo esses autores, o colapso nas populações glaciais no Atlântico das espécies que compõem o plexo menardii foi induzida por uma termoclina mais ventilada do que é atualmente. 


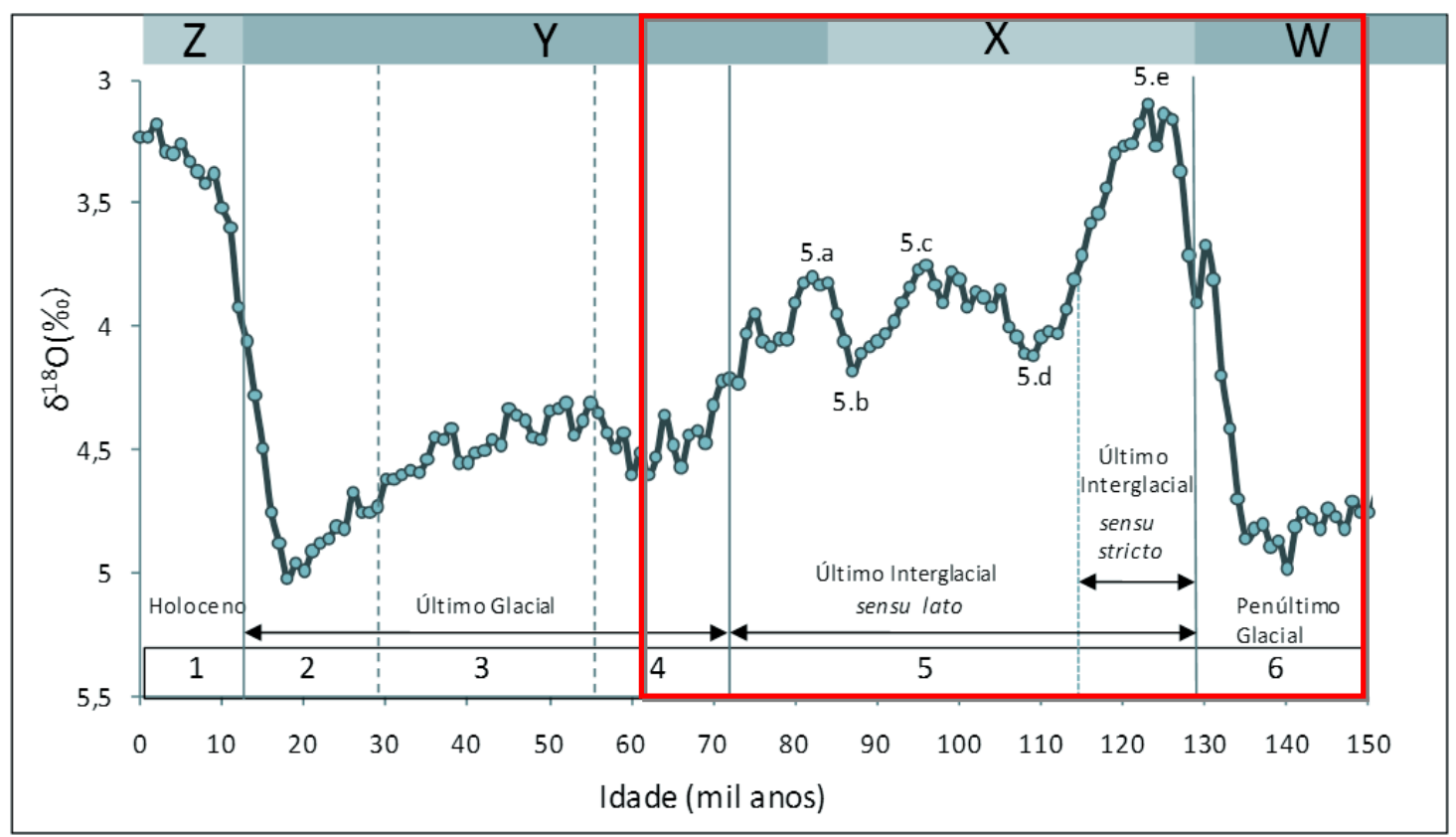

Figura 1: Estágios isotópicos marinhos (MIS) 6 a 1, seus limites, subdivisões e denominações, de acordo com os dados de Lisiecki e Raymo (2005) e biozoneamento de foraminíferos planctônicos (W a Z) de acordo com Ericson e Wollin (1968). O quadrado vermelho delimita o período estudado neste trabalho.

\subsection{Espécies de foraminíferos planctônicos}

A seguir estão descritas as espécies de foraminíferos planctônicos relevantes a este estudo:

\section{- Indicadores de águas frias}

Globigerina bulloides: Globigerina bulloides é uma típica espécie transicional a polar e ocorre em altas abundâncias nessas regiões. Além disso, esta espécie caracteriza situações de ressurgência sem levar em conta sua posição geográfica. Sua composição isotópica estável é incomum, já que é enriquecida em $\delta^{13} \mathrm{C}$, enquanto que a maioria das outras espécies é empobrecida (Ganssen, 1983; Ganssen, 1983; Auras et al., 1988). É encontrada na coluna de água acima de $400 \mathrm{~m}$, mas, principalmente, acima da termoclina. Entretanto, não é restrita à zona fótica em águas mais frias, onde a maioria das espécies não-espinhosas é dominante (Hemleben et al., 1989).

Turborotalita quinqueloba: É uma espécie comumente encontrada em massas de água transicionais e polares. É um bom indicador de salinidade e exibe seu máximo de 
abundância quando a salinidade atinge 35, preferindo ambientes com pouca variação. $T$. quinqueloba prefere ambientes com pouca variabilidade vertical, como as observadas no inverno. Sua ocorrência em baixas latitudes não está associada a ambientes de ressurgência (Hilbrecth, 1996).

Globorotalia inflata: é uma espécie que ocorre comumente em ambientes transicionais entre as massas de água polares e subtropicais. Exibe relação com a temperatura superficial e salinidade apresentando vasta tolerância em relação a estes parâmetros. Entretanto $G$. inflata exibe uma preferência por massas de água com pouca variação sazonal na salinidade e, apresenta uma boa relação com as condições estruturais da coluna de água observadas durante o inverno (Hilbrecth, 1996). O valor desta espécie na interpretação climática é complementar a das espécies menardiformes (Rogl e Bolli, 1973).

Neogloboquadrina incompta: é uma espécie que havia sido classificada previamente como Neogloboquadrina pachyderma dextral. Inclusive, a variação temporal no sentido de enrolamento de $N$. pachyderma era interpretada como resultado de variações de parâmetros ambientais (por ex.temperatura). No entanto, estudos genéticos recentes revelaram que estes dois morfotipos com direções opostas de enrolamento apresentam padrões genéticos distintos (Darling et al., 2000; Bauch et al., 2003). Baseado então nas diferenças genéticas e distribuição geográfica destes morfotipos, Darling et al. (2006) sugeriu que o morfotipo dextral deveria ser reconhecido como Neogloboquadrina incompta (Cifelli). Nos oceanos atuais, o genótipo sinistral de $N$. pachyderma domina os ambientes polares de altas latitudes enquanto o dextral é encontrado mais frequentemente em zonas temperadas $\left(10-14^{\circ} \mathrm{C}\right.$ ) (Bé e Tolderlund, 1971; Reynolds e Thunell, 1985; Kuroyanagi e Kawahata, 2004), habitando os 100 primeiros metros da coluna de água (Schiebel et al., 2001). Embora atualmente não se saiba se esta espécie possui simbiontes, em outras espécies do gênero Neogloboquadrinids não há evidência mostrando a presença de algas simbiontes hospedadas (Ortiz et al., 1995).

\section{- Indicadores de Águas Quentes}

Globigerinoides ruber: É uma espécie que exibe dois morfotipos, pink e white, e ocupa abundantemente os ambientes tropicais e subtropicais, apresentando uma clara relação 
com a temperatura superficial marinha. Ambos os morfótipos exibem um claro padrão de distribuição na direção dos valores mais elevados de temperatura superficial marinha. Globigerinoides ruber (pink) exibe uma relação que é notadamente diferente de $G$. ruber (white), sugerindo adaptações distintamente diferentes: o morfotipo pink prefere ambientes mais quentes enquanto que a white ocupa preferencialmente as regiões subtropicais (Hilbrecth, 1996).

Globigerinoides sacculifer: é uma espécie abundante nas massas de água tropicais que vive na zona fótica, exibe um ciclo reprodutivo lunar e é mais variável na morfologia da câmara terminal. G. sacculifer é uma espécie que exibe maior tolerância com as condições de verão e prefere massas de água com baixa sazonalidade na temperatura superficial e no gradiente vertical de temperatura, não sendo um bom indicador de salinidade. Em seu estágio terminal, esta espécie desenvolve uma câmara distinta, em forma de "saco".

Espécies menardiformes: Estão incluídas neste grupo: G. cultrata, G. menardii, $G$. tumida tumida, e G. tumida flexuosa. Todas estas espécies são típicas de águas tropicais/subtropicais, sendo que G. tumida está confinada as áreas mais quentes. Ericson e Wollin (1968) utilizaram este grupo de espécies para a formulação de sua conhecida curva climatológica. Exibe uma relação com gradientes verticais de temperatura e estratificação assim como com a baixa densidade superficial do hábitat desta espécie.

\subsection{Histórico dos intervalos MIS 5 e Eemiano}

A primeira evidência do período quente que os geólogos chamaram de estágio isotópico marinho 5 foi encontrada nos sedimentos europeus por Harting, em 1852, o qual nomeou o período de Eemiano ao descrever uma unidade estratigráfica das áreas de Amsterdam e Amersfoort caracterizada por espécies de moluscos de águas quentes e fósseis de diatomáceas luistanas e mediterrâneas (Bosch, et al., 2000). Em seguida foi conduzida a investigação em Denmark associando o período as amplas florestas de Quercus, Corylus e Carpinus (Jessen e Milthers, 1928). Nos anos 60, Zagwijn (1961) constatou uma expansão similar de florestas decíduas na Alemanha. O MIS 5 foi o último interglacial ocorrido a cerca de 100 ka atrás. 
A partir da correlação entre dados isotópicos bentônicos e de pólen (Turon, 1984), além da contagem das camadas laminadas anualmente na sequência de Bispingen, norte da Alemanha (Müller, 1974), chegou-se a duração do Eemiano de 126 a 115 ka atrás. No entanto, no nordeste da França, o Eemiano não é o equivalente terrestre do MIS 5e, mas contém o MIS 5e inteiro e ainda parte do MIS 5d. Nesta região, o Eemiano ocorreu entre 130 e 108 ka, período de 22.000 anos (Kukla et al., 1997, 2002b; Kukla, 2000). Já na Península Ibérica, o Eemiano durou menos tempo, 16.000 anos, de 126 a 110 ka atrás (Shackleton et al., 2002, 2003; Sánchez Goñi et al., 2005). O Último Interglacial sensu lato (nomenclatura por LIGA Members, 1991) foi um período de mínimo volume de gelo que durou de 130 a 75 ka atrás.

No oeste da Europa, o período mais quente foi seguido por dois intervalos de clima temperado (interglacial) conhecidos por St. Germain I e St. Germain II separados por duas fases muito frias: Mélisey I e Mélisey II (Woillard, 1978). O período de floresta St. Germain I foi interrompido por um evento frio de escala suborbital chamado Montaigu (Reille et al., 1992).

\subsection{O Último Interglacial no Hemisfério Norte}

Pressume-se que uma mudança bem difundida nas condições de contorno da superfície oceânica pode influenciar o clima terrestre em grande escala, principalmente na Europa. A partir da análise de sedimentos da Elevação de Bermuda no lado oeste do Atlântico Norte subtropical, Lehman et al. (2002) encontraram uma série de eventos abruptos de resfriamento dentro do MIS 5 correlacionáveis a evidências de aumento no fornecimento de banquisas de gelo nas latitudes subpolares e redução da formação da massa de água profunda do Atlântico Norte - NADW (North Atlantic Deep Water). Os autores, através da correlação da temperatura do oceano subtropical com o registro de pólen de Grande Pile na França, sugeriram que o período mais quente do Eemiano europeu terminou repentinamente em resposta às mudanças oceanográficas. Também identificaram anomalias quentes em torno de 112 e 121 ka atrás, associadas a concentrações altas de alquenona, o que não é comum, e podem ter relação com os eventos vulcânicos documentados por Wästegard e Rasmussen (2001). O fim do subestágio $5 \mathrm{e}$ com o contínuo aumento do $\delta^{18} \mathrm{O}$ planctônico seguindo o resfriamento repentino foi atribuído ao aumento do volume de gelo inferido pelo $\delta^{18} \mathrm{O}$ bentônico. A temperatura da superfície do mar (SST) média encontrada foi $22,6^{\circ} \mathrm{C}$ durante a parte 
mais quente do MIS 5e simular ao valor médio anual na mesma região atualmente $\left(22,8^{\circ} \mathrm{C}\right.$ a $0 \mathrm{~m}$; Antonov et al., 1998). A SST média do Holoceno tardio estimada a partir de análise de sedimentos de box cores coletados nas proximidades é cerca de $1^{\circ} \mathrm{C}$ menor que a do MIS 5e (Sachs e Lehman, 1999). Para os subestágios interestadiais 5c e 5a, as temperaturas da superfície do mar durante os períodos mais quentes foram $21^{\circ} \mathrm{C} \mathrm{e}$ $20^{\circ} \mathrm{C}$, respectivamente. Estes subestágios quentes do MIS 5 foram marcados por episódios breves de resfriamento de 2 a $5^{\circ} \mathrm{C}$ e com duração de várias centenas de anos. Ao fim do MIS 5e houve um resfriamento repentino seguido por um significante aquecimento da superfície oceânica sustentado pelo aumento de gelo que resultou no MIS 5d. Ruddiman e McIntyre (1979) sugerem que a combinação transitiva do aquecimento oceânico e um resfriamento continental podem ter promovido o crescimento do gelo no Hemisfério Norte.

Ruddiman et al. (1984) reconhece que, em latitudes médias do Atlântico Norte, o aquecimento oceânico segue o máximo valor isotópico do MIS 5e. No entanto, o Último Interglacial no nordeste da Europa (Eeminano) e em outras partes do mundo foi, até os anos 2000, considerado sincrônico com e limitado pelo MIS 5e (um intervalo de aproximadamente $10 \mathrm{ka}$ ) (Shackleton, 2002; Turner, 2002).

McManus et al. (2002), Oppo et al. (2001) e Chapman e Shackleton (1999) confirmaram o atraso do aquecimento da superfície do mar e indicaram que o declínio desse aquecimento ocorreu com uma série de eventos de resfriamento milenares abruptos.

Os eventos frios durante o Último Interglacial sensu lato foram nomeados de C26 a C19 (Lehman et al., 2002; Oppo, 2001, 2006) (Figura 2). São resfriamentos inesperados e breves, caracterizados por desvios de um regime climático predominantemente quente. Covariância entre as séries de SST e IRD (ice rafted debris) (Figura 2) indicaram uma resposta oceânica à forçante gelo que extendeu-se das latitudes subpolares até as subtropicais. Segundo Weertman (1964) e Oerlemans (1993), a dimuição das SSTs promovendo aporte de gelo é improvável devido ao relativamente longo período de resposta da forçante climatológica. O mecanismo mais provável de ampliação dos efeitos de resfriamento do aporte e derretimento do gelo é o enfraquecimento da formação de água profunda. 
(A)
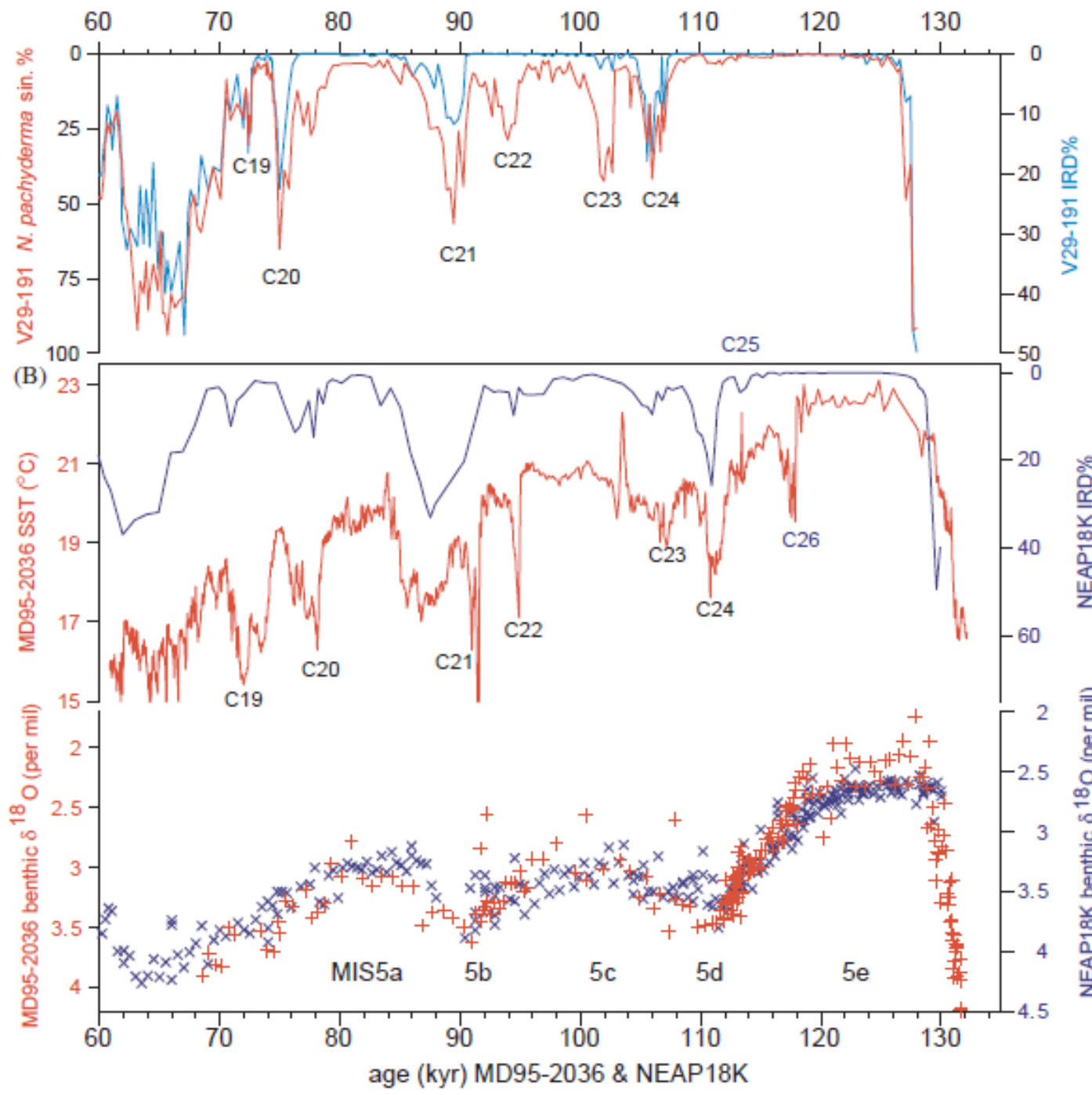

Figura 2: Registros de fauna e IRD do Atlântico Subpolar comparados ao registro de SST MD 95-2036 - do MIS 5: (A) Abundância relativa de $N$. Pachyderma (linha vermelha) e porcentagem de IRD - V29-191 (linha azul) (McManus et al., 1994); (B) SST - MD 95-2036 (linha vermelha) e IRD -NEAP18K (linha azul) (Chapman and Shackleton, 1999). Os eventos frios indicados por C19 a C24 foram originariamente descritos por (McManus et al., 1994) e o C25 e C26 foram identificados mais tarde NEAP18K por Chapman and Shackleton, op. cit) (modificada de Lehman, 2002).

McManus (1994), Kukla et al. (1997) e McManus (2002) argumentaram que o Eeminao europeu pode ter se extendido até a fase de crescimento do gelo do MIS 5d. Em contrapartida, Shackleton (1969), Mangerud et al. (1979), Turner (2002) e Shackleton et al. (2002) acreditam que o Eemiano equivale ao MIS 5e apenas.

Heusser e Oppo (2003) considera que a melhoria no clima terrestre do período deglacial, o qual é quase sincrônico com a diminuição do gelo, alcançou seu máximo 
pouco antes do volume de gelo mínimo dentro do MIS 5e. Quanto ao resfriamento no fim do Último Máximo Interglacial iniciou-se antes do crescimento de gelo.

A diferença marcante entre a duração sugerida das condições interglaciais no oeste da Europa, isto é, 16-17 ka na França e em Portugal, e 10-11 ka na Alemanha) (Turner, 2002) pode refletir gradientes climáticos abruptos no noroeste da Europa de $\sim 5-6 \mathrm{ka}$.

As oscilações suborbitais correlacionáveis de florestas Pinus (pinhos) e Quercus (carvalhos) da costa da Georgia e Carolina do Sul e variabilidade da superfície do mar correspondem aos intervalos estadias e interestadiais presentes nos testemunhos de gelo da Groelândia (Heusser, 2003). Os registros de pólen do norte da Flórida, alternando períodos de dominância de Pinus e Quercus estão associados tanto a oscilações milenares (eventos Heinrich) quanto às climáticas de escala orbital (Grimm, 1993). A temperatura média mensal na costa subtemperada da Carolina do Sul e da Georgia varia de $\sim 27^{\circ} \mathrm{C}$ durante os verões úmidos quentes a $\sim 1,1^{\circ} \mathrm{C}$ durante os invernos breves e moderados.

Durante o MIS 5e, a concentração de pólen é mínima. A maior abundância no MIS 5d e 5 b pode refletir o aumento do transporte fluvial e eólico do pólen associada a alta ocorrência de precipitações, fortes ventos de oeste e/ou maior aproximação da vegetação e discarga fluvial durante os baixos níveis dos mares (Delcourt, 1984; Kutzbach, 1987).

Oppo et al. (1997) sugere que produção de água profunda e transporte de calor em direção ao norte pode ter sido dramaticamente reduzida em resposta à rápida descarga de gelo e à deglaciação. Rind et al. (1986) através de modelagens previram que um resfriamento na parte subpolar do Atlântico Norte tem uma influência muito maior sobre a temperatura do oeste da Europa que no sudeste da América do Norte.

Os eventos frios milenares do MIS 5 no Atlântico Norte subtropical estavam intimamente ligados a menor contribuição da NADW (Lehman et al., 2002; Heusser e Oppo, 2003).

A principal hipótese a ser testada neste trabalho é que os sedimentos marinhos dos testemunhos estudados registraram as variações climáticas ocorridas antes, durante e depois do Último Interglacial s.l.. Além disso, os padrões obtidos pelos dados micropaleontológicos e geoquímicos devem ser comparáveis temporalmente com aqueles de outras localidades na Terra, ou seja, a manifestação de eventos similares ocorre em diferentes latitudes e regiões dos oceanos. 


\section{OBJETIVO}

O presente estudo pretende apresentar um registro de alta taxa de acumulação de sedimentos marinhos recuperados de dois testemunhos da porção sudoeste do Oceano Atlântico Sul (margem continental brasileira). Estes registros sedimentares forneceram dados inéditos e detalhados da progressão climática desde o Penúltimo Glacial, com a subsequente deglaciação (Terminação II), início do Último Interglacial s.s., e então a glaciação, que marca o final do Último Interglacial s.l. para a região do Oceano Atlântico.

Os objetivos específicos são:

- Identificar o estágio interglacial MIS 5 e seus limites com base em isótopos de oxigênio em foraminíferos bentônicos;

- Correlacionar estes registros isotópicos com a cronologia orbital padrão de alta resolução (LR04 de Lisiecki e Raymo, 2005) para poder inferir se a idade do estabelecimento e declínio dos eventos climáticos no sudoeste do Oceano Atlântico Sul são similares aos registrados em outros oceanos;

- Avaliar a sensibilidade de algumas espécies de foraminíferos planctônicos indicadoras de águas mais quentes ou mais frias, às prováveis variações climáticas observadas ao longo do período estudado através da elaboração de curvas climáticas;

- Comparar os dados isotópicos e curvas climáticas obtidas com dados de testemunhos de gelo e de sedimentos marinhos de outras regiões.

\section{MOTIVAÇÃO}

A importância deste trabalho está baseada na ausência e na necessidade de estudos realizados na porção sudoeste do Atlântico Sul do período conhecido internacionalmente como Último Interglacial sensu lato que equivale ao estágio isotópico marinho 5, correspondente ao intervalo de 130 a 71 mil anos atrás, já que este possui características climáticas/oceanográficas semelhantes à época atual. Tais informações têm essencial importância para futuras pesquisas em paleoclimatologia e paleoceanografia, uma vez que tais estudos baseiam-se, principalmente, nas variações isotópicas de oxigênio em foraminíferos e da análise qualitativa e quantitativa de foraminíferos planctônicos em períodos glaciais e interglaciais. 


\section{4. ÁREA DE ESTUDO}

A região abrangida neste estudo compreende a Bacia de Campos e a Bacia de Santos, ambas localizadas na margem continental sudeste brasileira (Figura 3). Mattos (2006) considerou a margem sudeste, o espaço entre os Cabos de São Tomé (RJ) e de Santa Marta Grande (SC) $-21^{\circ} \mathrm{S}$ a $28^{\circ} 30^{\prime}$ S. De acordo com Zembruscki (1979), a plataforma continental é considerada ampla, com relevo geral suave e com contornos batimétricos que acompanham a configuração da costa. O setor do Embaiamento de São Paulo é onde a plataforma possui largura máxima com $230 \mathrm{~km}$ de extensão. Neste setor, a quebra da plataforma ocorre entre 120 e $180 \mathrm{~m}$ de profundidade e o talude continental, apresenta uma largura entre 59 e $122 \mathrm{~km}$ e uma declividade entre $1^{\circ}$ e $1^{\circ} 45^{\prime}$ (Zembruscki, 1979).

A Bacia de Campos compreende a seção entre os paralelos $20,5^{\circ} \mathrm{S}$ e $23^{\circ} \mathrm{S}$ (Rangel et al. 1994). Seus limites são: ao norte, o Alto de Vitória ; ao sul, o Alto de Cabo Frio; e a leste, a isóbata de 3.400 m, ocupando uma área de aproximadamente $100.000 \mathrm{~km}^{2}$ (Viana et al., 1998). Segundo esse mesmo autor, a plataforma continental nesta área tem uma largura média de $100 \mathrm{~km}$, e a quebra da plataforma varia entre $80 \mathrm{~m}$ (ao norte) e $130 \mathrm{~m}$ (ao sul). O talude continental apresenta largura de $40 \mathrm{~km} \mathrm{e}$ declividade média de $2,5^{\circ}$.

A Bacia de Santos localiza-se entre os paralelos $23^{\circ} \mathrm{S}$ e $28^{\circ} \mathrm{S}$ e limita-se a norte pelo Alto de Cabo Frio e, ao sul, pelo Alto de Florianópolis abrangendo cerca de $206.000 \mathrm{~km}^{2}$ até a isóbata de $2.000 \mathrm{~m}$ (Moreira et al., 2001).

Na região do Embaiamento de São Paulo, as condições climáticas são mais homogêneas e a sedimentação na área externa da plataforma e talude superior parece ser uma resposta combinada à morfologia de fundo, ao fluxo perpendicular às isóbatas, associado ao meandramento da Corrente do Brasil e ao transporte da Água Costeira na direção do mar aberto (Mahiques et al., 2002). 


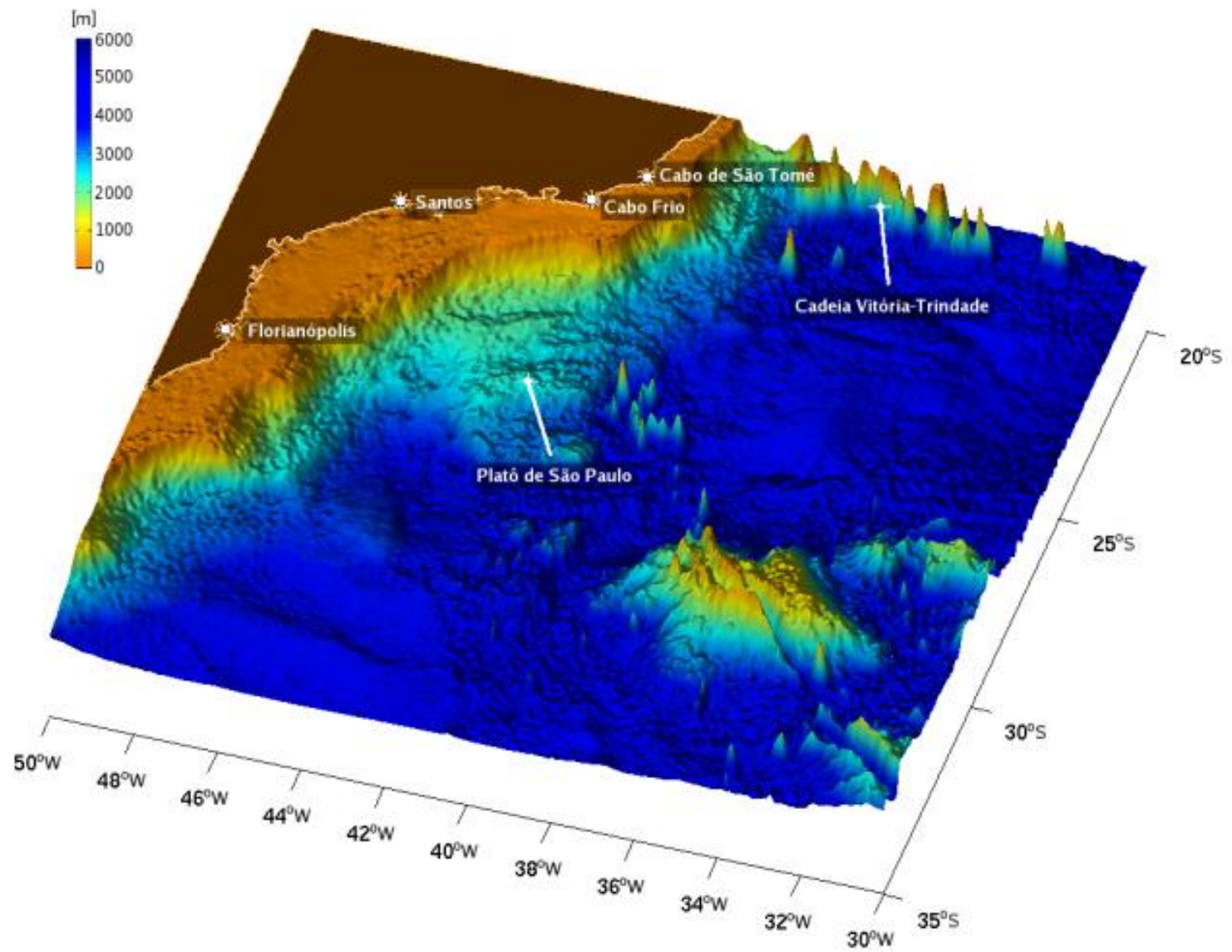

Figura 3: Topografia de fundo da costa sudeste brasileira (modificada de Mattos, 2006).

A principal componente hidrodinâmica superficial na região de estudo é a Corrente do Brasil (BC). A BC é a corrente de contorno oeste do Giro Subtropical do Atlântico Sul que flui para sul (Siveira, 2001) (Figura 4). Sua origem dá-se na bifurcação do ramo sul da Corrente Sul Equatorial (SESC) ao sul de $10^{\circ} \mathrm{S}$. O ramo da SESC que flui para norte origina a Corrente Norte do Brasil (NBC) (Stramma, 1991; Silveira et al., 1994). A BC deixa o continente sul-americano a sua direita até a região da Convergência Subtropical (33-38 $\mathrm{S})$, onde encontra a Corrente das Malvinas (MC) e se afasta da costa, fluindo para leste. Segundo Evans e Signorini (1985), a BC tem espessura de $500 \mathrm{~m}$ ao largo do sudeste brasileiro. A Corrente de Benguela representa a corrente de contorno leste do Giro Subtropical do Atlântico Sul, e flui para noroeste juntando-se a SESC completando o Giro (Figura 4). Apesar de não fazerem parte deste grande giro anticiclônico, a Corrente das Agulhas (AC), Malvinas e a Circumpolar Antártica influenciam diretamente sua configuração (Stramma e England, 1999). 

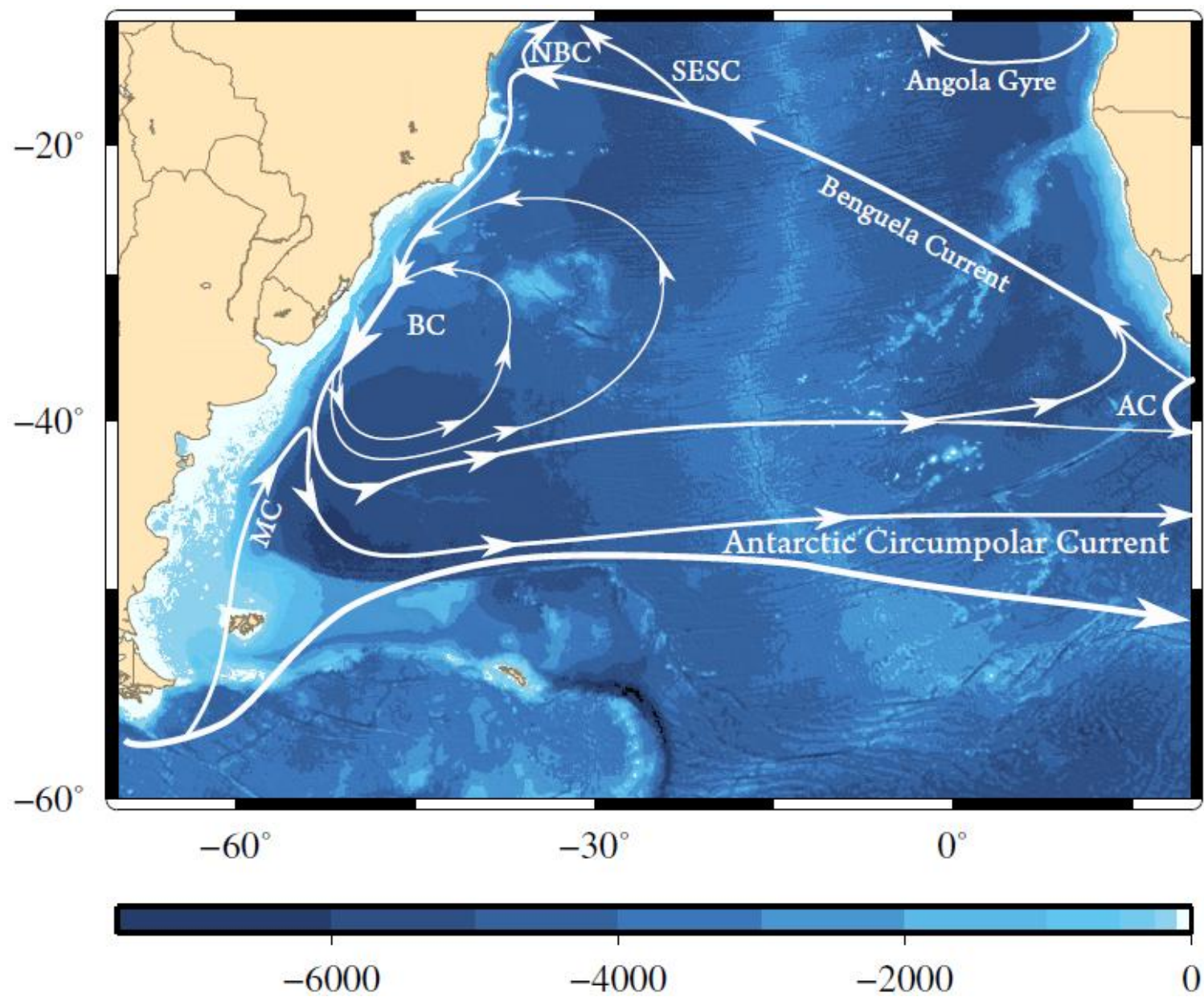

Figura 4: Representação esquemática da circulação superficial do Atlântico Sul. SESC: Corrente Sul-Equatorial; NBC: Corrente do Norte do Brasil; BC: Corrente do Brasil; MC: Corrente das Malvinas; AC: Corrente das Agulhas; Angola Gyre: Giro de Angola; Benguela Current: Corrente de Benguela; Antarctic Circumpolar Current: Corrente Circumpolar Antártica. (modificada de Peterson e Stramma, 1991; Signorelli, 2013).

$\mathrm{Na}$ região da $\mathrm{BC}$ estão empilhadas as massas de água características do Atlântico Sul: Água Tropical (TW), Água Central do Atlântico Sul (SACW), Água Intermediária Antártica (AAIW), Água Profunda do Atlântico Norte (NADW) (Figura 5). A TW e a SACW são as principais constituintes da BC.

Emilson (1961) descreveu a TW como parte da massa de água quente (temperaturas maiores que $20^{\circ} \mathrm{C}$ ) e salina (salinidades acima de 36) que ocupa a superficie do Atlântico Sul Tropical, a qual é transportada para o sul pela BC. A TW possui baixa concentração de nutrientes e, desta forma, está associada a ambientes oligotróficos (Ciotti et al., 1995).

A SACW é encontrada fluindo na região da picnoclina para sul ao largo da costa brasileira, e com temperaturas entre 6 e $20^{\circ} \mathrm{C}$, e salinidades entre 34,6 e 36 (Miranda, 1985). 
Subjacente à SACW está a AAIW cuja temperatura varia de 3 a $6^{\circ} \mathrm{C}$ e salinidade, de 34,2 a 34,6 (Sverdrup et al., 1942). A AAIW move-se em direção ao equador ao norte de $25^{\circ} \mathrm{S}$ e para sul em $28^{\circ} \mathrm{S}$, em níveis abaixo da picnoclina (Muller et al., 1998) (Figura 5). O fluxo para nordeste associado à AAIW é denominado Corrente de Contorno Oeste Intermediária.

A NADW, massa de água profunda sob a AAIW é caracterizada por valores de temperatura entre $3^{\circ} \mathrm{C}$ e $4^{\circ} \mathrm{C}$ e de salinidade entre 34,6 e 35 . A NADW flui para o sul ao longo do contorno oeste até cerca de $32^{\circ} \mathrm{S}$, onde pelo menos parte da corrente retoma em direção ao Equador (Reid, 1989; Weatherly, 1993).

A composição isotópica característica da água $\left(\delta^{18} \mathrm{O}_{\mathrm{w}}\right)$ da NADW é cerca de $0,25 \%$ mais elevada do que a média de $\delta^{18} \mathrm{O}_{\mathrm{w}}$ global (Ostlund et al., 1987). Em contraste, águas profundas formadas na região Antártica são mais frias e menos salinas, com menor valor de $\delta^{18} \mathrm{O}_{\mathrm{w}}$, aproximadamente $0,2 \%$ menor que a média global (Waelbroeck, 2002).

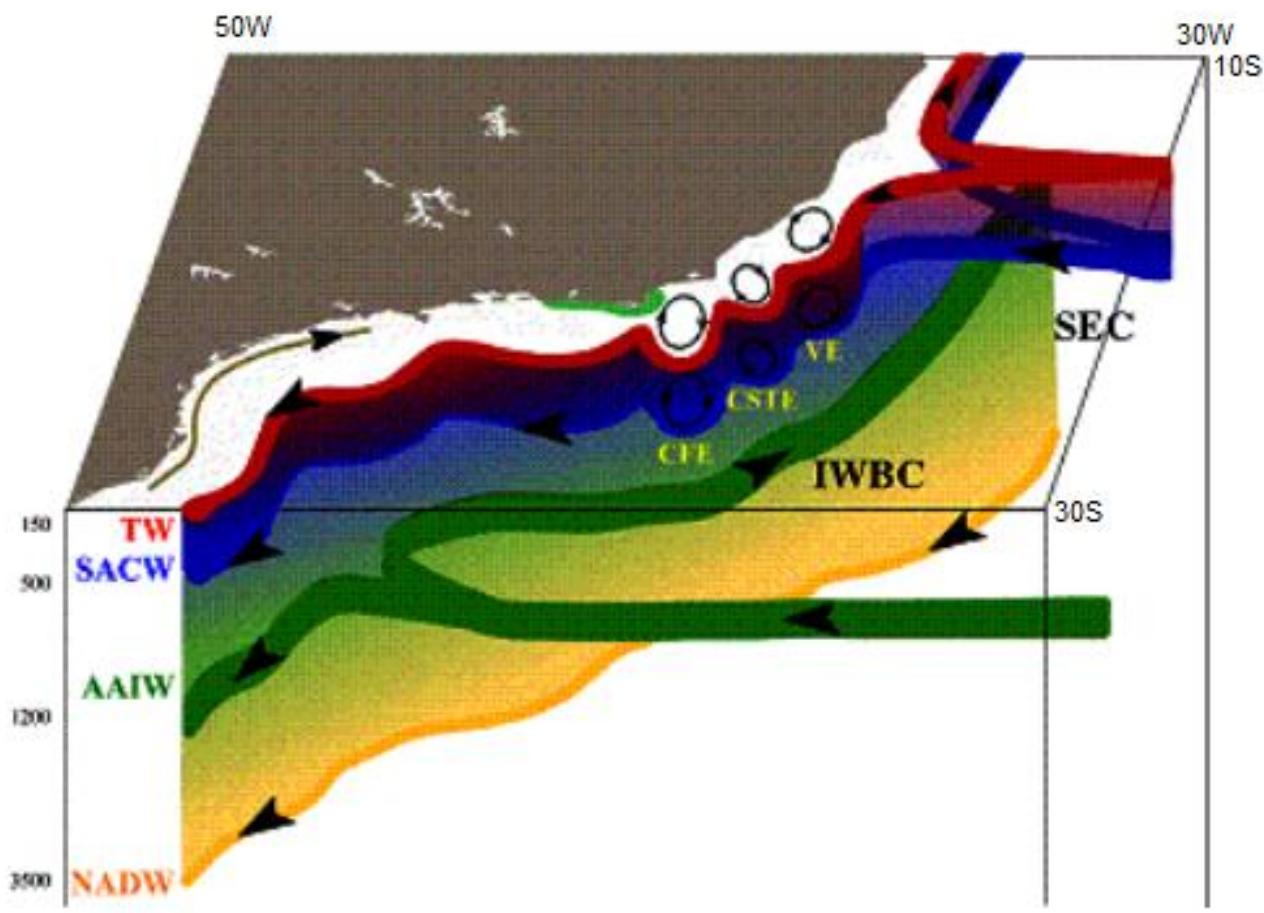

Figura 5: Esquema das principais feições na região ao largo da costa leste-sudeste brasileira. VE: Vórtice de Vitória; CSTE: Vórtice de Cabo de São Tomé; CFE: Vórtice de Cabo Frio; SEC: Corrente Sul Equatorial; IWBC: Corrente de Contorno Oeste Intermediária; TW: Água Tropical; SACW: Água Central do Atlântico Sul; AAIW: Água Intermediária Antártica; NADW: Água Profunda do Atlântico Norte (modificado de Projeto SPOC I-2004). http://www.smast.umassd.edu/modeling/SPOC/spoc_proposal.pdf 
$\mathrm{O}$ vigoroso meandramento da $\mathrm{BC}$ é observado desde a costa de Vitória até a Bacia de Santos, com a descrição de vórtices recorrentes, como o VE, CSTE e CFE (Figura 5) (Soutelino, 2008).

Atualmente, a temperatura da superfície da água do mar na região de estudo é, em média, $24^{\circ} \mathrm{C}$ variando sazonalmente em $4^{\circ} \mathrm{C}$. A salinidade média anual da superfície do mar está em torno de 36,5 (Levitus e Boyer, 1994).

A circulação atmosférica na região sudeste do Brasil é dominada pela Alta Subtropical do Atlântico Sul (ASAS), um sistema de alta pressão permanente, localizado em torno de $30^{\circ} \mathrm{S}$ de latitude, de ar subsidente seco e quente. Este sistema está associado a circulação média meridional da atmosfera, surgindo devido as células de Hadley (Bastos e Ferreira, 2000; Ito e Ambrizzi, 2000). Os centros de alta pressão movimentam-se devido ao gradiente de temperatura existente entre os continentes e os oceanos. Durante o verão, se localizam sobre os oceanos devido ao fato de os continentes estarem mais quentes. Já no inverno, quando os oceanos é que estão mais aquecidos relativamente, os centros de alta pressão migram para o continente. No entanto, as frentes frias polares, podem causar uma mudança neste padrão.

A Zona de Convergência Intertropical (ITCZ) também influencia o clima tropical e a circulação oceânica para a região da América do Sul. A ITCZ representa uma zona de baixa pressão onde ocorre convergência de ventos alísios, criando uma ascendência de massas de ar que, geralmente, carregam bastante umidade proveniente do oceano equatorial. Devido à inclinação do eixo da Terra em órbita, a ITCZ sofre deslocamento para norte em julho (verão boreal) e para sul em janeiro (verão austral) (Figura 6).

Durante o inverno austral, a precipitação máxima sobre o continente está localizada ao norte do equador, enquanto na parte central do continental sul americano (incluindo o sul da região amazônica) observa-se a estação seca. Ao final de outubro, ocorre uma rápida mudança na convecção em direção a sul e durante o verão austral, uma grande área de intensa precipitação se estende da bacia amazônica até o norte da Argentina. No outono, a região de máxima precipitação retorna gradualmente ao norte da América do Sul (Garreaud, 2009). 

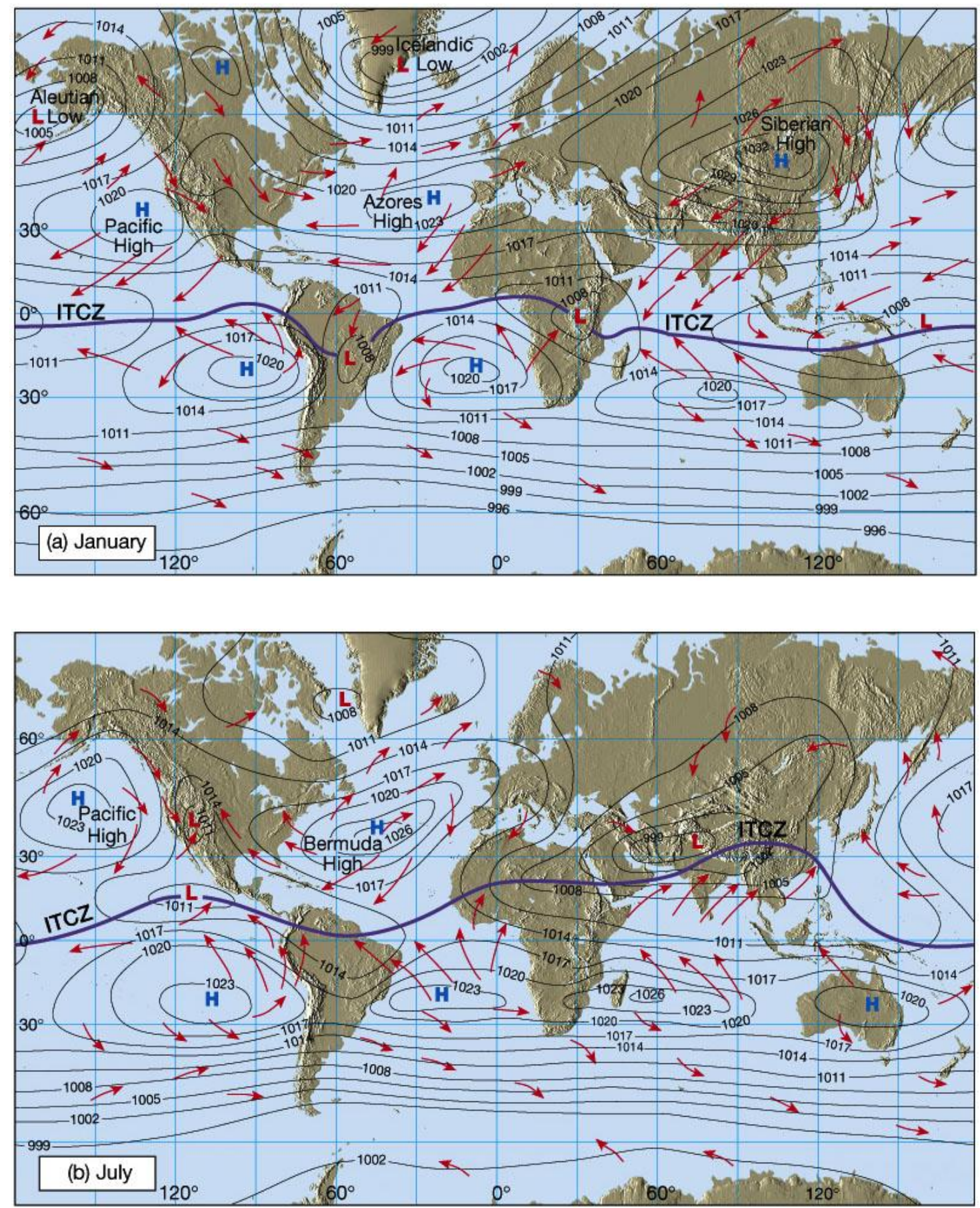

Figura 6: Circulação atmosférica padrão mundial associada aos centros de baixa e alta pressão, e a Zona de Convergência Intertropical (ITCZ) indicada pela linha espessa roxa: (a) verão austral e (b) verão boreal (extraída de The Atmosphere, 8th edition, Lutgens and Tarbuck, 2001)

O deslocamento em direção ao norte ou ao sul da ITCZ reflete uma mudança na direção do vento o que resulta nas monções. As monções são sistemas eólicos que apresentam uma reversão sazonal pronunciada em sua direção. No inverno, o fluxo é predominantemente para fora do continente mantendo-o seco. No verão, o fluxo é do oceano para o continente, trazendo condições mais úmidas. 


\section{MATERIAL E MÉTODOS}

Neste estudo foram utilizados os testemunhos: KF-12 coletado no talude da Bacia de Campos, a $1.503 \mathrm{~m}$ de profundidade, localizado em $21^{\circ} 09^{\prime} 47,6^{\prime \prime} \mathrm{S}$ e $39^{\circ}$ 57'14,3''W e KF-18 coletado no talude da Bacia de Santos, a 2.220 m de profundidade com coordenada geográfica igual a $25^{\circ} 12^{\prime} 14^{\prime} \mathrm{S}$ e $42^{\circ} 37^{\prime} 19^{\prime \prime W}$ (Figura 7).

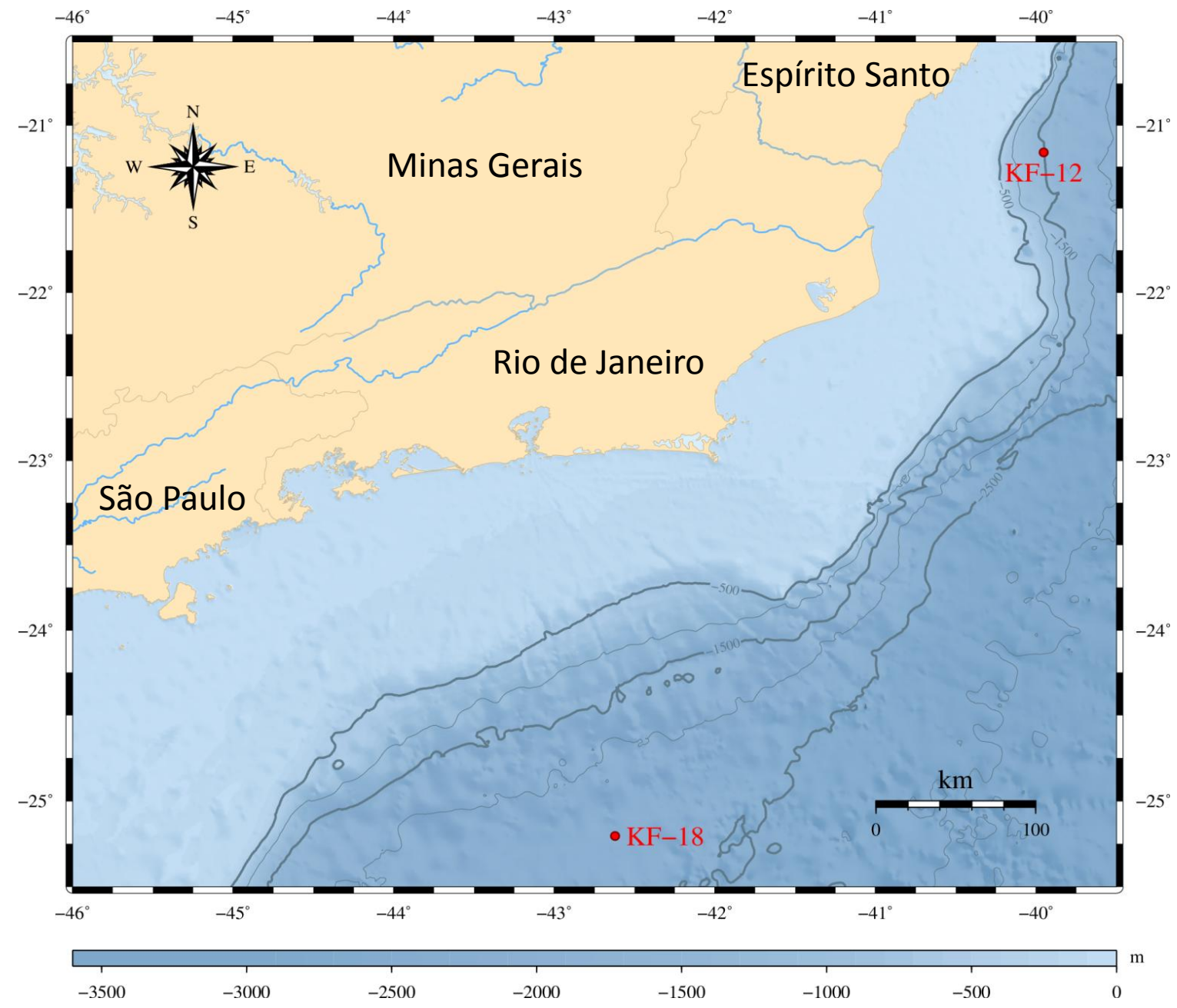

Figura 7: Localização dos testemunhos KF-12 e KF-18 na margem continental sudeste brasileira, porção oeste do Atlântico Sul.

O testemunho KF-12 está situado na parte estreita do talude continental a cerca de 75 km da costa sul do Espírito Santo, na região norte da Bacia de Campos (Figura 7). Nesta porção, a costa e a plataforma continental tem orientação predominantemente NS. Ao sul, já na Bacia de Santos, está o outro testemunho, KF-18, onde a orientação da costa e da plataforma continental assume a direção E-W e o talude é mais largo e pouco inclinado (Figura 7). Na região intermediária, entre o norte do Cabo de São Tomé e Cabo Frio, a orientação é NE-SW. 


\subsection{Amostragem}

A separação das amostras, com espaçamento médio de $5 \mathrm{~cm}$, para análise geoquímica e micropaleontológica foi realizada, no mês de janeiro de 2006, no Laboratório de Testemunhos da PETROBRAS/Cenpes (RJ). De um modo geral, somente uma bioestratigrafia preliminar (presença/ausência de determinadas espécies de foraminíferos planctônicos) é estabelecida nos laboratórios durante a descrição dos testemunhos, porém não é efetuada de forma sistemática ao longo de todo o testemunho e sim, somente onde são identificadas, visualmente, mudanças de fácies e mudanças de cor dos sedimentos.

O testemunho KF-12 teve recuperação total de $\sim 1.960 \mathrm{~cm}$. As 331 amostras deste testemunho estão armazenadas no Laboratório de Paleoceanografia do Atlântico Sul (LaPAS) - Instituto Oceanográfico da Universidade de São Paulo (IOUSP) e disponíveis para análises. Neste trabalho utilizou-se 189 amostras de sedimentos do KF12, entre as profundidades 575 e $1.560 \mathrm{~cm}$, as quais foram preparadas de acordo com o modo padrão utilizado em estudos de bioestratigrafia e paleoclima.

O testemunho KF-18 teve recuperação total de $2.038 \mathrm{~cm}$. Neste trabalho foram utilizados os dados de isótopos de oxigênio em foraminíferos planctônicos e bentônicos, fauna total de foraminíferos planctônicos, paleotemperatura e teor de carbonato das amostras entre as profundidades 136 e $640 \mathrm{~cm}$. As 101 amostras deste intervalo compreendem o período de interesse, ou seja, todo o MIS 5 e as transições MIS 6/5 e MIS 5/4. Cabe salientar que todos os dados apresentados para o testemunho KF-18 foram gerados pela equipe do Laboratório de Paleoceanografia do Atlantico Sul (LaPAS), uma vez que este testemunho faz parte de um projeto de Rede Temática de Micropaleontologia da Petrobras.

As amostras separadas no Centro de Pesquisas Leopoldo Américo Miguez de Mello (Cenpes) foram levadas ao Laboratório de Paleoceanografia do Atlântico Sul (LaPAS), onde foram realizadas todas as etapas de preparação das amostras como descrito a seguir.

\subsection{Processamento das amostras}

As amostras ainda úmidas foram pesadas e depois levadas à estufa sob temperatura de $50^{\circ} \mathrm{C}$. Após estarem secas, foram guardadas em dessecador, até seu 
resfriamento, e pesadas novamente. Só após esta etapa, iniciou-se o processo de lavagem da amostra com água destilada, através de uma peneira de malha $63 \mu \mathrm{m}$, e o auxílio de um pincel de cerdas macias para conservar-se integralmente as testas presentes nas amostras. A seguir, os sedimentos, desta vez separados em fração maior que $63 \mu \mathrm{m}$ e fração menor que $63 \mu \mathrm{m}$, foram secos em estufa a $50^{\circ} \mathrm{C}$. Então, peneirouse a fração grossa (maior que $63 \mu \mathrm{m}$ ) em malha de $150 \mu \mathrm{m}$. As amostras maiores que $150 \mu \mathrm{m}$ passaram pelo processo de fracionamento, que consiste em separar, de modo aleatório, um número entre 300 e 600 testas de foraminíferos planctônicos, representantes de cada profundidade seccionada do testemunho, para a posterior elaboração das lâminas micropaleontológicas. No estudo dos foraminíferos planctônicos, a utilização da fração maior que $150 \mu \mathrm{m}$ garante a inclusão de espécies importantes do registro e, exclui das análises, espécimes juvenis e de tamanhos muito pequenos, os quais podem gerar incertezas taxonômicas (Climap, 1976; Toledo, 2007).

\subsection{Identificação dos foraminíferos (KF-12 e KF-18)}

Após a recuperação dos foraminíferos a partir dos sedimentos e, separação de 300 a 600 testas que são armazenadas em lâminas micropaleontológicas devidamente identificadas, efetuou-se o reconhecimento das espécies planctônicas contidas nestas lâminas. A contagem e identificação a nível específico dos foraminíferos planctônicos foram feitas em estereomicroscópio binocular seguindo os critérios taxonômicos de Bé (1967, 1977); Bolli e Saunders, (1989); Hemleben et al. (1989) e Kemle von Mücke e Hemleben (1999).

\subsection{Análise isotópica de oxigênio $\left(\delta^{18} \mathrm{O}\right)(\mathrm{KF}-12$ e KF-18)}

As análises isotópicas de oxigênio foram conduzidas em amostras uniespecíficas de foraminíferos planctônicos e bentônicos da fração maior que $150 \mu \mathrm{m}$. As testas foram observadas sob lupa binocular para a separação de espécimes do foraminífero planctônico Globigerinoides ruber (morfotipo white) e bentônico Cibicidoides wuellerstorfi.

A espécie de foraminífero planctônico Globigerinoides ruber é considerada um dos indicadores mais confiáveis para reconstruções paleoambientais em latitudes 
tropicais e subtropicais, pois vive próximo à superficie, calcifica suas testas nos primeiros $25 \mathrm{~m}$ da coluna de água, é abundante em todo o testemunho e, calcifica sua testa em equilíbrio isotópico de oxigênio com a água em que vive (Deuser e Ross, 1989; Ravelo et al.,1990; Toledo, 2000). A razão isotópica planctônica do KF-12 foi obtida por Tokutake (2005). Quanto ao testemunho KF-18, foram separados espécimes sensu stricto de G. Ruber (white) pela equipe do LaPAS, nos quais efetuou-se a análise isotópica de oxigênio.

O gênero Cibicidoides também precipita sua testa aproximadamente em equilíbrio isotópico com o $\delta^{18} \mathrm{O}$ da água do mar circunjacente (Costa et al., 2006). Entre as espécies de Cibicidoides, C. wuellerstorfi é a mais utilizada para a análise de $\delta^{18} \mathrm{O}$. Nas amostras onde não foi encontrada esta espécie, foram separados espécimes do mesmo gênero ou da espécie Planulina costata, a qual é muito semelhante à $C$. wuellerstorfi. Ainda quando não havia mais espécimes das espécies listadas, separou-se espécimes de Uvigerina spp., uma espécie infaunal que calcifica sua testa sob influência da água intersticial. A identificação das espécies de foraminíferos bentônicos foi baseada em Wylie (1981) e van Morkhoven et al. (1986).

A partir destes espécimes foram efetuadas análises de isótopos de oxigênio $\left(\delta^{18} \mathrm{O}\right)$ por digestão ácida usando um banho ácido comum automatizado com interface para um espectrômetro de massa de razão isotópica (IRMS) ThermoScientific MAT 253, acoplado a um periférico KIEL-IV com dispositivo para carbonato. As análises foram conduzidas pelo Laboratório de isótopos estáveis, Ciências Planetárias e da Terra da Universidade da Califórnia - Santa Cruz. As amostras são submetidas à reação, a $90^{\circ} \mathrm{C}$, com ácido ortofosfórico (gravidade específica $=1,92 \mathrm{~g} / \mathrm{cm}^{3}$ ) para gerar dióxido de carbono e água. A água é criogenicamente removida do $\mathrm{CO}_{2} \mathrm{e}$ os gases que não condensam são bombeados para fora, antes da introdução $\mathrm{CO}_{2}$ purificado dentro do IRMS. Durante a ocorrência da sequência, o padrão Marble Carrera calibrado é usado para corrigir os dados, incluindo a correção de deriva. Duas amostras calcárias de NBS19 são analisadas junto com as outras amostras para monitorar-se o controle de qualidade e a perforamance a longo prazo. Marble Carrera é extensivamente calibrada contra materiais de referência padrão NIST (NBS-19, NBS-18 e LSVEC) e como parte de estudos comparativos com outros laboratórios de isótopos estáveis. Valores da razão corrigidos são expressos em relação aos padrões internacionais VPDB (Vienna PeeDee Belemnite) para $\delta 1^{3} \mathrm{C}$ and $\delta^{18} \mathrm{O}$. A precisão das análises que utilizam o padrão de carbonato do National Bureau of Standards NBS-19 é $\pm 0,07$ para $\delta^{18} \mathrm{O}$. 
É importante observar que o testemunho KF-18 tem uma maior quantidade de dados de fauna de foraminíferos planctônicos e de isótopos, já o KF-12 possui dados de elementos/Ca, obtidos por Fritz (2012). Deste modo, as interpretações serão baseadas naquele testemunho que tiver mais dados disponíveis do parâmetro em questão.

\subsection{Modelo de Idade (KF-12 e KF-18)}

Os modelos de idade foram efetuados com base na curva isotópica de oxigênio $\left(\delta^{18} \mathrm{O}\right)$ obtida a partir de foraminíferos bentônicos do KF-12 (Error! Reference source not found.) e KF-18 (equipe LaPAS) em correlação à curva LR04 (Lisiecki e Raymo, 2005). A curva LR04 também é formada por dados de isótopo de oxigênio de foraminíferos bentônicos, porém, é composta por dados globais interligados orbitalmente de 57 pontos. Atualmente, é a curva padrão para obtenção da idade através do método de correlação. O programa utilizado na identificação dos pontos correspondentes (tie points) e interpolação dos dados foi o Analyseries 2.0 (Paillard et al., 1996).

\subsection{Estimativas de paleotemperatura obtidas pela rede neural artificial (ANN) (KF-18)}

A arquitetura geral da rede neural foi desenvolvida por Malmgren e Nordlund (1997). Na primeira etapa do processamento, os sinais de entrada (neste caso, os dados de fauna do conjunto de dados de calibração), são propagados pelas diversas partes da rede até o ponto de saída onde fornecem estimativas de temperatura. A comparação das estimativas geradas com a saída desejada (temperatura conhecida) indica o erro. $\mathrm{Na}$ segunda etapa, o erro é retropropagado na rede e os pesos das conexões são reajustados de forma a minimizar o erro. As redes utilizadas neste trabalho são as mesmas utilizadas por Kucera et al. (2005b), cujo processamento é baseado em dados específicas por bacia oceânica. No caso do Atlântico Sul, são considerados 26 grupos taxonômicos (Tabela 2). O erro médio das estimativas de SST fornecidas pelo método é de $\sim 1^{\circ} \mathrm{C}$ (Malmgren et al., 2001). 
Tabela 2: Lista das espécies utilizadas para estimar paleotemperaturas através das redes neurais artificiais.

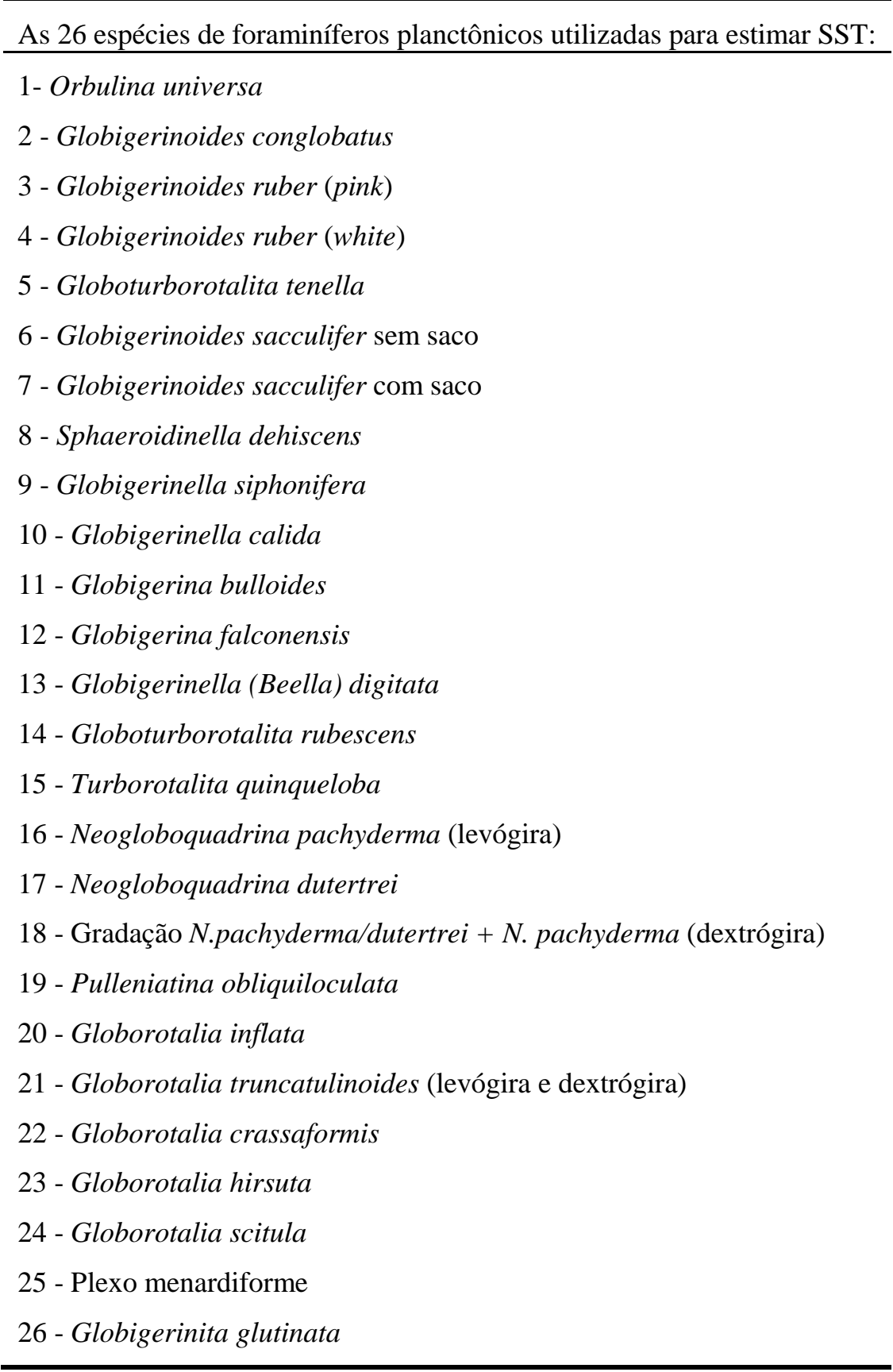

\subsection{Análise de elementos-traço (KF-12)}

Os dados de elementos-traço foram obtidos por Fritz (2012) a partir da fração fina do sedimento (menor que $63 \mu \mathrm{m}$ ) de 145 amostras, pelo Método US-EPA 3052 (digestão ácida assistida de matrizes silicosas e bases orgânicas em microondas).

A capacidade do microondas permitia a análise de apenas 6 amostras por vez. Primeiramente, alíquotas de cerca de $0,2 \mathrm{~g}$ de amostra eram reagidas com $10 \mathrm{ml}$ de 
ácido nítrico dentro de unidades digestoras e aquecidas no microondas durante 45 minutos. Após o esfriamento das unidades, adicionou-se $15 \mathrm{ml}$ de ácido fluorídrico às amostras e repetiu-se o aquecimento no microondas. A próxima etapa foi inserir $3 \mathrm{ml} \mathrm{de}$ peróxido de hidrogênio nos tubos digestores. Quando a efervescência cessou, aqueceuse novamente os tubos digestores. Então, as amostras foram transferidas para béqueres de teflon e, utilizando $\mathrm{HNO}_{3} 5 \%$, enxaguou-se a unidade digestora para transferência total do remanescente no tubo. Os béqueres foram acomodados sobre chapa aquecida a $200^{\circ} \mathrm{C}$ dentro da capela. Esperou-se aproximadamente $1 \mathrm{~h}$ para a evaporação até que a amostra se reduzisse ao volume de uma gota. Outra adição de $10 \mathrm{ml}$ de $\mathrm{HNO}_{3} 5 \%$ foi efetuada em cada um dos béqueres de teflon. Evaporou-se mais uma vez as amostras, dessa vez, por 30 minutos. Quando chegou-se ao volume de uma gota, a amostra foi transferida para o tubo Falcon de $50 \mathrm{ml}$ e foi acrescentado $\mathrm{HNO}_{3} 5 \%$ até atingir-se o volume de $30 \mathrm{ml}$.

Após o processo de digestão total dos sedimentos, as amostras foram conduzidas para análise por Espectrometria de Emissão Óptica com Plasma Acoplado Indutivamente (ICP-OES) a fim de medir-se as concentrações dos elementos: $\mathrm{Fe}, \mathrm{Ca}$, Ba,Ti e K.

\subsection{Teor de carbonato (KF-12 e KF-18)}

O teor de carbonato foi estimado por Fritz (2012) na fração fina (menor que 63 $\mu \mathrm{m})$ de 144 amostras do testemunho KF-12 e 88 amostras do KF-18, que abrangem o período foco deste estudo (60 a $130 \mathrm{ka}$ ). O método utilizado foi o ataque ácido em $\sim 1 \mathrm{~g}$ de amostra por $\mathrm{HCl} 10 \%$ para eliminação do $\mathrm{CaCO}_{3}$ através da reação descrita a seguir:

$$
\mathrm{CaCO}_{3}+2 \mathrm{HCl} \rightarrow \mathrm{CaCl}_{2}+\mathrm{H}_{2} \mathrm{O}+\mathrm{CO}_{2}
$$

Assim, conhecendo-se o peso do béquer, pesa-se a amostra antes e depois do ataque ácido e a diferença do peso representa a quantidade de $\mathrm{CaCO}_{3}$ na amostra. $\mathrm{O}$ cálculo do teor de carbonato (\%) foi realizado através da equação:

$$
\mathrm{CaCO}_{3}(\%)=\frac{\text { Peso } 1-\text { Peso } 2}{\text { Peso } 1} * 100
$$

Onde:

$\mathrm{CaCO}_{3}(\%)=$ concentração, em porcentagem, de carbonato; 
Peso 1 = peso inicial da amostra (peso da amostra antes de ser submetida ao ataque ácido);

Peso 2 = peso final da amostra (peso da amostra seca, após seu conteúdo carbonático ser eliminado pelo ácido).

\subsection{Aplicação da relação de Rögl e Bolli (1973), adaptada por Vicalvi (1997), em estudos paleoclimáticos e paleoceanográficos.}

Para obter uma curva representativa das mudanças climáticas ao longo do período de tempo abordado, este estudo utilizou a Relação de Rögl e Bolli (1973) adaptado por Vicalvi (1997). As espécies típicas de águas quentes e frias foram selecionadas e suas percentagens em relação à fauna total foram determinadas. As formas de água fria selecionadas são Globigerina bulloides, Globorotalia inflata, e Turborotalita quinqueloba. Os indicativos de águas quentes são Globigerinoides ruber, G. sacculifer e grupo formado pelas espécies menardiformes (Globorotalia menardii, G. tumida e G.tumida flexuosa). A proporção de três espécies típicas de águas quentes contra importantes espécies de águas frias e quentes é expressa pela seguinte equação:

\section{G. ruber + G. sacculifer + espécies menardiformes $\mathrm{x} 100$}

G. ruber + G. sacculifer + espécies menardiformes + G. bulloides + T. quinqueloba + G. inflata

\section{RESULTADOS E DISCUSSÕES}

\subsection{Modelo de Idade}

\section{- KF-18}

A Divisão de Geoquímica Marinha do LaPAS estabeleceu uma estratigrafia isotópica de alta resolução e construiu um modelo de idade para o testemunho KF-18 de acordo com a ligação dos dados de isótopos de oxigênio em carapaças de foraminíferos bentônicos (C. wuellerstorfi) deste testemunho com a curva de referência global LR04, $\delta^{18} \mathrm{O}$ em foraminíferos bentônicos (Lisiecki e Raymo, 2005). Essa correlação entre os dados isotópicos das duas curvas foi realizada através do programa computacional de análise de séries temporais (AnalySeries 2.0.4.2. para Mac, Paillard et al., 1996). 
Efetuou-se análises de radiocarbono em três amostras do topo do testemunho KF-18, uma datação absoluta para auxiliar no estabelecimento do modelo de idade. As análises foram realizadas na Universidade da Califórnia - EUA (Earth and Planetary Sciences- Stable Isotope Laboratory). Primeiramente, estabeleceu-se um modelo de idade de topo, abrangendo os primeiros $51 \mathrm{~cm}$, apenas com os dados da datação absoluta. Este curto intervalo se deve ao limite de detecção e confiabilidade do método de radiocarbono $\left({ }^{14} \mathrm{C}\right)$. As idades obtidas por este método foram corrigidas para efeito reservatório de acordo com o modelo de Butzin et al. (2005) e transformadas em idade calendário (A.P.) de acordo com Fairbanks et al. (2005). Portanto, para o estabelecimento do modelo de idade do KF-18, a idade das 9 primeiras amostras $(0-51$ $\mathrm{cm}$ ) foi utilizada como pontos de controle (Figura 8a).

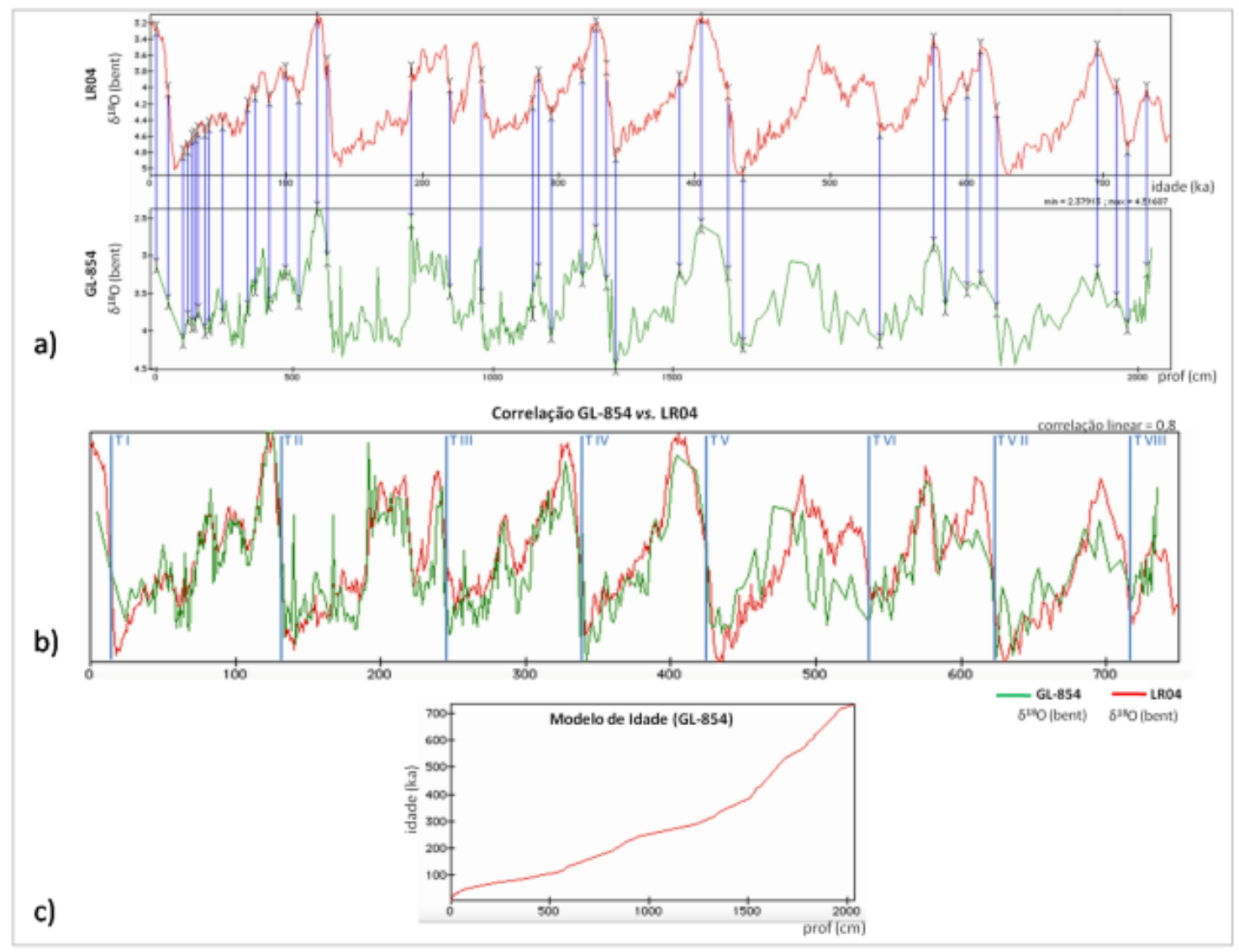

Figura 8: Configuração do modelo de idade: a) Curvas isotópicas de oxigênio (LR04 e KF-18) com os pontos de controle utilizados, b) correlação entre as respectivas curvas ilustrando as terminações glaciais e, c) modelo de idade final do KF-18.

Para o restante do testemunho utilizou-se as terminações glaciais como pontos de controle, além de outros pontos correspondentes identificados visualmente (Figura 8a). Terminações glaciais são designadas como rápidas transições que ocorrem entre os 
intervalos glaciais e as condições interglaciais. Em curvas isotópicas de oxigênio estes eventos são prontamente reconhecidos como o ponto médio da maior variação isotópica identificada (Lisiecki e Raymo, 2005) (Figura 8b).

Uma escala de tempo foi, desta forma, estabelecida para o KF-18. As idades são apresentadas em milhares de anos e ao longo do texto serão referidas pela abreviação ka (kilo annum). A correlação linear entre as curvas isotópicas de referência (LR04) e do KF-18 é alta (r=0,8). O modelo de idade está apresentado na Figura 8c. Entre os pontos de controle as idades foram calculadas por interpolação linear considerando-se que a taxa de sedimentação foi constante nos intervalos.

Antes de obter-se o modelo de idade final, foram construídos modelos de idade alternativos utilizando como pontos de controle as idades estabelecidas na literatura para os limites das biozonas de G. menardii (Vicalvi, 2009 e Kohn et al., 2004). Entretanto, a fim de delinear um modelo de idade independente, optou-se por não adotar idades pré-estabelecidas na literatura para os limites de outras regiões geográficas (p.ex. Golfo do México), pois, neste modo, assume-se que não houve diacronismo, o que muitas vezes não é verdadeiro. Como as curvas de variação isotópica de oxigênio respondem primeiramente à variação do volume de gelo (sinal global), as mesmas são independentes da adaptação da biota às condições ambientais (sinal regional/local). Outras vantagens em estabelecer o modelo de idade desta forma, é que se obtêm idades "locais" para os limites bioestratigráficos e verifica-se a existência ou não de diacronismos. Deste modo, a interpretação paleoambiental torna-se mais confiável.

\section{- KF-12}

Para o testemunho KF-12, também foram realizadas diversas tentativas de obtenção de um modelo de idade. A primeira tentativa, foi realizar a correlação da curva isotópica bentônica do KF-12 com a curva de referência global LR04 (Lisiecki e Raymo, 2005) através do programa computacional de análise de séries temporais (AnalySeries 2.0.4.2. para Mac, Paillard et al., 1996).

Diante da dificuldade em estabelecer os pontos de controle entre as duas curvas, principalmente em sua parte intermediária, usou-se a curva de $\delta^{18} \mathrm{O}$ de um testemunho coletado a $1.269 \mathrm{~m}$ de profundidade, próximo à area de estudo, fornecido por Delia Oppo (via comunicação pessoal). Assim, primeiramente, correlacionou-se esta curva com a curva referência LR04 $(\mathrm{r}=0,92)$ (Figura 9) para estabelecer a idade do 
testemunho de Oppo, pois seus dados isotópicos estavam em função da profundidade. O procedimento seguinte foi a correlação entre a curva KF-12 e Oppo $(r=0,84)$ para a obtenção dos pontos de controle entre as duas curvas (Figura 10). Só então foi possível correlacionar os dados isotópicos do KF-12 com a curva referência LR04 ( $\mathrm{r}=0,93)$, através da utilização dos pontos encontrados (Figura 11).

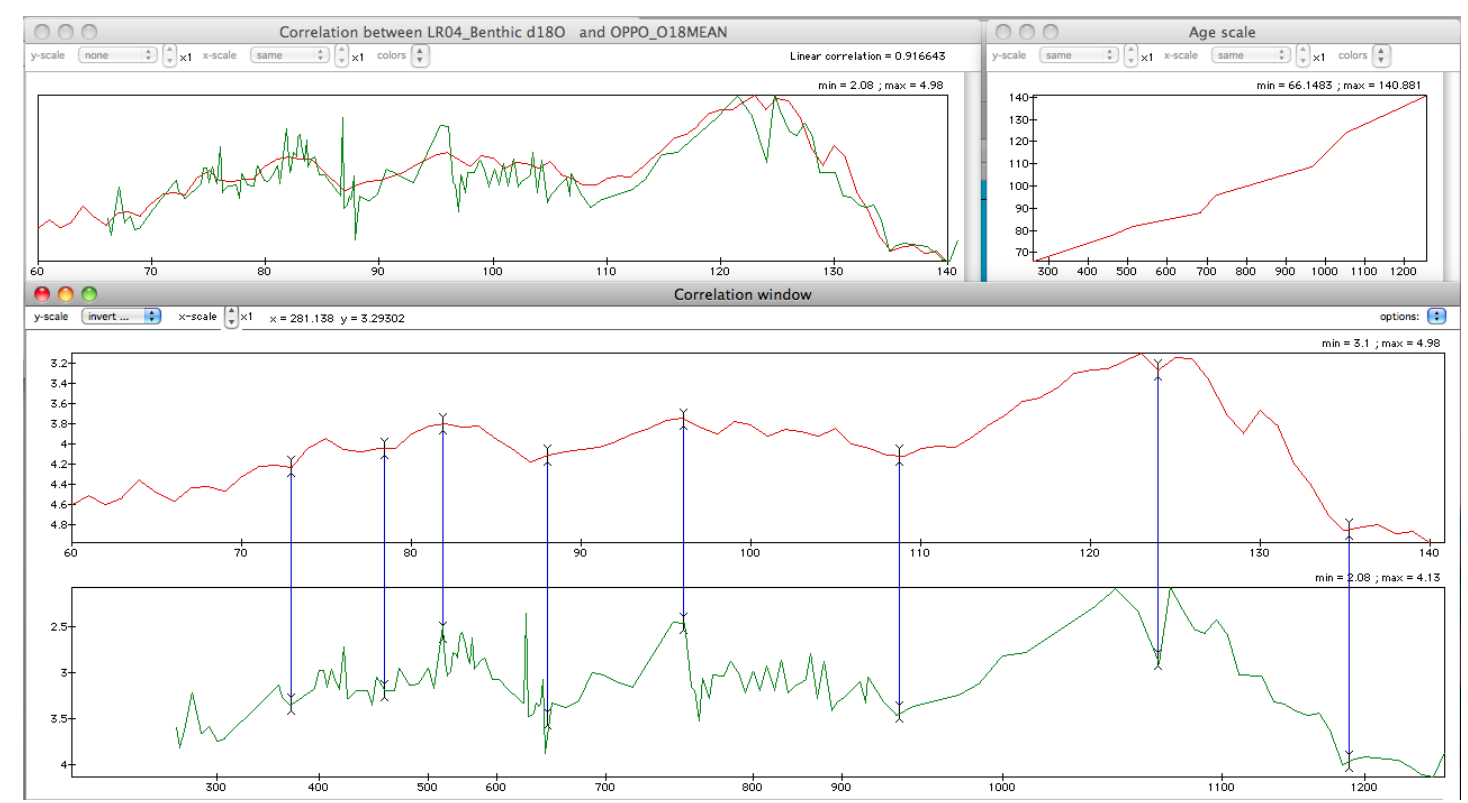

Figura 9: Correlação entre as curvas isotópicas LR04, linha vermelha, e a fornecida por Oppo, linha verde. Os pontos de controle das duas curvas estão interligados pelas linhas azuis.

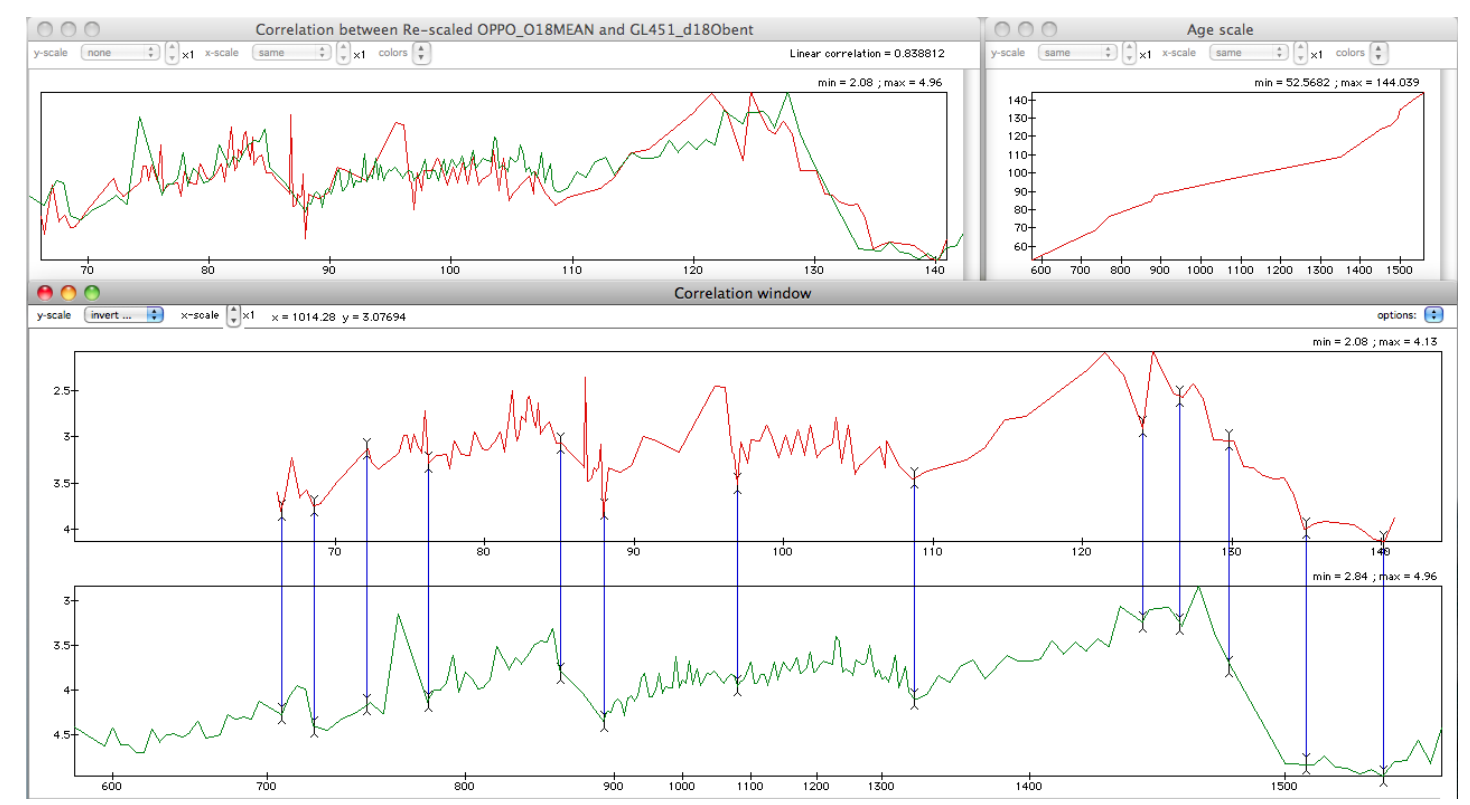

Figura 10: Correlação entre as curvas isotópicas de Oppo, linha vermelha, e do testemunho KF-12, linha verde. Os pontos de controle das duas curvas estão interligados pelas linhas azuis. 


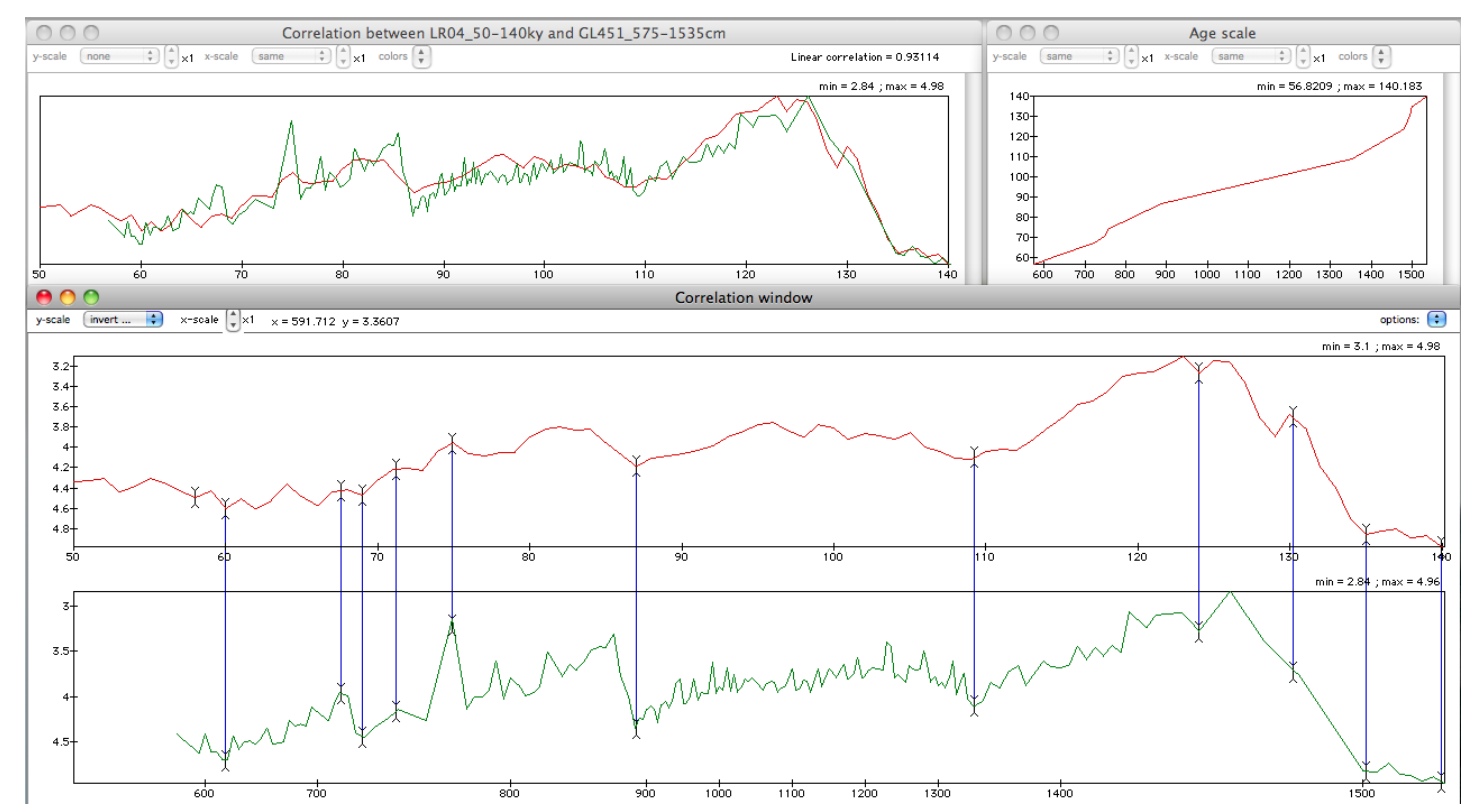

Figura 11: Correlação entre as curvas isotópicas LR04, linha vermelha, e do testemunho KF12 , linha verde. Os pontos de controle das duas curvas estão interligados pelas linhas azuis.

Outras alternativas foram testadas, como a correlação com os testemunhos de gelo da Antártica (VOSTOK) $(\mathrm{r}=-0,82)$ e da Groenlandia (NGRIP) $(\mathrm{r}=-0,72)$. A primeira foi feita utilizando-se a curva de temperatura obtida pelos valores de $\delta \mathrm{D}$ (Figura 12) e, a segunda, através dos dados de $\delta^{18} \mathrm{O}$ do gelo (Figura 13).

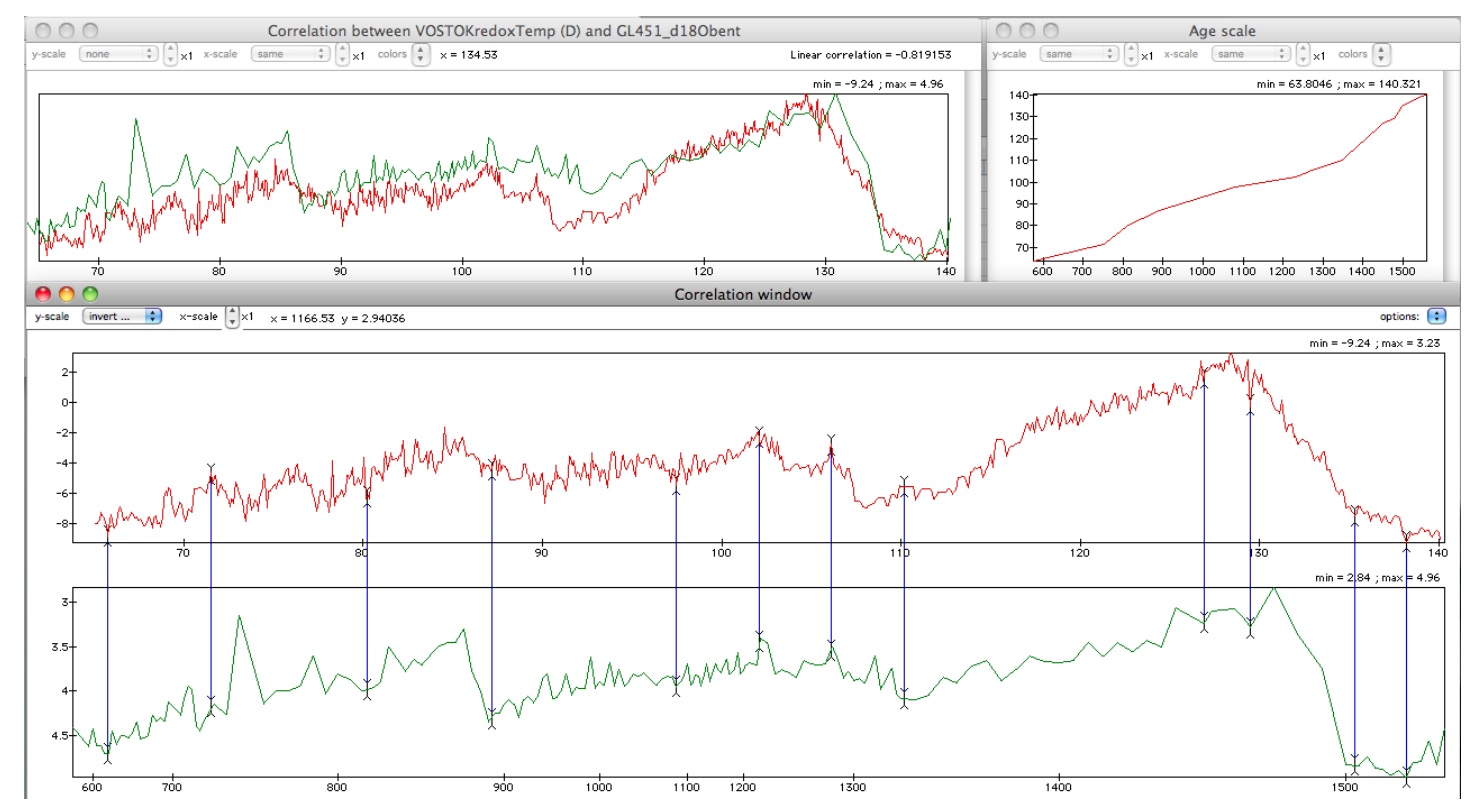

Figura 12: Correlação entre as curvas isotópicas VOSTOK $(\delta D)$, linha vermelha, e do testemunho KF-12 $\left(\delta^{18} \mathrm{O}\right)$, linha verde. Os pontos de controle das duas curvas estão interligados pelas linhas azuis. 


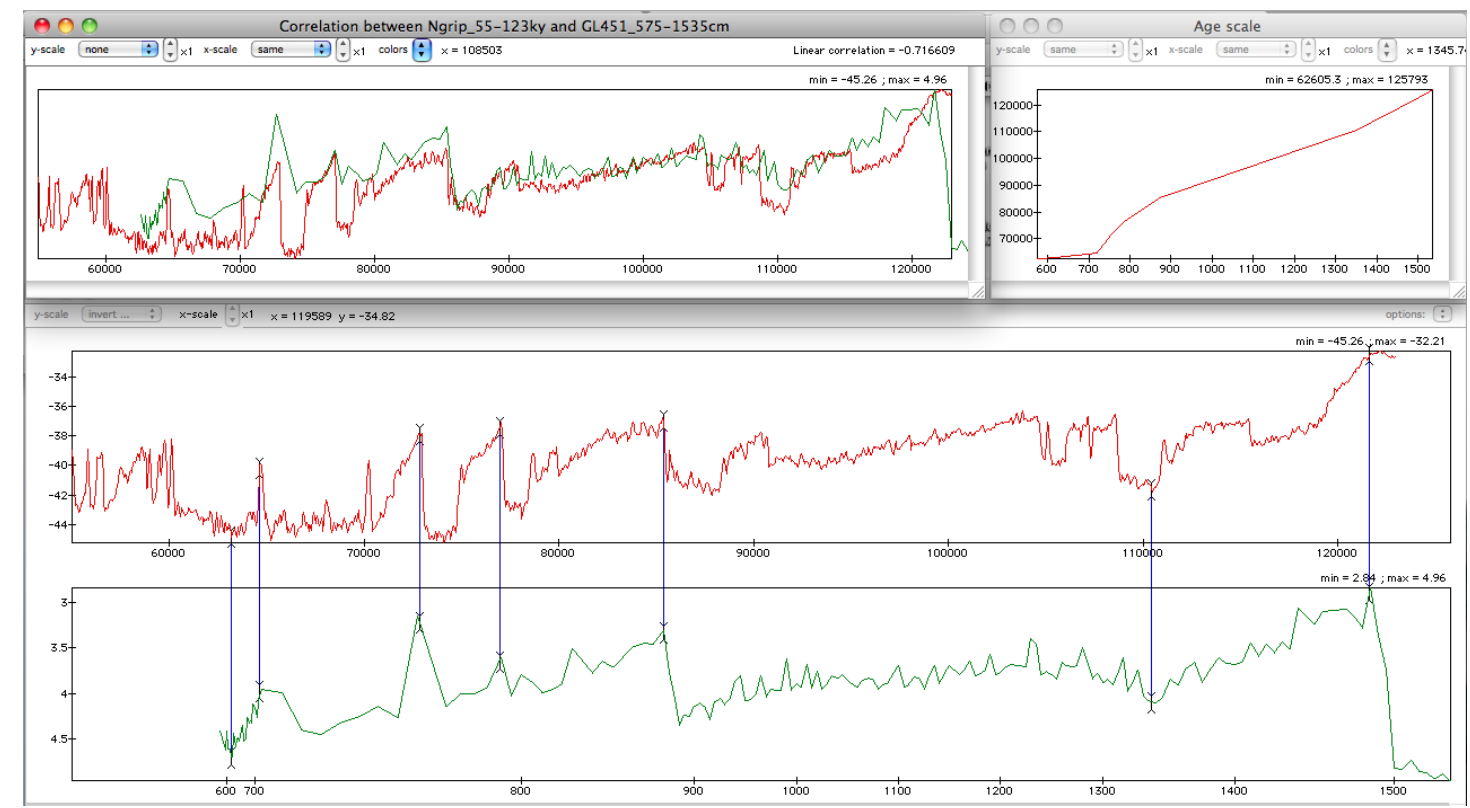

Figura 13: Correlação entre as curvas isotópicas NGRIP, linha vermelha, e do testemunho KF12, linha verde. Os pontos de controle das duas curvas estão interligados pelas linhas azuis.

Por fim, como a cronologia do testemunho KF-18 foi bem definida e sua localização é próxima ao testemunho KF-12, decidiu-se optar pelo modelo de idade obtido através da sua correlação $(r=0,88)$ (Figura 14). Desta forma, o limite inferior do estágio isotópico marinho 5 inferido foi 129,5 e o superior, 71,1 ka.

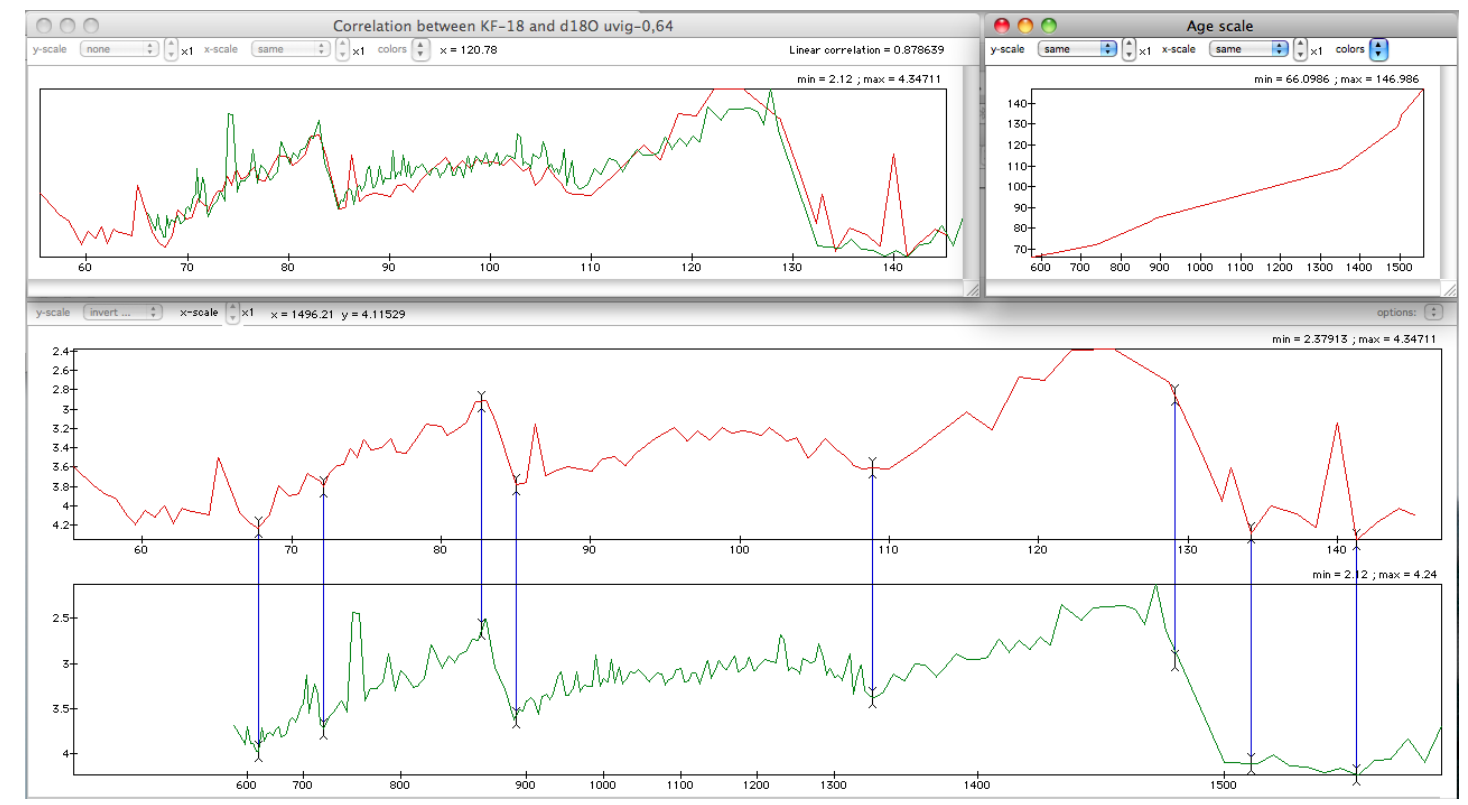

Figura 14: Correlação entre as curvas isotópicas dos testemunhos KF-18, linha vermelha, e KF-12, linha verde. Os pontos de controle das duas curvas estão interligados pelas linhas azuis. 
A Figura 15 resume todas os modelos de idade elaborados para o testemunho KF-12. Como pode-se observar, os valores de regressão das retas, próximos a 1,0, indicam uma boa correlação entre as curvas de referência e a do KF-12. Porém, a fim de comparar-se o período dos eventos climáticos reconhecidos nos registros do KF-12 com as ocorrências em outros locais mais distantes (p. ex. polos e hemisfério norte) optou-se pelo modelo obtido através da correlação com o registro isotópico mais próximo do testemunho KF-18, com cronologia independente e bem estabelecida.

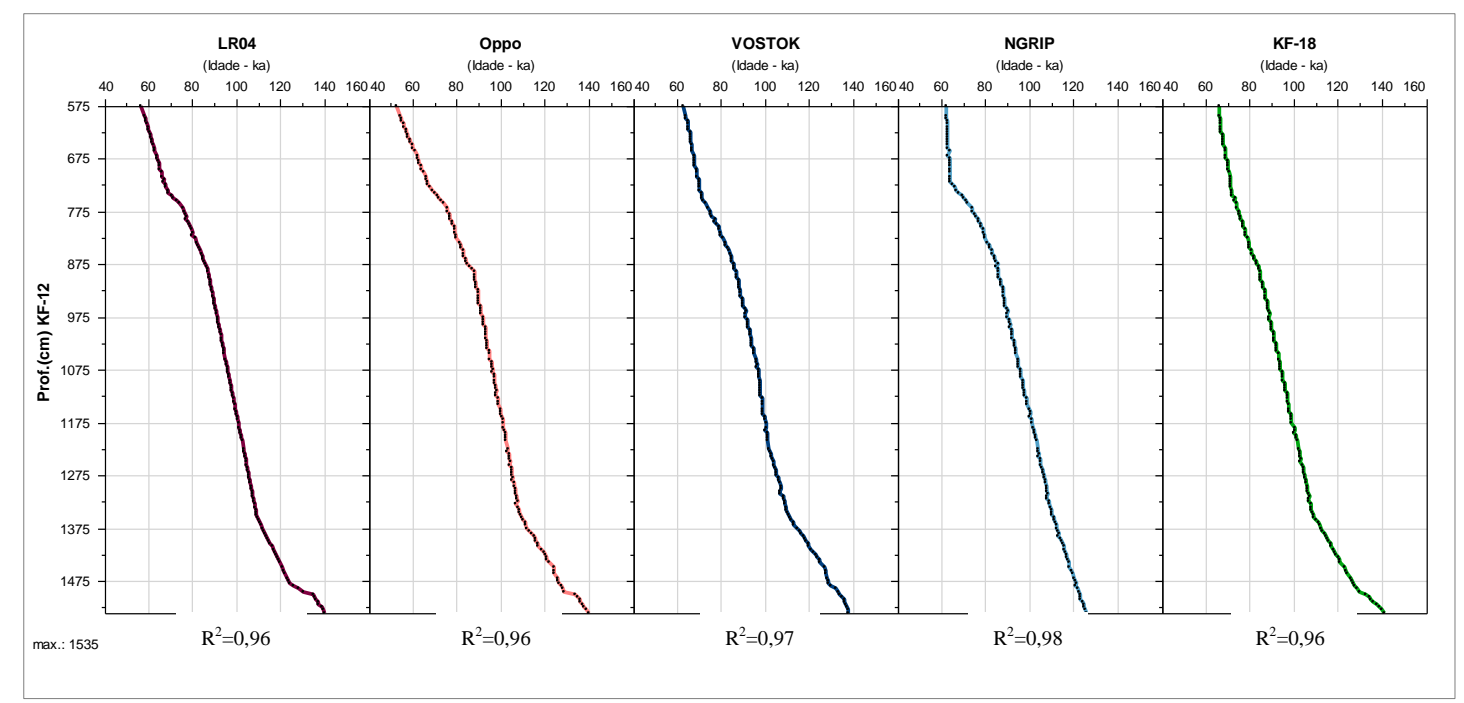

Figura 15: Modelos de idade para o testemunho KF-12 elaborados com diferentes curvas de referência e seus respectivos valores de regressão.

\subsection{Taxa de sedimentação}

O testemunho KF-12 possui uma elevada taxa de sedimentação média igual a $16,4 \mathrm{~cm} / 10^{3}$ anos. A menor taxa, $1,8 \mathrm{~cm} / 10^{3}$ anos, ocorreu entre 134,3 e 129,1 ka antes do Presente (AP). Em 129,1 ka AP, subiu para 7,2 cm/10 3 anos, aumentando ainda mais em 108,9 ka, para $19,4 \mathrm{~cm} / 10^{3}$ anos. Há 85,0 ka a taxa de sedimentação regride para 8,0 $\mathrm{cm} / 10^{3}$ anos por pouco tempo, até 82,7 quando eleva-se para $12,5 \mathrm{~cm} / 10^{3}$ anos. Em 72,1 ka AP ocorre a taxa máxima do intervalo estudado, igual a $26,6 \mathrm{~cm} / 10^{3}$ anos (Figura 16).

Quanto ao testemunho KF-18, a taxa de sedimentação média é $6,8 \mathrm{~cm} / 10^{3}$ anos, consideravelmente menor que a do testemunho KF-12. O menor valor do KF-18, 1,0 $\mathrm{cm} / 10^{3}$ anos, ocorre após o menor valor do KF-12, entre 128,0 e 125,0 ka AP. De 122,2 a 108,8 $\mathrm{ka}$ AP a taxa sobe para 2,0 cm/10 3 anos. Em 108,8 ka, há um aumento para 8,0 $\mathrm{cm} / 10^{3}$ anos, e a taxa de sedimentação oscila pouco até $77,0 \mathrm{ka}$, quando atinge o valor 
máximo do período analisado, igual a $11,2 \mathrm{~cm} / 10^{3}$ anos. Essa taxa maior ocorre, relativamente, por pouco tempo, pois em 71,0 ka, há uma diminuição da taxa para 7,5 $\mathrm{cm} / 10^{3}$ anos.

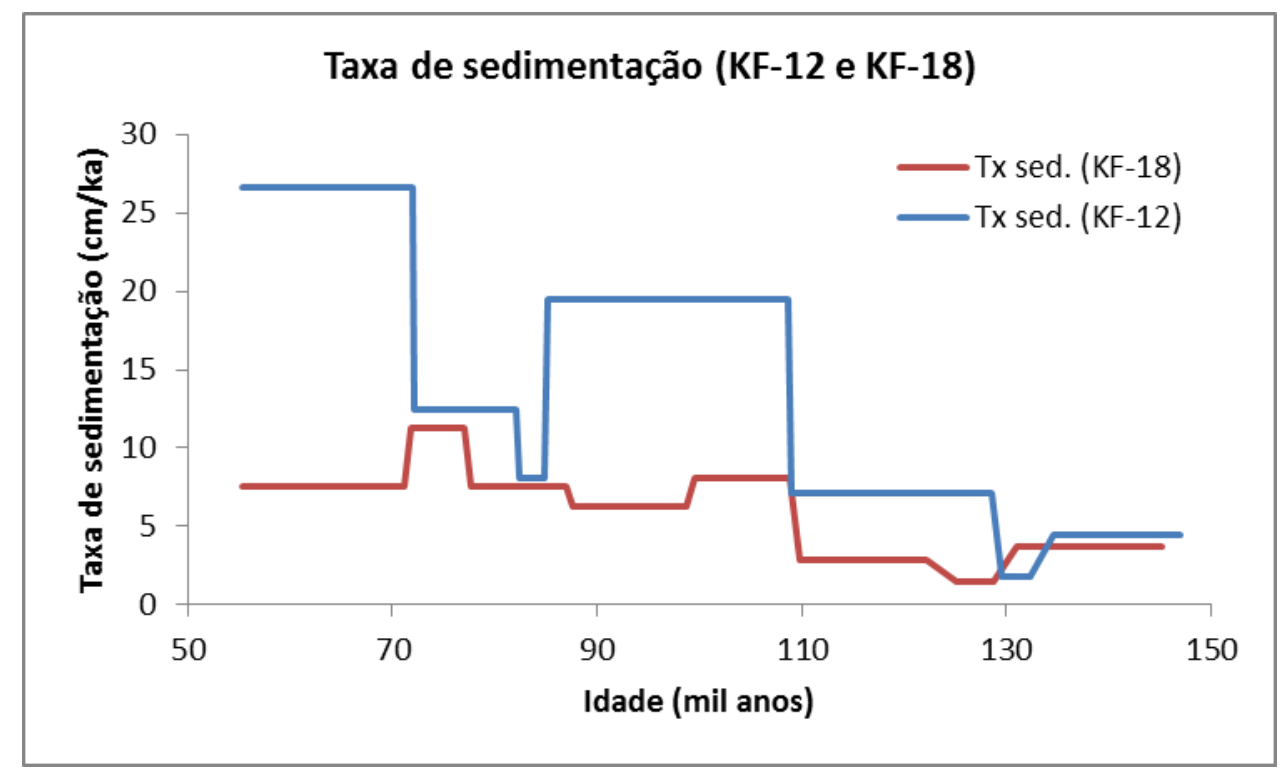

Figura 16: Taxa de sedimentação dos testemunhos KF-12, linha azul, e KF-18, linha vermelha. Nestas estimativas, a taxa é considerada constante dentro de um mesmo intervalo.

\subsection{Bioestratigrafia}

- $\mathrm{KF}-18$

As biozonas de Ericson e Wollin (1968) foram identificadas no testemunho KF-18 a partir dos intervalos de abundância e os intervalos de escassez ou ausência do plexo menardii ao longo do período estudado. O plexo menardii é composto pelas espécies: G. menardii, G. cultrata, G. tumida, G. tumida flexuosa e G. fimbriata. 


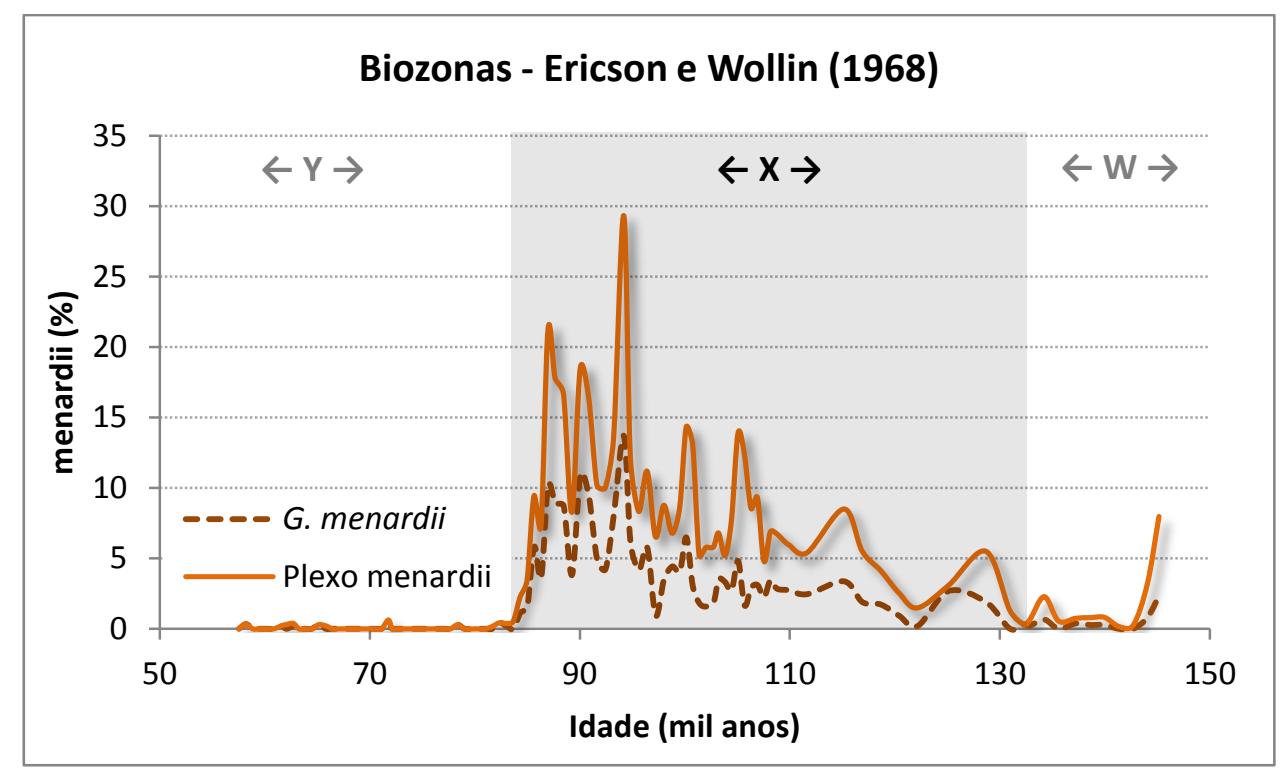

Figura 17: Biozonas $\mathrm{X}$ e seus limites com as biozonas W e Y no intervalo estudado.

Biozona $\mathrm{W}$ : $\mathrm{O}$ início da zona $\mathrm{W}$ é marcado pela diminuição repentina da abundância relativa do plexo menardii. Esta curta biozona possui 10 amostras que incluem a as amostras $631 \mathrm{~cm}$ a $588 \mathrm{~cm}$, que correspondem ao intervalo de de 142,7 a 131,0 ka AP (Figura 17). Destas, apenas duas ultrapassam o valor de 1\% da abundância relativa. É interessante notar que, apesar de se tratar de um período notoriamente desfavorável à proliferação das espécies que compõem o plexo menardii, não foi observado valor de abundância relativa igual à zero ao longo deste intervalo. $G$. menardii, G. cultrata e G. tumida estão presentes em proporções bem baixas (inferiores a 1\%). G. tumida flexuosa é ausente neste intervalo (Figura 18).

Biozona X: O começo da zona $\mathrm{X}$ é caracterizado pelo aumento significativo da abundância relativa das espécies que compõem o plexo menardii. Esta unidade bioestratigráfica possui 45 amostras compreendidas em $230 \mathrm{~cm}$ de comprimento, de 583 cm a $358 \mathrm{~cm}$, que representam o período de 128,7 a 84,3 ka AP. As espécies $G$. menardii, G. tumida e a subespécie G. tumida flexuosa exibem uma clara tendência de aumento ao longo deste intervalo. A exceção é $G$. cultrata que exibe uma clara tendência de diminuição de sua abundância relativa, sendo observada a sua ausência a partir de aproximadamente a metade desta biozona. Na porção superior desta biozona foi observado o maior valor de abundância relativa do plexo menardii em todo o testemunho, 29,34\% na amostra $424 \mathrm{~cm}$ (94,2 ka AP). Ao analisarmos as espécies separadamente, observa-se que a espécie G. tumida exibe a maior abundância relativa 
entre as menardiformes, $15,4 \%$, que também representa o valor mais alto de sua abundância relativa ao longo de todo o KF-18. O topo da zona $\mathrm{X}$ é caracterizado pelo desaparecimento da subespécie G. tumida flexuosa.

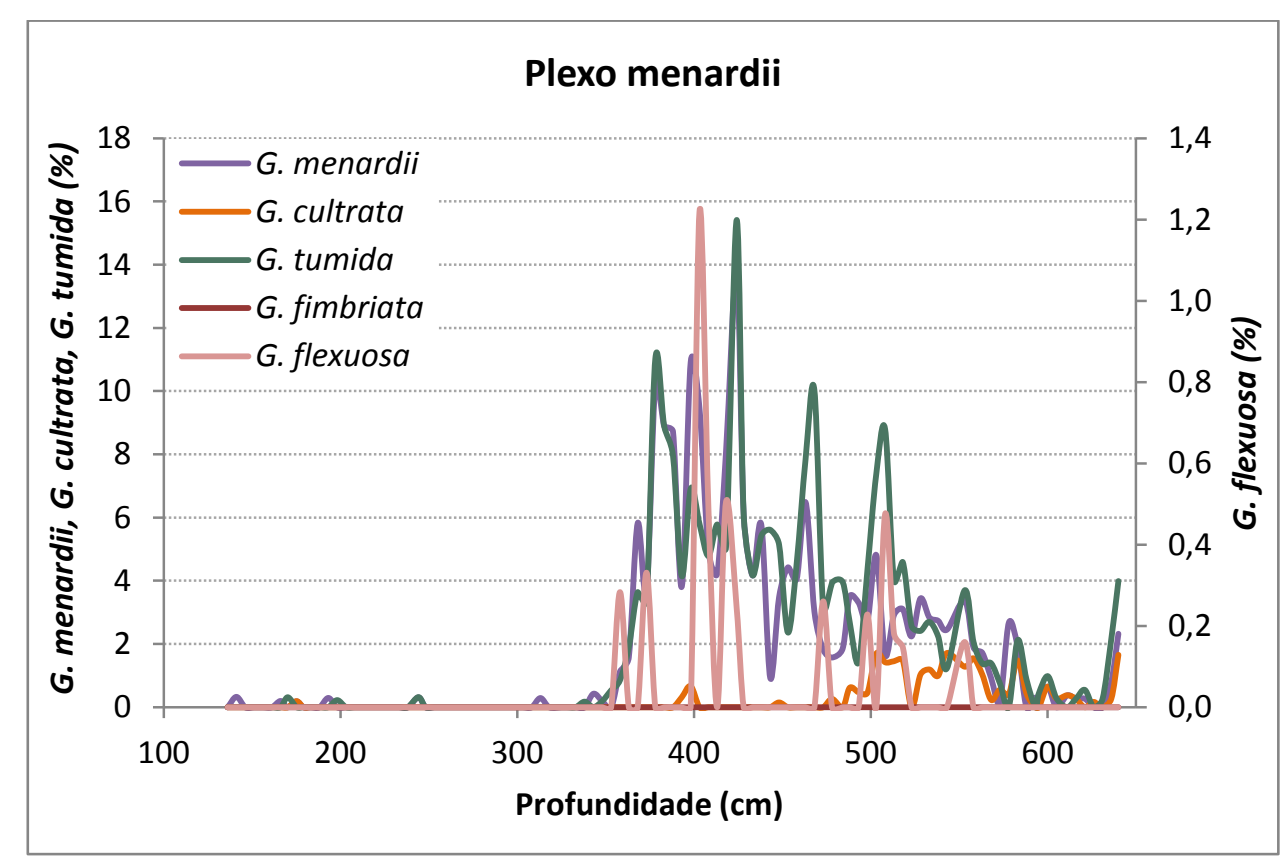

Figura 18: Abundância relativa das espécies que compõem o plexo menardii, do testemunho KF-18.

Biozona Y: A queda na abundância relativa do plexo menardii caracteriza o início da Zona Y. Esta unidade possui 68 amostras incluídas em $347 \mathrm{~cm}$ de comprimento, de $353 \mathrm{~cm}$ à $14 \mathrm{~cm}$. O intervalo analisado neste estudo, contém apenas o início dessa biozona em 83,7 ka AP. Este intervalo se caracteriza por ser a biozona onde foram observados os menores valores de abundância relativa do plexo menardii em todo o testemunho. Somente 17 amostras deste intervalo apresentam valores de abundância relativa maior que zero; entre estas o maior valor observado foi $0,63 \%$, na amostra 244 cm (71,8 ka AP). G. menardii é a espécie mais frequente neste intervalo, seguido por $G$. tumida e G. cultrata, com apenas uma ocorrência nesta biozona.

\section{- $\mathrm{KF}-12$}

No caso do testemunho KF-12, efetuou-se uma compilação dos dados de interesse a partir dos estudos de Santarosa (2007) e Marins (2009). Santarosa selecionou o espaçamento médio, entre as amostras analisadas, de 20 ou $50 \mathrm{~cm}$, em função da 
magnetoestratigrafia. Marins utilizou espaçamentos em intervalos regulares de $30 \mathrm{~cm}$ ou de acordo com as variações litológicas apresentadas. Os autores não realizaram a contagem da espécie G. cultrata e Marins não identificou e contabilizou a G. fimbriata. Como esta espécie só foi encontrada próximo ao topo do testemunho, não está incluída em nosso intervalo. A Figura 19 mostra o biozoneamento obtido para o testemunho KF12.

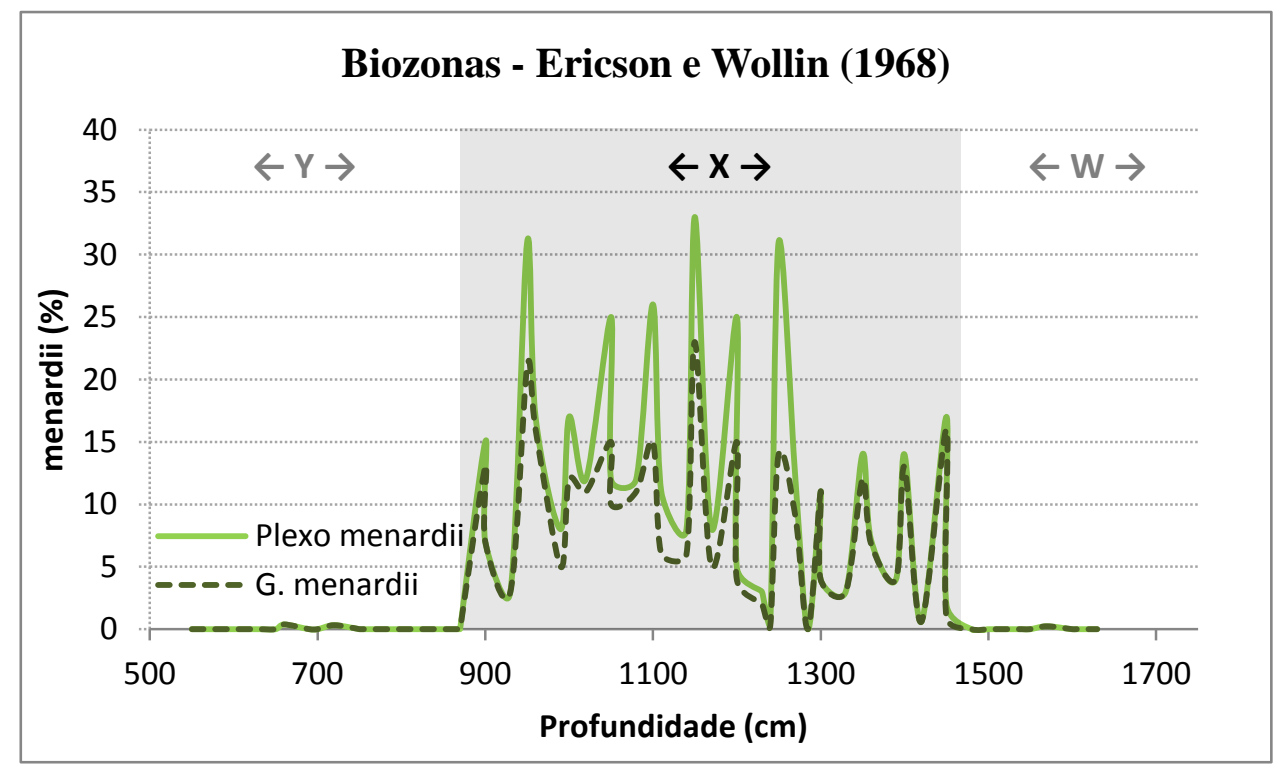

Figura 19: Biozonas $\mathrm{X}$ e seus limites com as biozonas $\mathrm{W}$ e $\mathrm{Y}$ no intervalo estudado.

Biozona W: $\mathrm{O}$ início da zona $\mathrm{W}$ não aparece no intervalo analisado. Quanto ao final dessa biozona, é marcado pela aparição das 3 espécies analisadas: G. menardii, $G$. tumida e a subespécie G. tumida flexuosa na profundidade $1.450 \mathrm{~cm}$ equivalente a 122,9 ka AP. G. Menardii é a mais abundante dentre as 3 espécies, com $16 \%$ de abundância relativa neste período. G. tumida é $1 \%$ e G. flexuosa, $0,5 \%$ (Figura 20). 


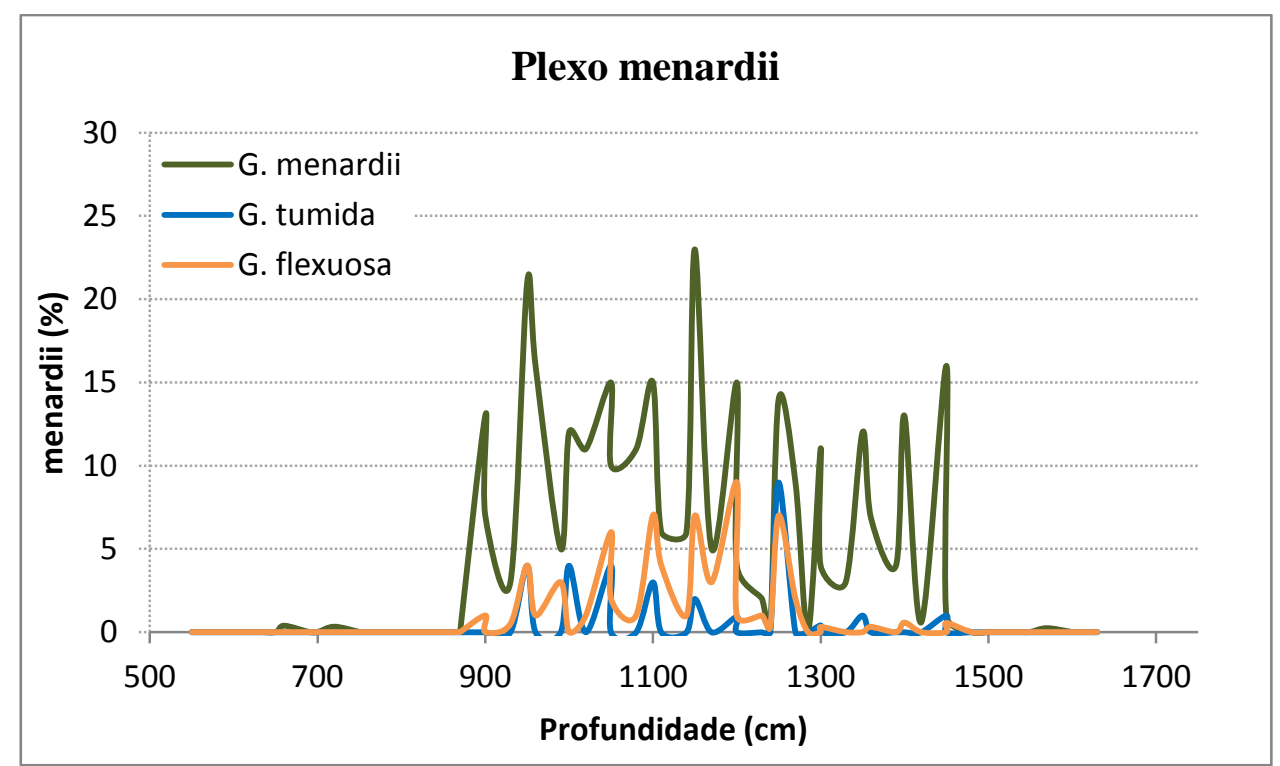

Figura 20: Abundância relativa das espécies que compõem, em parte, o plexo menardii, do testemunho KF-12.

Biozona X: O começo da zona X é notado pela aparição repentina das espécies do plexo menardii, principalmente de G. Menardii. em 122,9 ka AP. Esta unidade bioestratigráfica possui 28 amostras compreendidas entre 1.450 e $900 \mathrm{~cm}$, ou seja, até 85,7 ka AP. G. flexuosa tem um aumento considerável apenas em $1.250 \mathrm{~cm}$, junto $G$. tumida. Mas, logo em seguida, ambas as abundâncias diminuem, voltando a aumentar em $1.200 \mathrm{~cm}$. G. tumida é a primeira espécie a se ausentar, em $950 \mathrm{~cm}(88,31 \mathrm{ka} \mathrm{AP})$ depois a $G$. flexuosa juntamente com a $G$. menardii em $900 \mathrm{~cm}(85,74$ ka AP). $G$. Menardii é a espécie mais abundante em toda a biozona $\mathrm{X}$. Em segundo lugar se encontra a G. Flexuosa e a menos abundante é a G. tumida.

Biozona Y: A ausência completa do plexo menardii caracteriza o início da Zona Y em $870 \mathrm{~cm}$ que corresponde a 83,0 ka AP. G. Menardii ainda aparece próximo à profundidade $700 \mathrm{~cm}$, com abundância relativa menor que $0,5 \%$. As outras 2 espécies estão ausentes até o fim do intervalo analisado neste estudo.

Os limites inferidos para a biozona $X$, foi 135,6 a 82,3 ka AP para o testemunho KF-18, e 133,5 a 88,4 ka AP para o KF-12.

\subsection{Estratigrafia isotópica}


Os valores de isótopos de oxigênio obtidos por foraminífero bentônico Uvigerina spp., no testemunho KF-12, apresentaram-se sempre maiores que os valores de $\delta^{18} \mathrm{O}$ de Cibicidoides. Assim, realizou-se a correção dos dados de Uvigerina, subtraindo-se do seu valor isotópico de oxigênio 0,64, de acordo com Raymo et al.(2004). As outras espécies bentônicas utilizadas na análise isotópica não apresentaram valores muito discrepantes em relação aos de Cibicidoides wuellerstorfi, então, não foi necessária a correção.

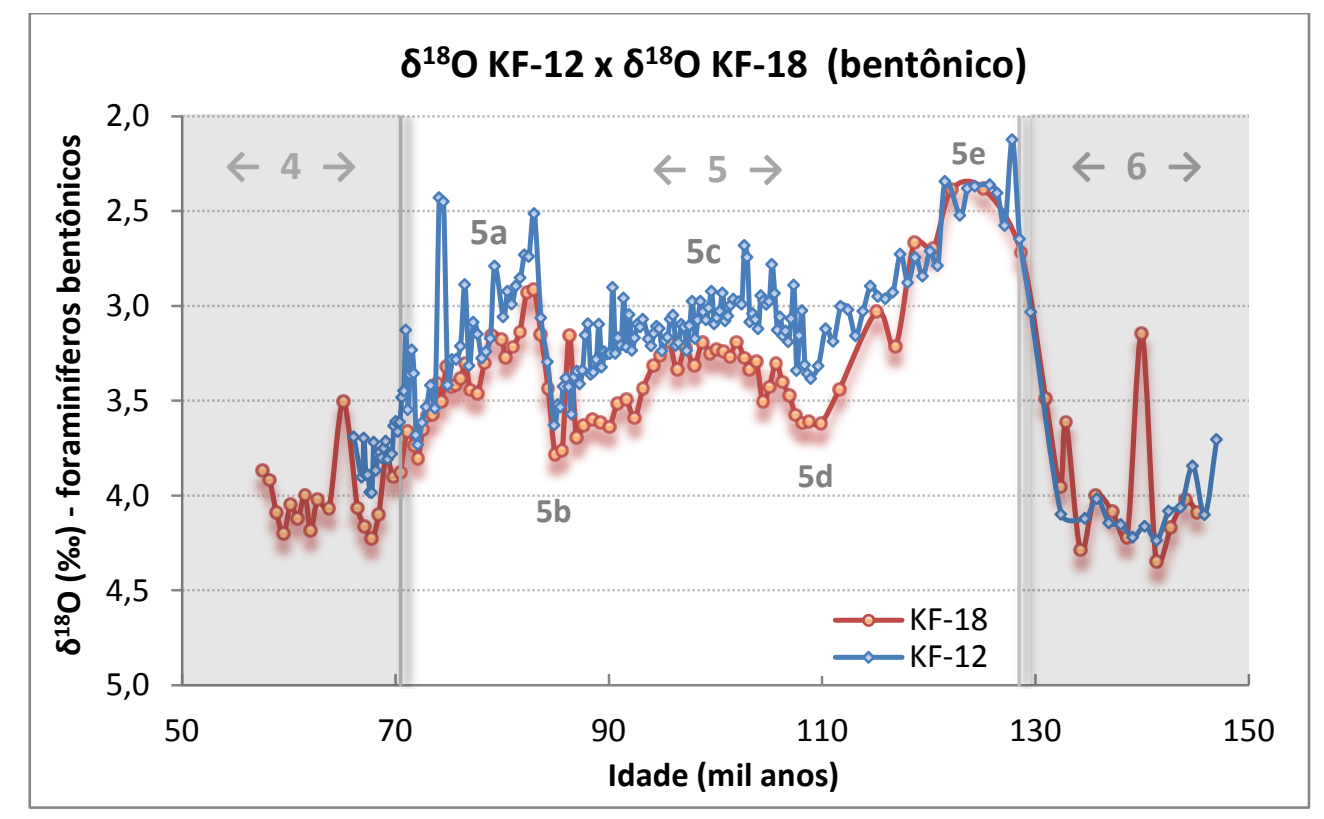

Figura 21: Curva isotópica de oxigênio em foraminíferos bentônicos ao longo dos testemunhos KF-18 (linha vermelha) e KF-12 (linha azul). Os estágios isotópicos marinhos glaciais, MIS 4 e 6 estão indicados pela área sombreada. As linhas verticais cinzas indicam os limites MIS 4-5 e MIS 5-6. Os subestágios do período interglacial, MIS 5, estão indicados por 5a, 5b, 5c, $5 \mathrm{~d}$ e $5 \mathrm{e}$.

A partir da curva isotópica em foraminíferos bentônicos, tanto do testemunho KF-12 quanto do KF-18, pôde-se observar os subestágios estadiais (5d e 5b) e interestadiais (5e, 5c e 5a) do MIS 5 (Figura 21). Também foram identificados os limites MIS 6 - 5, em 71,1 ka, que está relacionado à deglaciação, denominado também de Terminação Glacial II; e MIS 5 - 4, em 129,5 ka, que representa a transição para o período glacial. Desta forma, foi estabelecida a estratigrafia isotópica de ambos os testemunhos para o período estudado. O eixo das ordenadas está invertido de acordo com a forma convencional. 
As duas curvas exibiram uma mesma tendência, no entanto, os dados de $\delta^{18} \mathrm{O}$ do testemunho KF-18 são mais pesados que os dados isotópicos do KF-12 em, aproximadamente $0,3 \%$ principalmento na parte intermediária do MIS 5 .

O menor valor isotópico está associado ao subestágio 5e que acredita-se ser o período que mais se assemelha às condições atual.

A seguir, é apresentada uma breve descrição dos estágios isotópicos no testemunho, KF-18:

\section{- MIS 6 - Glacial}

O MIS 6 compreende o intervalo entre 191 e 130 ka. No testemunho KF-18, este estágio isotópico correspondeu o intervalo entre 190,5 e 131 ka. Este MIS corresponde a $218 \mathrm{~cm}$ de sedimentos $(806-588 \mathrm{~cm})$ e está representado por 45 amostras.

- MIS 5 - Interglacial

O MIS 5 compreende o intervalo entre 130 e 71 ka. No KF-18 este estágio isotópico correspondeu o intervalo entre 128,7 e 71,1 ka. O MIS 5 corresponde a 345 cm de sedimentos $(583-238 \mathrm{~cm})$ e está representado por 69 amostras. O teor de carbonato das amostras do MIS 5 foi variável (de $14 \%$ a $56 \%$ ) e a média foi $22,8 \%$. A amplitude isotópica entre o MIS 6 e o MIS 5 foi de 1,9\%o. Os subestágios ou eventos isotópicos individuais nos MISs são indicados por letras minúsculas ou no sistema decimal, por exemplo, o MIS 5 é dividido em subestágios quentes 5.1, 5.3 e 5.5 (ou 5a, 5 c e 5 e) e subestágios frios 5.2 e 5.4 (ou 5 b e 5 d) do topo para a base.

- MIS 4 - Glacial

O MIS 4 compreende o intervalo entre 71 e $57 \mathrm{ka}$. No KF-18 este estágio isotópico correspondeu ao intervalo entre 70,5 e 57,5 k.a. Este MIS corresponde a 97 cm de sedimento $(233-136 \mathrm{~cm})$ e está representado por 21 amostras. O MIS 4 apresentou os menores teores de carbonato, em média 13\%. A amplitude isotópica entre o MIS 5 e o MIS 4 foi de 1,85\%.

6.5 Isótopos de oxigênio em foraminíferos planctônicos (KF-12 e KF-18) 
O início do intervalo estudado se encontra dentro do MIS 6, caracterizado por valores isotópico de oxigênio mais elevados, $0,23 \%$. O ponto médio da maior variação dos valores de $\delta^{18} \mathrm{O}$ está próximo a $0,8 \%$ e caracteriza o ponto de transição entre o MIS 6 e o subestágio 5e. O valor de $\delta^{18} \mathrm{O}$ é mínimo no interestadial 5e, igual a -1,66\% (KF12) e - $1,24 \%$ (KF-18), equivalendo ao menor volume de gelo, provavelmente, devido a maior temperatura do período. A partir desse período a curva isotópica apresenta algumas oscilações com o aumentos dos valores isotópicos nos estadiais $5 \mathrm{~d}$ e $5 \mathrm{~b}$. Também é possível observar uma tendência geral de aumento dos valores, até chegar ao valor máximo, 0,49\% no KF-18, já dentro do MIS 4. No testemunho KF-12 o aumento do $\delta^{18} \mathrm{O}$ não é tão acentuado, o valor máximo no início do MIS 4 é - 0,16\%.

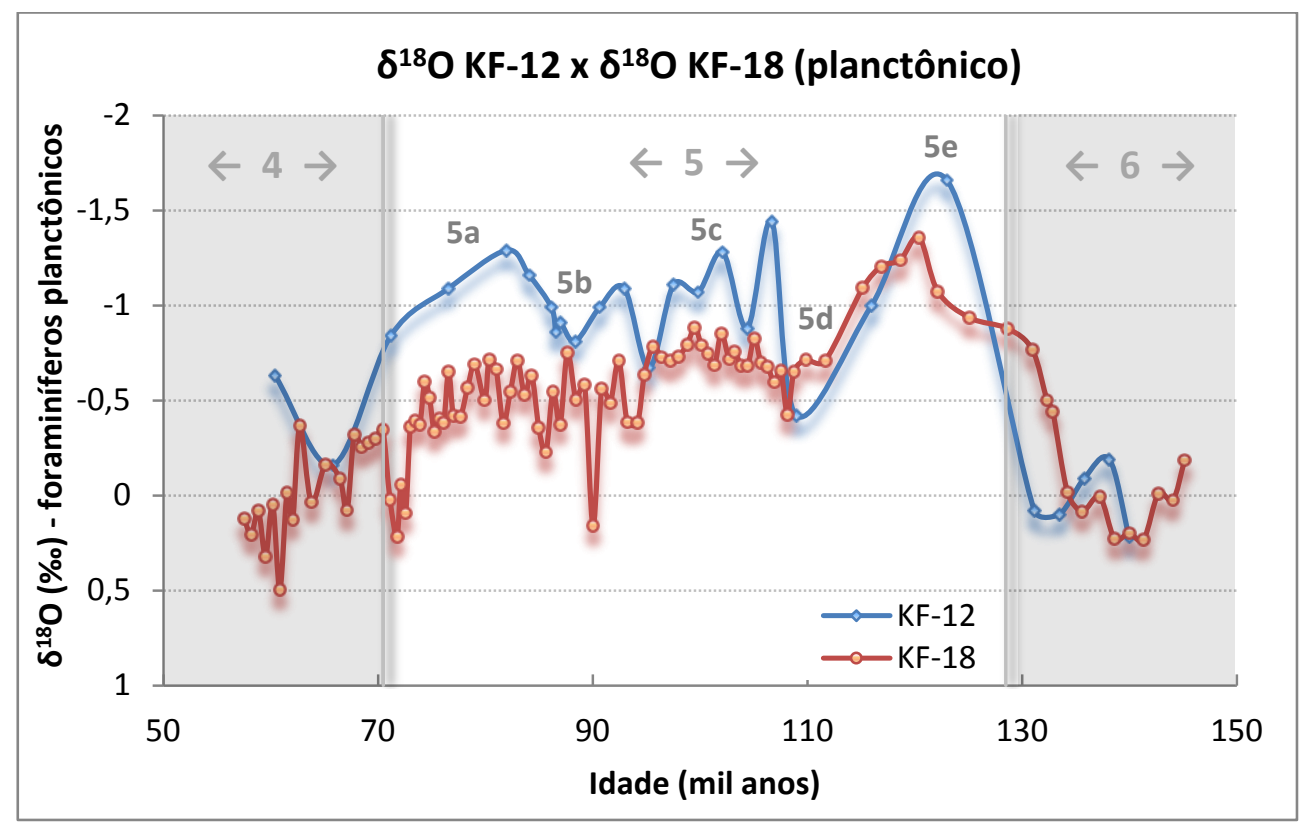

Figura 22: Curva isotópica de oxigênio em foraminíferos planctônicos ao longo dos testemunhos KF-18, linha vermelha, e KF-12, linha azul. Os estágios isotópicos marinhos glaciais, MIS 4 e 6 estão indicados pelas áreas sombreadas. As linhas verticais cinza indicam os limites MIS 4-5 e MIS 5-6. Os subestágios do período interglacial, MIS 5, estão indicados por $5 a, 5 b, 5 c, 5 d$ e $5 e$.

Comparando-se as curvas isotópicas de foraminíferos planctônicos dos dois testemunhos, nota-se um comportamento semelhante, com maior destaque ao Último Máximo Interglacial associado aos menores valores de $\delta^{18} \mathrm{O}$. Os subestágios do MIS 5 foram identificados de forma tentativa de acordo com a variação dos dados do testemunho KF-12. Observando o limite MIS 5-4, é possível perceber um aumento abrupto do $\delta^{18} \mathrm{O}$ de cerca de $0,5 \%$ o. Esse evento dura cerca de 1,5 ka apenas. Quanto aos 
valores de $\delta^{18} \mathrm{O}$ do KF-12, durante o início do MIS 4, retomam condições interglaciais de forma inesperada.

\subsection{Curvas climáticas com base na fauna de foraminíferos planctônicos (KF-12 e KF-18)}

De acordo com a classificação de Ruddiman (1977), a margem ocidental do Atlântico Sul apresenta as condições ideais para a utilização de foraminíferos em reconstruções paleoceanográficas. Algumas características dos foraminíferos planctônicos ou assembleias de foraminíferos planctônicos utilizadas como proxies são: as variações na composição faunal (por ex. Imbrie e Kipp, 1971; Pflaumann et al., 1996), o sentido de enrolamento (por ex. Ericson et al., 1955; Naidu e Malmgren, 1996), a composição isótopica (por ex. Emiliani, 1954; Shackleton, 1982), o conteúdo de elementos traços (por ex. Lea e Boyle, 1991; Nürnberg et al., 1996) e o tamanho das testas (por ex. Schmidt et al., 2003a, 2003b). Tais variações são utilizadas para estimar diversas variáveis incluindo paleotemperatura, paleossalinidade, paleoprodutividade e profundidade da camada de mistura.

Sob o ponto de vista paleoceanográfico, a avaliação dos dados de abundância das assembleias dos foraminíferos planctônicos envolve mais que uma compilação direta de variações da temperatura global e a presença ou ausência de determinadas espécies. Uma vez que a abundância individual de uma espécie varia dentro de sua faixa absoluta de temperatura, a contagem acurada das abundâncias relativas em uma assembleia nos permite inferir as condições paleoceanográficas, o que seria impossível de estimar com dados relativos à simples presença/ausência de uma determinada espécie (Mix, 1987).

As paleotemperaturas da superfície do mar (SST) para a região sudoeste do Atlântico Sul foram obtidas através da Rede Neural Artificial (ANN) no testemunho KF-18. As estimativas de SST foram divididas em: verão, inverno e anual (Figura 23). A média das estimativas de verão é cerca de $26^{\circ} \mathrm{C}$; enquanto que a média de inverno é $4^{\circ} \mathrm{C}$ a menos. A média das temperaturas anuais, então, tem valor intermediário. $\mathrm{O}$ menor valor obtido para esse parâmetro foi $18,6^{\circ} \mathrm{C}$ em torno de 71 ka durante o inverno. O valor mínimo de SST das três curvas, coincidiram com o limite MIS 5-4. Quanto aos valores máximos de cada curva, foram encontrados em 102,7 ka. A maior SST $\left(27,8^{\circ} \mathrm{C}\right)$ foi obtida durante o verão, como esperado. $\mathrm{O}$ interessante na análise deste dado é que a SST máxima não ocorre durante o subestágio 5e, considerado o Último Máximo 
Interglacial, mas sim, dentro do subestágio 5c que também é um subestágio interestadial. Assim como na curva de $\delta^{18} \mathrm{O}$ em foraminífero planctônico do KF-12, após a diminuição dos valores de paleotemperatura na glaciação MIS 5-4, as paleotemperaturas estimadas voltam a subir no início do MIS 4.

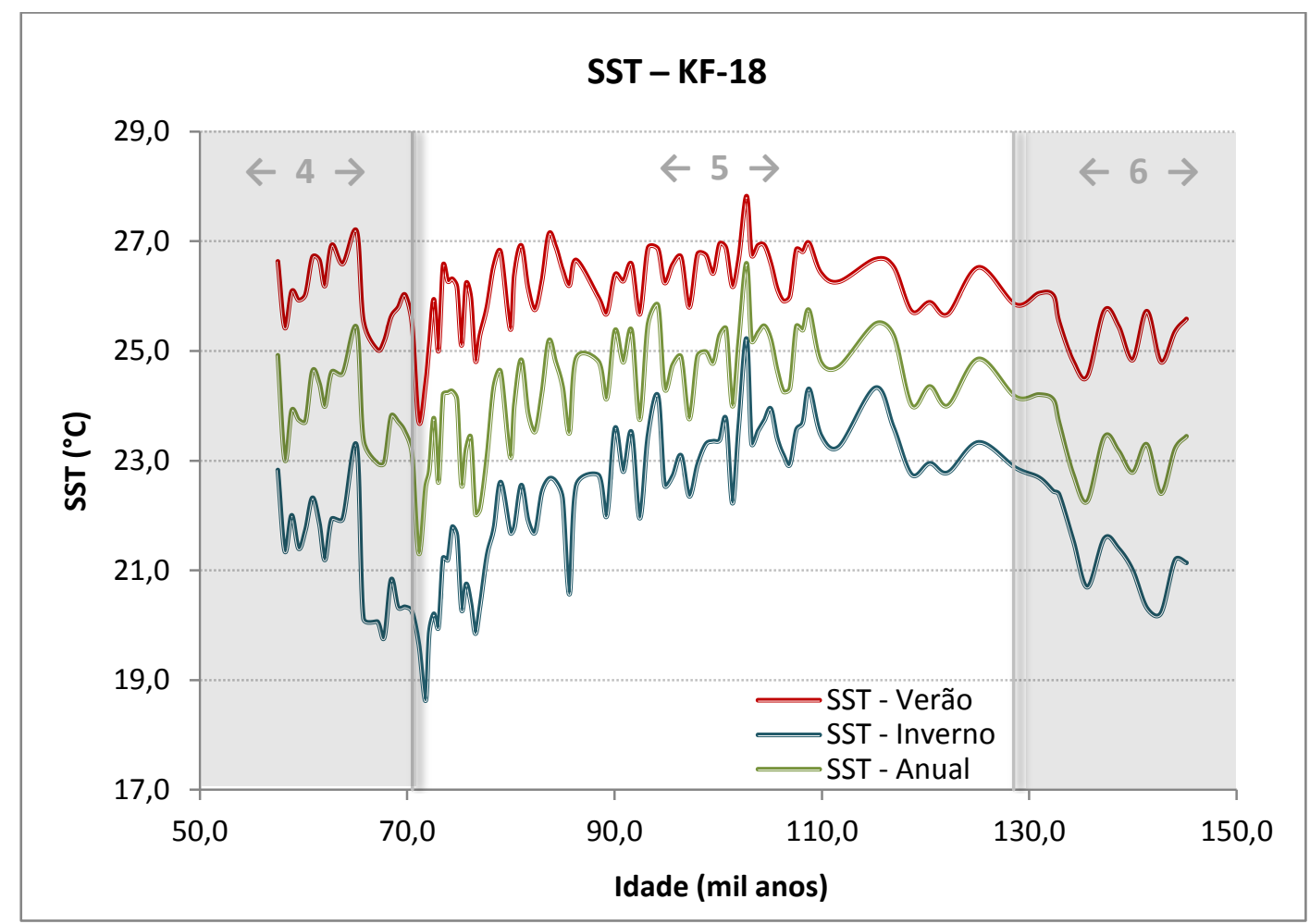

Figura 23: Paleotemperaturas obtidas através da rede neural artifical. São temperaturas de verão (linha vermelha), inverno (linha azul) e anual (linha verde) ao longo do testemunho $\mathrm{KF}$ 18. Os estágios isotópicos marinhos glaciais, MIS 4 e 6 estão indicados pelas áreas sombreadas. As linhas verticais cinza indicam os limites MIS 4-5 e MIS 5-6.

A curva da abundância relativa de foraminífero planctônico que melhor se correlacionou com a curva de paleotemperatura anual foi a curva de G. inflata (d'Orbigny, 1839) tanto do testemunho KF-18 quanto do KF-12 que está menos detalhado (Figura 24). Essa espécie é uma excelente indicadora de zonas transicionais, que separam águas subpolares e subtropicais (Bé e Tolderlund, 1971). A sua distribuição atual nos oceanos está relacionada a massas de água com pequena variação sazonal da salinidade, apresentando maior preferência à condições de inverno (Hilbrecht, 1996). Desta forma, durante o Último Máximo Interglacial quando a temperatura alcançou seus níveis mais elevados, a espécie atingiu seus níveis mínimos. Como descrito por Pivel (2010) e Santarosa (2010), esta espécie é rara ou ausente no 
lado oeste do Atlântico Sul durante o Holoceno. Na transição do MIS 5 para o MIS 4, a curva de $G$. Inflata obtida do testemunho KF-18 apresenta um breve e intenso aumento em sua abundância e logo em seguida uma diminuição abrupta. A glaciação, normalmente é bem gradual, enquanto a deglaciação acontece de forma mais eficiente.

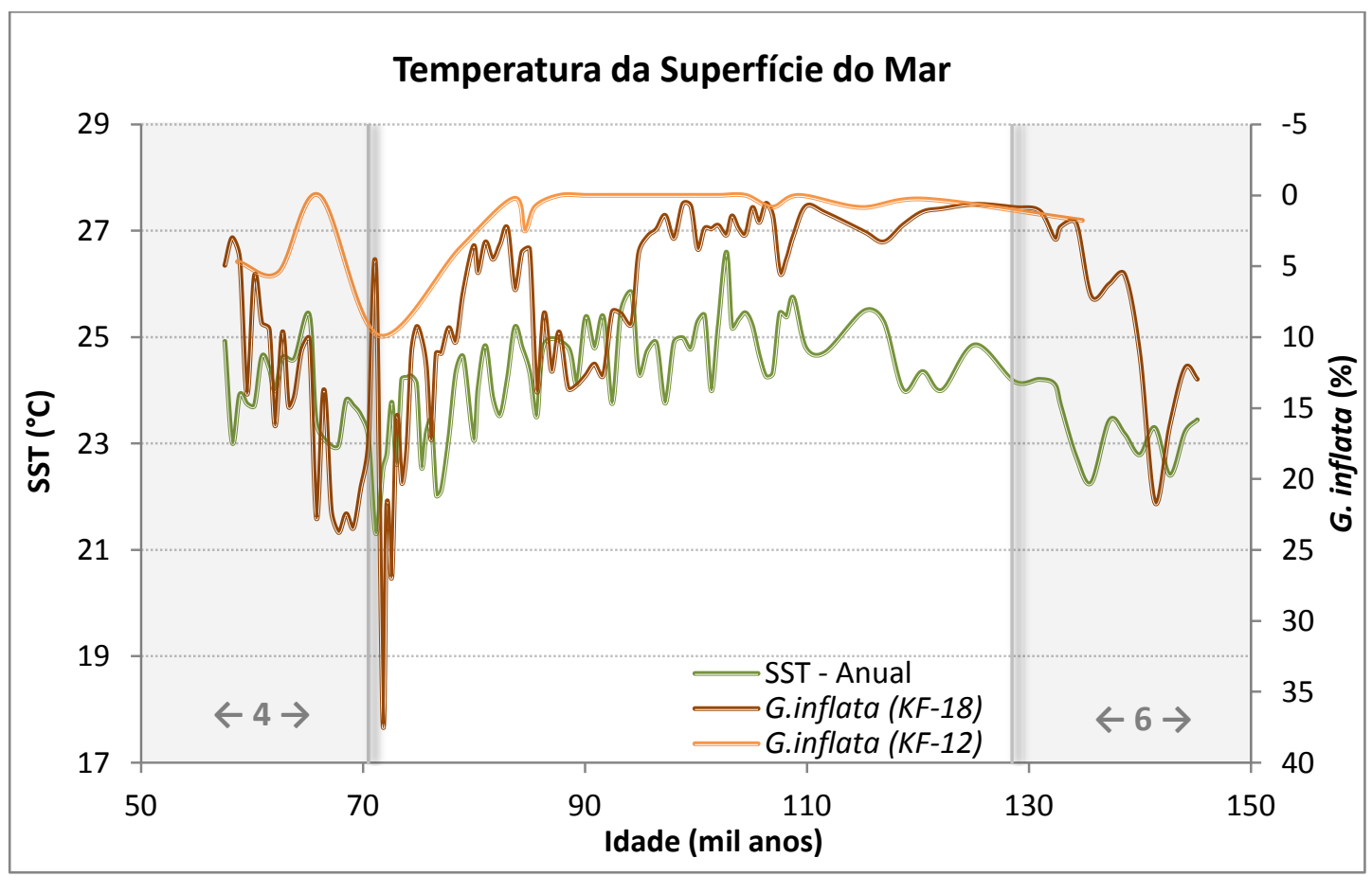

Figura 24: Análise comparativa da curva de paleotemperatura anual com a abundância relativa da espécie de foraminífero planctônico Globorotalia inflata dos dois testemunhos. Os estágios isotópicos marinhos glaciais, MIS 4 e 6 estão indicados pelas áreas sombreadas. As linhas verticais cinza indicam os limites MIS 4-5 e MIS 5-6.

Outra maneira de estudar as mudanças climáticas ocorridas no passado é através da razão entre as espécies típicas de águas quentes e a soma das espécies de águas quentes e de águas frias da região estudada, ou seja, a relação de Rögl e Bolli (1973) adaptada por Vicalvi (1997). As formas de água fria mais representativas são Globigerina bulloides, Globorotalia inflata, e Turborotalita quinqueloba. Os indicativos de águas quentes são Globigerinoides ruber, G. sacculifer e o grupo formado pelas espécies menardiformes (Globorotalia menardii, G. tumida e G.tumida flexuosa).

Como a fauna só foi descrita por completo no testemunho KF-18, não foi possível calcular essa razão para o testemunho KF-12. Nesta estimativa, o subestágio 
interstadial 5e não é distinguível dentro do seu período de ocorrência. Os valores da razão de Rögl e Bolli do início do MIS 5 são baixos, eles aumentam na parte intermediária do intervalo e voltam a cair no fim do MIS 5, já na transição para o MIS4, quando curiosamente se elevam.

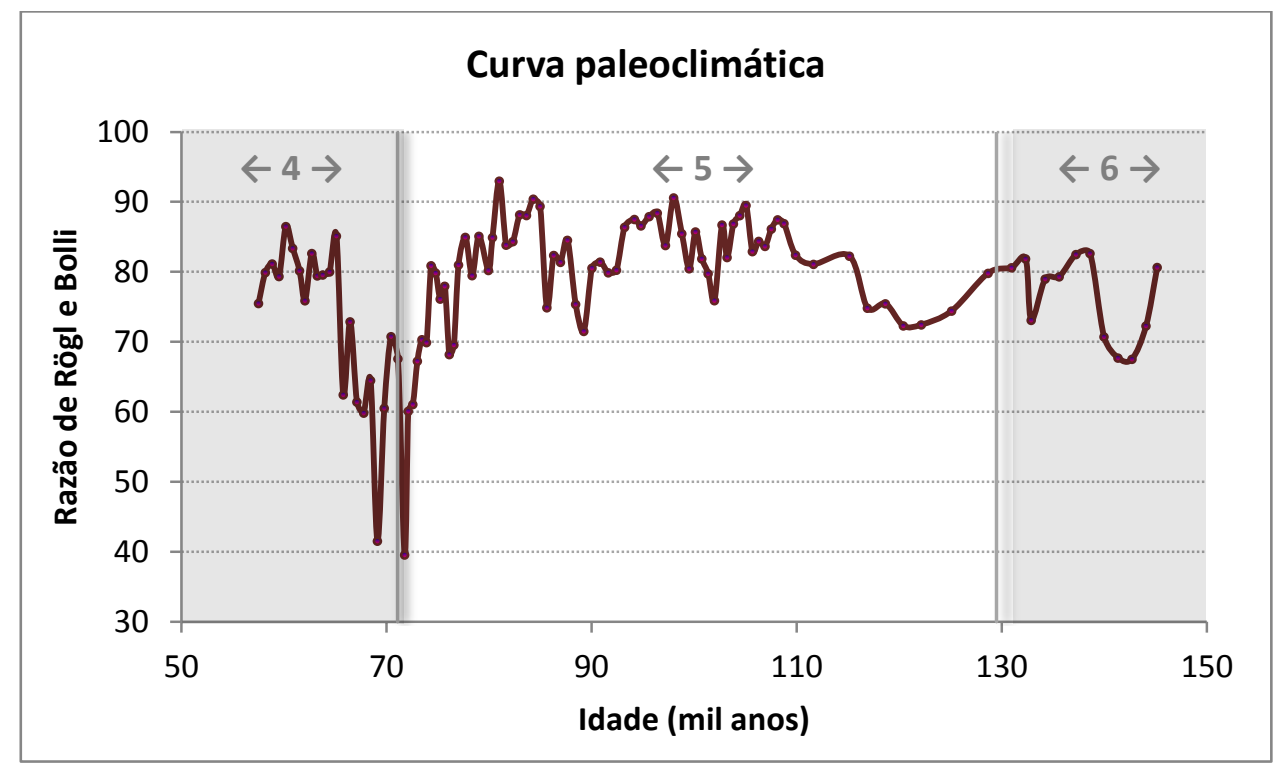

Figura 25: Curva paleoclimática do período estudado obtida pela relação de Rögl e Bolli (1973) adaptada por Vicalvi (1997).

\subsection{Variação do nível do mar (KF-18)}

A curva do nível do mar para o período estudado foi calculada a partir de Lea (2002). Na região do testemunho KF-18, o nível do mar alcançou 20 m acima do nível atual durante o subestágio 5e (Figura 26). Em 108,2 ka atrás, o nível do mar estava 72 m mais profundo, subestágio 5d. De 105,7 a 94,8 ka, os valores variaram pouco em torno de $-36 \mathrm{~m}$ equivalente ao interestadial 5c. Em seguida, a amplitude aumentou consideravelmente, com os valores oscilando entre -95 e $-17 \mathrm{~m}$ até $83 \mathrm{ka}$, subestágios $5 \mathrm{~b}$ e 5a, respectivamente. Após o valor mais elevado do nível do mar durante o 5e, a curva apresentou uma tendência decrescente até o início do MIS 4. Logo após o limite MIS 54, o nível do mar estava 107,6 m abaixo do que o atual em 67,8 ka atrás.

Segundo Cutler et al. (2003), através de estudos em corais da Península Huon, Papua Nova Guinea e Barbados, o MIS 5e terminou antes de 113,1 \pm 0,7 ka quando o nível do mar era -19 m. Para Stirling et al.(1998); Schellmann e Radtke (2004), este 
intervalo mais quente dentro do MIS 5 é caracterizado por um nível do mar de 0 a $6 \mathrm{~m}$ acima do atual. Durante o MIS 5b, o nível do mar era $-57 \mathrm{~m}$ em 92,6 $\pm 0,5 \mathrm{ka}$, sendo que na transição MIS 5c-5b houve uma queda de $40 \mathrm{~m}$ em cerca de $10 \mathrm{ka}$. O nível do mar então subiu mais que $40 \mathrm{~m}$ na transição MIS 5b-5a, também em aproximadamente $10 \mathrm{ka}$. O MIS 5a durou até pelo menos 76,2 $\pm 0,4 \mathrm{ka}$ com um nível do mar de $-24 \mathrm{~m}$. O nível do mar caiu quase $60 \mathrm{~m}$, a metade da amplitude entre o glacial-interglacial, em menos de 6 ka durante a transição MIS 5-4. Essa magnitude equivale aproximadamente ao volume de gelo atual sobre a Antártica. A acumulação de gelo provavelmente foi facilitada pelo transporte eficiente de umidade proveniente das baixas latitudes.

Assim, as estimativas calculadas neste estudo, mostraram uma variedade maior que as calculadas por Cutler (2003) que estipula o nível do mar durante o MIS 5e de 0 a $6 \mathrm{~m}$ acima do atual, enquanto no KF-18, o cálculo para o período foi $20 \mathrm{~m}$, ous seja, 14 m mais elevado.

Woillard (1979) O estudo com registro de pólen no Grand Pile / França sugere que durante os subestágios $5 \mathrm{~d}, 5 \mathrm{c}$ e $5 \mathrm{~b}$, houve um período com características similares às condições glaciais que durou cerca de $30 \mathrm{ka} \mathrm{(115} \mathrm{a} 80 \mathrm{ka}$ ). Por isso o nível do mar esteve mais baixo durante este período.

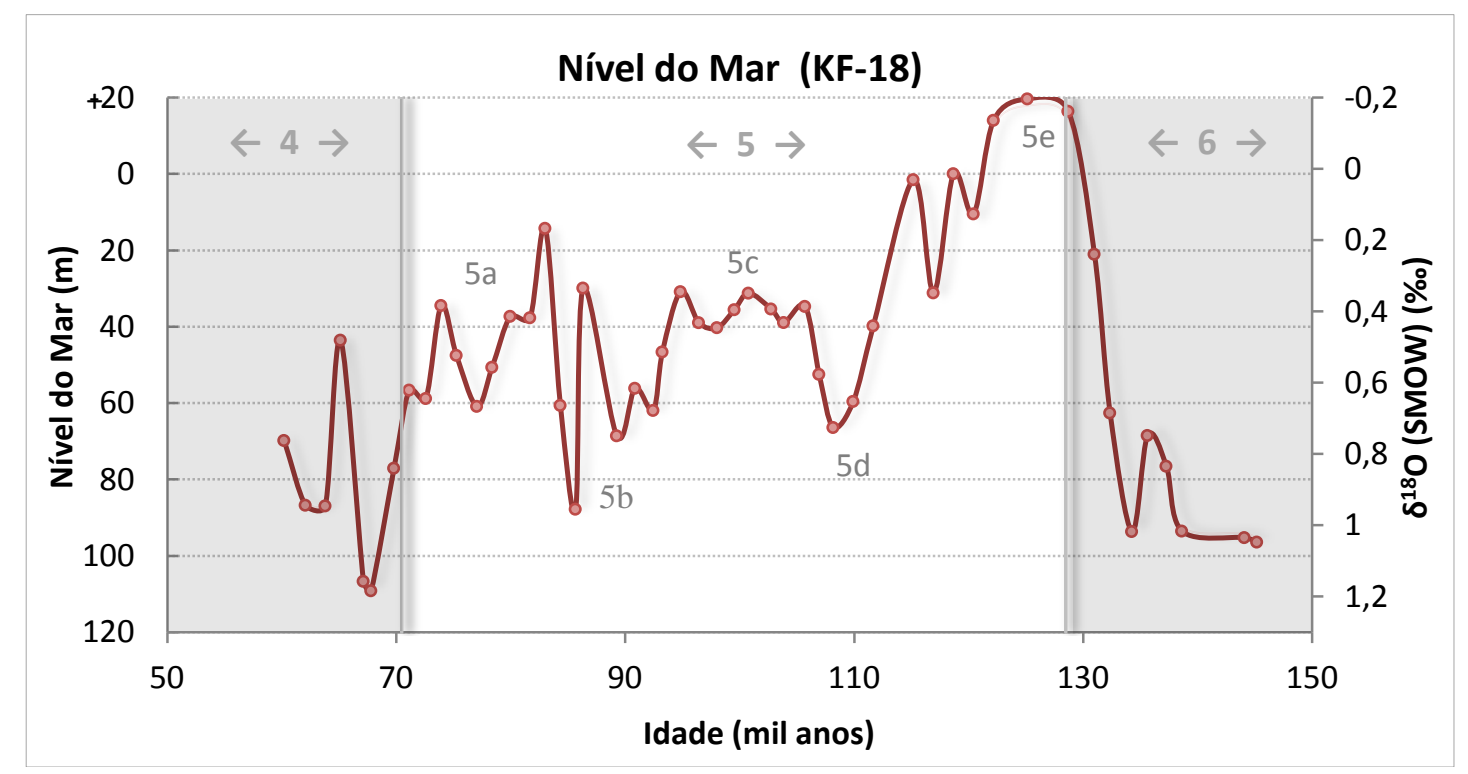

Figura 26: Estimativas da variação do nível do mar ao longo do intervalo de 60 a 130 ka no testemunho KF-18. Os estágios isotópicos marinhos glaciais, MIS 4 e 6 estão indicados pela área sombreada. As linhas verticais cinzas indicam os limites MIS 4-5 e MIS 5-6. 
Comparando-se as curvas das estimativas do nível do mar e das razões $\mathrm{Fe} / \mathrm{Ca}$ (Figura 27), constata-se um padrão espelhado. Desta forma, conclui-se que em níveis de mar mais altos (MIS 5e, 5c e 5a) o aporte de sedimentos terrígenos é reduzido, identificado pelos baixos valores da razão $\mathrm{Fe} / \mathrm{Ca}$. As razões $\mathrm{Fe} / \mathrm{Ca}$ mais altas foram encontradas durante os subestágios estadiais 5 d e 5 b, quando o nível do mar estava mais baixo e o aporte continental alcançava distâncias mais longas, mar adentro.

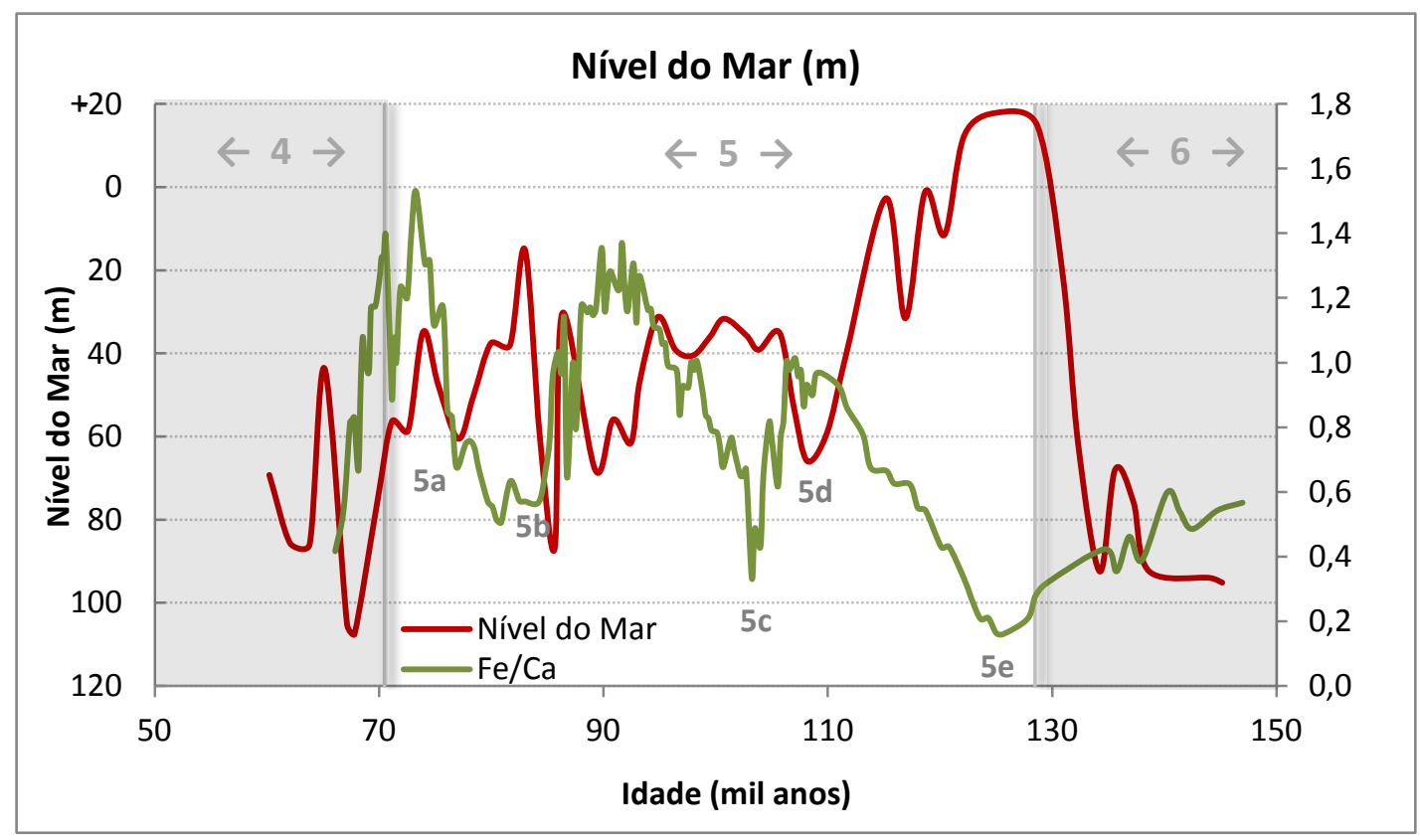

Figura 27: Variação do nível do mar e razão Fe/Ca no testemunho KF-18. Os estágios isotópicos marinhos glaciais, MIS 4 e 6 estão indicados pela área sombreada. As linhas verticais cinzas indicam os limites MIS 4-5 e MIS 5-6.

\subsection{Teor de carbonato}

O conteúdo real de carbonato de cálcio $\left(\mathrm{CaCO}_{3}\right)$ em sedimentos de mar profundo é controlado por uma interação complexa entre produção nas águas superficiais (produtividade de organismos calcários), diluição por fases nãocarbonáticas e dissolução na coluna de água, no fundo oceânico e em águas intersticiais já no sedimento. Deste modo, é bastante difícil isolar unicamente as alterações devido ao estado de saturação do carbonato em águas profundas dos demais fatores controladores. É fato que existe uma relação entre o conteúdo de calcita do sedimento e as condições climáticas sob as quais este foi depositado (Volat et al., 1980). A produtividade de organismos planctônicos calcários é influenciada pelas condições 
climáticas. Existem controvérsias quanto ao aumento de produtividade em intervalos glaciais ou interglaciais, uma vez que diferentes padrões de sedimentação/acumulação são observados em diferentes oceanos.

Alguns conceitos gerais já bem estabelecidos também podem causar controvérsias, p.ex. maior aporte de material de origem continental (terrígena) durante intervalos glaciais e maior sedimentação carbonática (biogênica) durante períodos interglaciais (Volat et al.,1980). Considera-se esta premissa devido ao fato de que em períodos glaciais um maior volume de material é transportado e, como consequência do rebaixamento do nível do mar, o material continental atinge as bacias oceânicas prontamente (ver Figura 27). Por outro lado, já foi comprovado que a sedimentação carbonática na verdade pode aumentar durante intervalos glaciais, porém esta componente é mascarada também pelo maior aporte terrígeno (Broecker et al., 1958; Ruddiman, 1971).

Apesar das discussões sobre os efeitos da variação de produtividade versus dissolução em relação ao percentual de carbonato nos sedimentos, foi observado um padrão estratigráfico bem documentado ao longo do Quaternário (Broecker, 1971; Berger, 1973; Volat et al., 1980; Dunn, 1982; Crowley, 1985; Hodell et al.,2001). Existem dois modelos estratigráficos para o conteúdo de carbonato em sedimentos de mar profundo: o tipo-Atlântico e o tipo-Indo-Pacífico. Os sedimentos com alto teor de carbonato no oceano Índico e Pacífico se correlacionam com episódios glaciais (maiores valores de $\delta^{18} \mathrm{O}$ ), enquanto no oceano Atlântico os sedimentos com alto conteúdo de carbonato se correlacionam com episódios interglaciais (menores valores de $\delta^{18} \mathrm{O}$ ). 


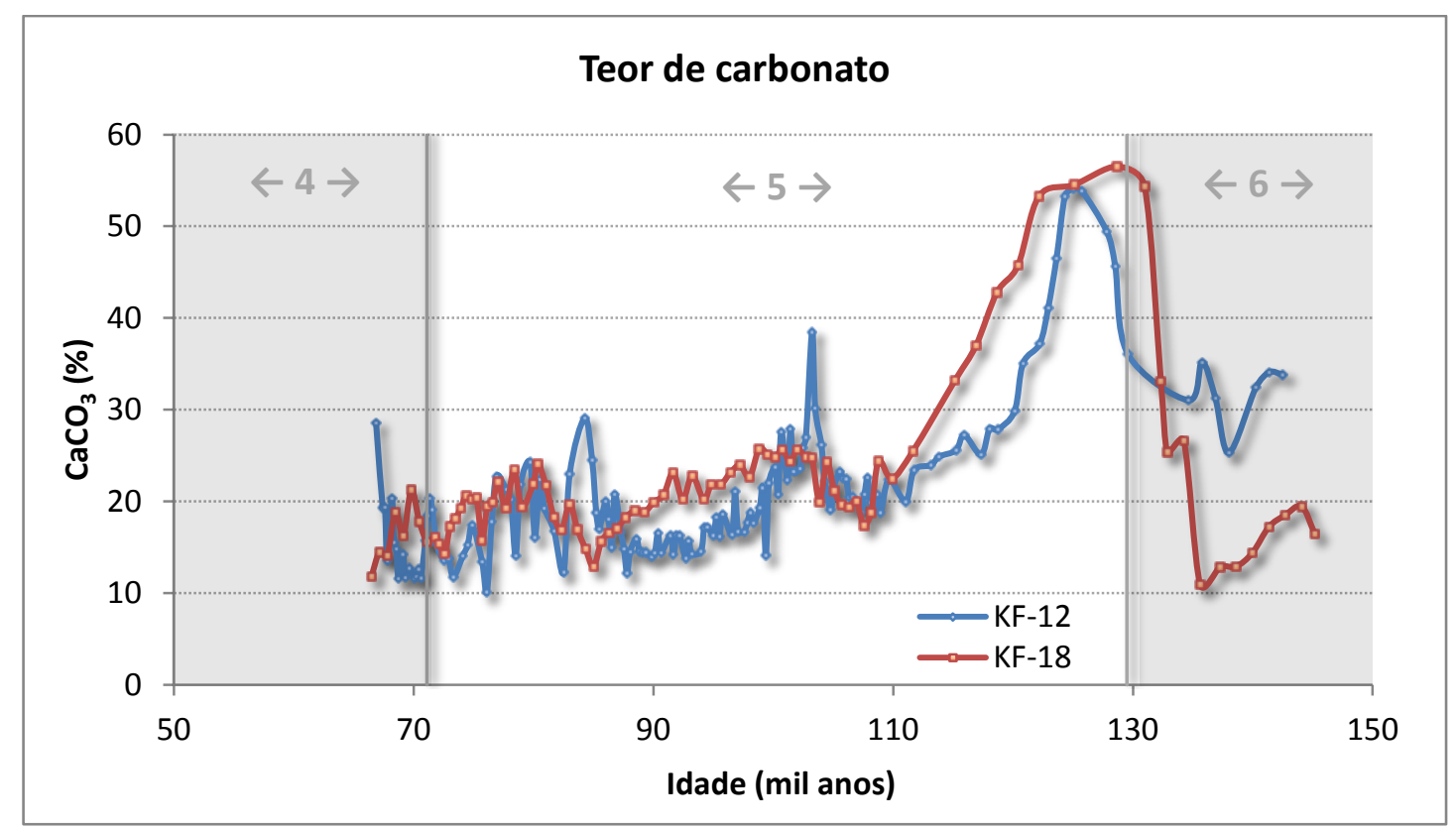

Figura 28: O teor de carbonato (\%) ao longo dos testemunhos KF-18 (linha vermelha) e KF-12 (linha azul). Os estágios isotópicos marinhos glaciais, MIS 4 e 6 estão separados pelo fundo cinza claro. A linha vertical cinza indica os limites MIS 4-5 e MIS 5-6.

Para melhor compreender o padrão estratigráfico do carbonato de cálcio na região de estudo realizou-se análise de teor de carbonato na fração fina das amostras dos dois testemunho, KF-12 e KF-18. Kowsmann et al. (2008) realizaram análises do conteúdo de carbonato em rocha total de 27 amostras do KF-18 como parte do procedimento de descrição dos testemunhos. Estes dados em rocha total apresentaram boa correlação $(0,6)$ com os dados obtidos da fração fina.

Os valores máximos de teor de carbonato ocorreram no início do MIS 5, durante o subestágio 5e (Figura 28), quando ocorreram também as maiores temperaturas e o nível do mar se encontrava mais alto. O maior valor de $\mathrm{CaCO}_{3}$ do testemunho KF-12 foi 54,1\% em $125 \mathrm{ka}$ AP e do KF-18, 56,5\% em 128,7\%. Após este período, os dois testemunhos apresentaram uma tendência decrescente do teor de $\mathrm{CaCO}_{3}$ até o MIS 4. A partir de $110 \mathrm{ka} \mathrm{AP}$, as concentrações de carbonato não variaram muito, oscilando em torno de $20 \%$. Houve algumas incursões positivas de carbonato no testemunho KF-12, em torno de 105 e 86,5 mil anos atrás, além de um abrupto aumento no início do MIS 4 quando ocorreu a glaciação.

\section{CONSIDERAÇÕES FINAIS}


A Figura 29 resume parâmetros bem correlacionados do testemunho KF-12. O eixo das ordenadas das razões $\mathrm{Ti} / \mathrm{Ca}$ e $\mathrm{Fe} / \mathrm{Ca}$ estão invertidos, assim como da razão isotópica de oxigênio, o que representa que seus menores valores, durante os interestadiais 5.5, 5.3 e 5.1, estão relacionados aos maiores valores de $\mathrm{CaCO}_{3}$ e insolação. Em períodos interestadiais, quando o volume de gelo é menor e a temperatura mais alta, geralmente ocorre o aumento na produção de sedimentos biogênicos representado pelo teor do carbonato de cálcio. Ao mesmo tempo, o aporte de terrígenos é menor devido ao o nível do mar estar mais elevado e à menor ocorrência de precipitação. Mais que $50 \%$ da precipitação anual acontece durante os meses de verão em grande parte da América do Sul tropical e subtropical, associada ao estabelecimento do Sistema de Monções da América do Sul (SASM) (Vuille e Werner, 2005). Durante o fim de novembro até o fim de fevereiro (a fase madura do SASM), a principal atividade convectiva está centrada na região central do Brasil e ligada a faixa de umidade e precipitação que vai do sul da Amazônia ao sudeste brasileiro e circunda o oceano Atlântico. Esta faixa de convexão é chamada Zona de Convergência do Atlântico Sul (SACZ). Uma convexão mais intensa sobre a bacia amazônica pode ocorrer pelo posicionamento mais ao sul da zona de convergência intertropical (ITCZ) e transporte de mais umidade. Sobre o período de 10 a 210 ka atrás, há uma notável correlação entre fases de crescimento de espeleotemas e tempos de alta insolação em $10^{\circ} \mathrm{S}$ durante o outono austral. Precipitação em tempos modernos nesta área ocorre principalmente durante o outono austral (fevereiro a maio), quando a ITCZ está próxima a sua posição mais ao sul.

Com a análise espectral dos dados de Ti/Ca, efetuada através do software PAST, constatou-se um pico referente ao período de 22 ka com nível de confiança acima de $99 \%$ (Figura 30), confirmando que a posição da ITCZ associada a precipitação na região equatorial e da SACZ resultam da componente precessional. Pode-se verificar na Figura 29 que as menores razões $\mathrm{Fe} / \mathrm{Ca}$ e Ti/Ca (lembrando-se que o eixo das ordenadas está invertido) coincidem com os baixos valores de insolação de verão. 

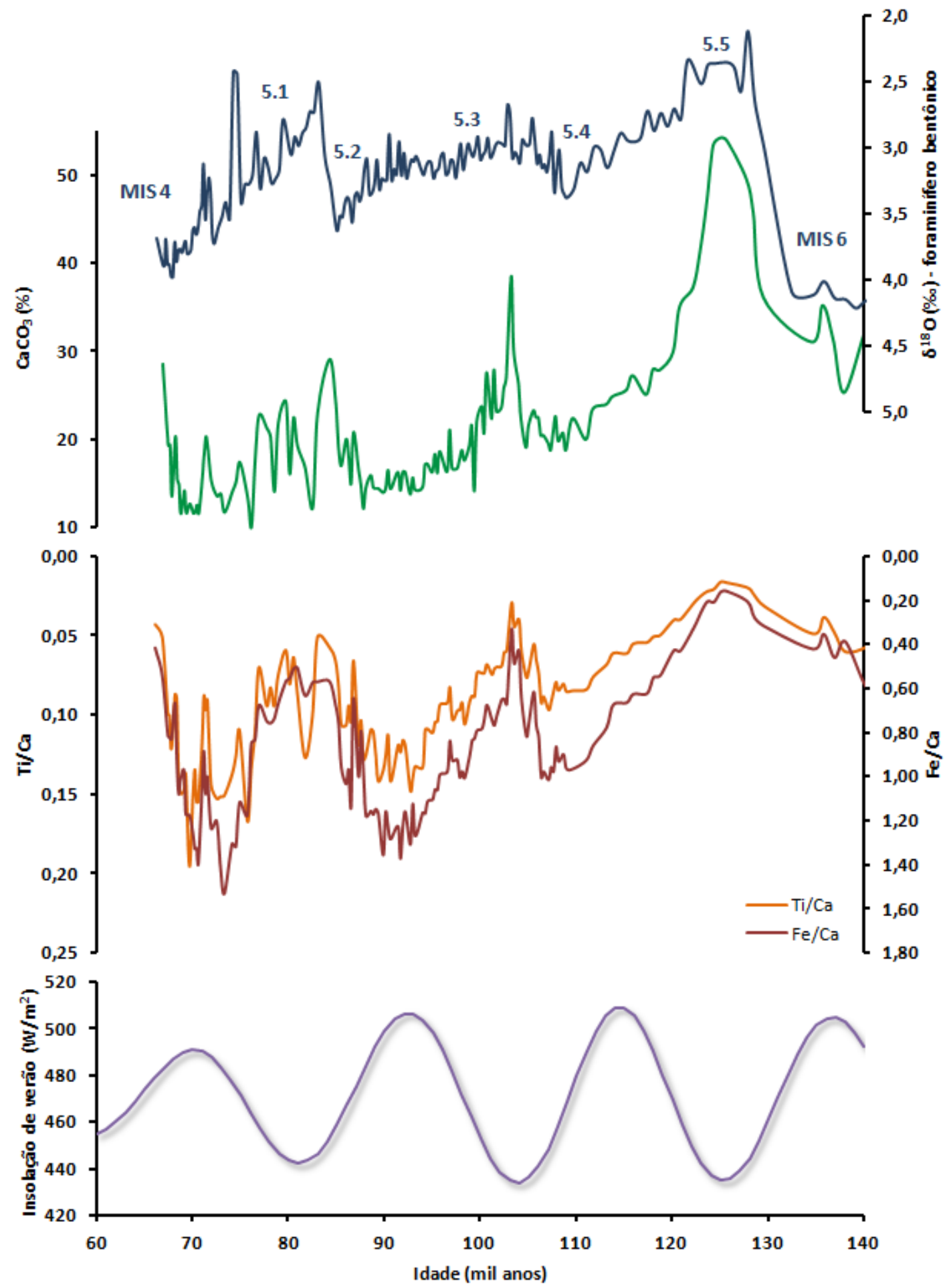

Figura 29: Dados obtidos do testemunho KF-12 e insolação de verão. De cima para baixo: Razão isotópica de oxigênio em foraminíferos bentônicos $\left(\delta^{18} 0\right)$ (linha azul); $\mathrm{CaCO}_{3}(\%)$ (linha verde); razão $\mathrm{Fe} / \mathrm{Ca}$ (linha vinho); razão Ti/Ca (linha laranja) e insolação de verão $25^{\circ} \mathrm{S}$ $\left(\mathbf{W} / \mathbf{m}^{2}\right)$ (linha roxa). 


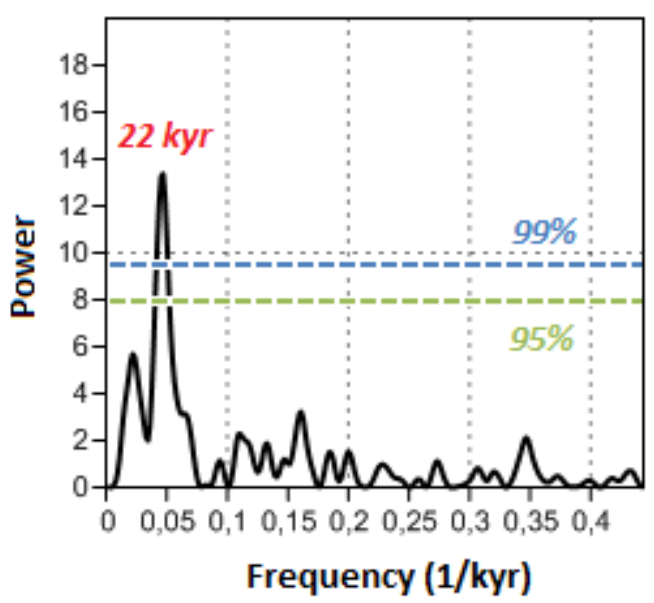

Figura 30: Análise espectral dos registros de Ti/Ca do KF-12 . O único pico que ultrapassa o nível de 99 \% de confiância representa o período (inverso da frequência) de 22 ka, similar ao período de precessão.

Com o intuito de investigar-se as variações climáticas ocorridas no passado, utilizou-se de diversas alternativas para a construção de curvas climáticas (Figura 31), e assim, foi possível também comparar os resultados obtidos. Os dados isotópicos de oxigênio em foraminífero planctônico refletem, de uma forma indireta, à temperatura da superfície do mar (SST), uma vez que as testas separadas para essa análise são de $G$. ruber (white), um foraminífero que vive nos primeiros $200 \mathrm{~m}$ da coluna de água. Através da curva isotópica foram separados os subestágios do MIS 5. O MIS 5.5 tem o valor mais leve igual a -1,36\% em 120,4 ka atrás. A curva composta por SSTs obtidas pelas redes neurais artificiais apresentou uma variação de 21,3 a $26,6^{\circ} \mathrm{C}$ no período estudado. Durante os períodos mais quentes, ou seja, MIS 5.5, 5.3 e 5.1, as SSTs são $25^{\circ} \mathrm{C}$ aproximadamente, com máximo valor observado no fim do MIS $5.3\left(26.6^{\circ} \mathrm{C}\right)$. Até 108,8 ka AP, a curva não tem uma boa definição, inclusive, a maior paleotemperatura está no MIS 5.3 e não no 5.5, como esperado. Quanto a curva obtida através da Razão de Rögl e Bolli, é semelhante a curva de SSTs, provavelmente devido ao fato que ambas utilizam a fauna identificada e quantificada ao longo do testemunho. A Razão de Rögl e Bolli não utiliza os dados de todas as espécies, mas usa os dados das mais representativas tanto as que vivem em água quente, como as de água fria. $\mathrm{O}$ menor valor da razão que vai de 0 a 100 foi 39, 53 em 71,8 ka, com outro evento frio logo em sguida de 41,51 em 69,1 ka. A razão mais alta foi 93,0 em $81 \mathrm{ka}$, dessa vez, dentro do MIS 5.1. Outra curva paleoclimática foi inferida através da abundância relativa de G. ruber, a mesma espécie utilizada na análise isotópica. Porém neste caso, são contabilizados os dois morfotipos, white e pink. Como dito anteriormente, essa espécie é típica de águas quentes, assim, o comportamento da curva é oposto ao das espécies $N$. incompta e $G$. 
inflata. A G. inflata é a espécie mais representativa de águas frias no Atlântico Sul. Os estudos do Atlântico Norte utilizam, geralmente, a espécie polar Neoglobaquadrina pachyderma, no entanto, a mesma não ocorre no Atlântico Sul subtropical. Assim, uma outra alternativa, é a $N$. incompta que já foi erroneamente classificada como $N$. pachyderma. Nos oceanos atuais, o genótipo sinistral de $N$. pachyderma domina os ambientes polares de altas latitudes enquanto o dextral é encontrado mais frequentemente em zonas temperadas $\left(10-14^{\circ} \mathrm{C}\right)$. O evento climático mais marcante que ocorre nas curvas das três espécies é a diminuição brusca da temperatura próxima a glaciação, no final do MIS 5. Estas estimativas mostram que o Último Interglacial não foi um período estável com a presença de eventos frios (Cs) caracterizados por baixas temperaturas, valores mais pesados de $\delta^{18} \mathrm{O}$ e elevadas abundâncias de espécies de águas frias Neogloboquadrina incompta and Globorotalia inflata.

Os eventos frios estão indicados na Figura 32, não são todos que ocorrem ao mesmo tempo no Hemisfério Norte. Os eventos frios correlacionáveis são o C21, C20 e C19, os quais no Atlântico sudoeste ocorrem em 89,4; 77,5 e 72,6, respectivamente.

Por fim, correlacionou-se as curvas isotópicas de oxigênio tanto do KF-12 quanto do KF-18, com os testemunhos de gelo do pólo norte, $\delta^{18} \mathrm{O}$ NGRIP, e do pólo sul, $\delta \mathrm{D}$ VOSTOK. Os eventos interestadiais na curva isotópica do NGRIP, denominados GIS, possuem seu correspondente nas razões isotópicas mais leves referentes ao menor volume de gelo dos testemunhos KF-12 e KF-18. A curva do $\delta \mathrm{D}$ VOSTOK não é tão detalhada quanto as outras curvas, e desta forma, não apresenta os subestágios. Porém, ao analisar a tendência da curva, nota-se que tanto com a diminuição da amplitude quanto da periodicidade, as curvas são correlacionáveis entre si. 

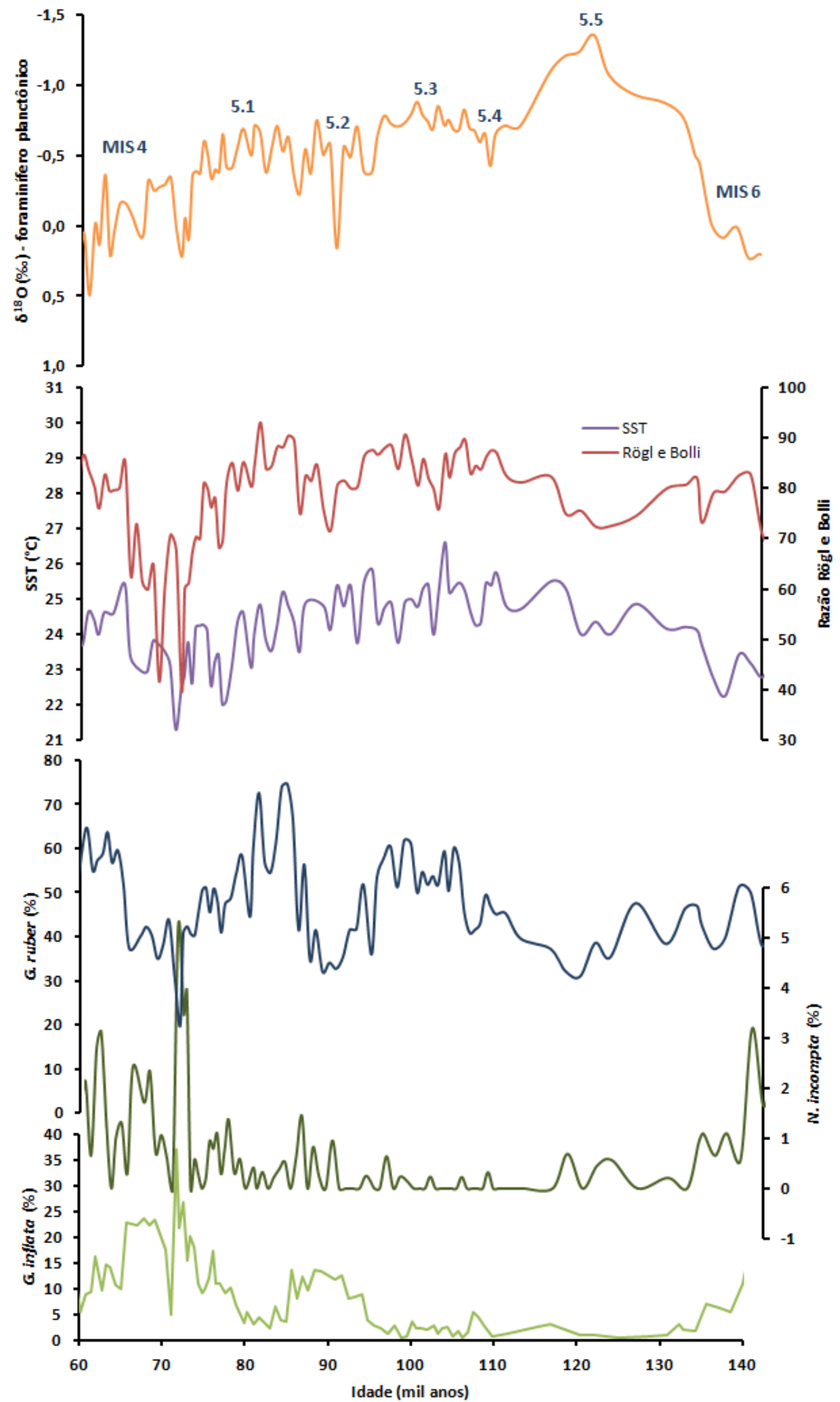

Figura 31: Curvas paleoclimáticas obtidas por diferentes proxies. De cima para baixo: $\delta^{18} \mathrm{O}$ (planctônico) (\%), Razão Rögl e Bolli, SST $\left({ }^{\circ} \mathrm{C}\right)$, G. ruber $(\%)$, N. incompta $(\%)$, G. Inflata (\%). 
Eventos frios (Cold events "Cs")
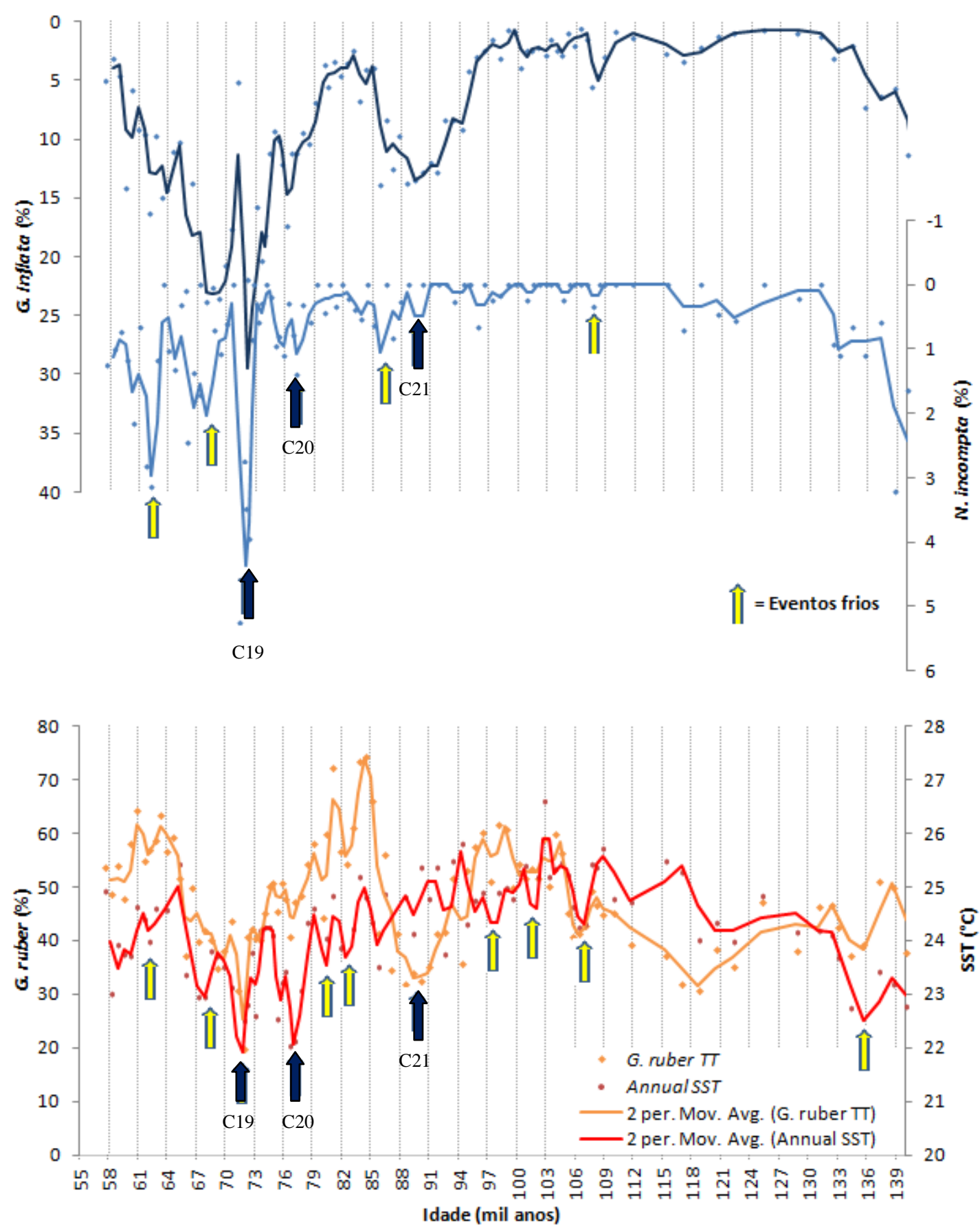

Figura 32: Eventos frios $(C s)$ indicados por setas nas curvas paleoclimáticas do testemunho KF-18. De cima para baixo: G. inflata, $N$, incompta, G. ruber (TT) (lado esquerdo) e $\operatorname{SST}\left({ }^{\circ} \mathrm{C}\right)$ (lado direito). 


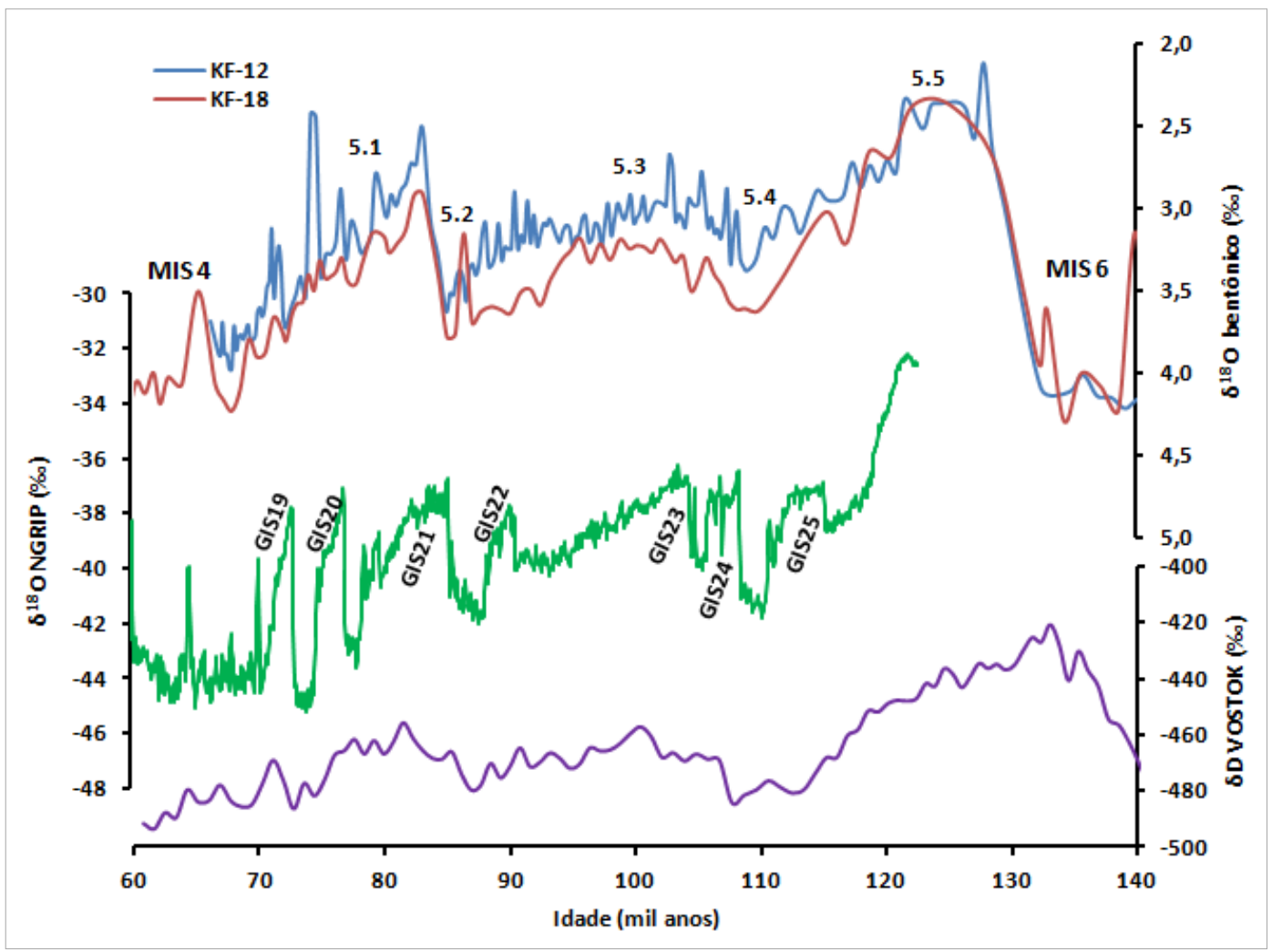

Figura 33: Comparação do proxy de volume de gelo $\left(\delta^{18} \mathrm{O}\right)$ nos testemunhos KF-12 e KF-18 com os testemunhos de gelo NGRIP $\left(\delta^{18} \mathrm{O}\right)$ e VOSTOK $(\delta \mathrm{D})$. As marcações "GIS" referem-se aos subestágios interestadias deste testemunho.

\section{CONCLUSÕES}

A alta taxa de acumulação de sedimentos marinhos nos dois testemunhos tornou possível verificar a existência de eventos climáticos relativamente breves, realizar a bioestratigrafia com base no plexo menardii e, a estratigrafia isotópica através dos dados de isótopos de oxigênio em foraminíferos bentônicos. Os limites inferidos para a biozona X, foi 135,6 a 82,3 ka AP para o testemunho KF-18, e 133,5 a 88,4 ka AP para o KF-12. O estágio isotópico marinho (MIS) 5, na região de estudo, encontrase entre 129,5 e 71,1 ka AP, em ambos os testemunhos. O MIS 5e, também chamado MIS 5.5, compreende o intervalo menor que o Eemiano, equivalente terrestre do subestágio interestadial que alcança o subestágio $5 \mathrm{~d}$.

As curvas paleoclimáticas construídas através da abundância relativa de espécies características de águas frias ou quentes, ou até mesmo na forma de razão entre as espécies quentes e as espécies quentes mais as espécies frias (razão de Rögl e Bolli), 
mostrou-se uma ferramenta importante para inferir-se certas alterações no ambiente em que viveram os foraminíferos e que ficou registrado em suas testas.

Através da correlação entre os registros isotópicos dos testemunhos KF-12 e KF-18 com as curvas paleoclimáticas de espécies de foraminíferos planctônicos indicadoras de águas mais quentes ou mais frias, encontrou-se quatro espécies principais mais sensíveis às variações climáticas: Globigerinoides ruber, Globorotalia inflata, e Neogloboquadrina incompta, a primeira de águas quentes e as outras de águas frias.

Também foram utilizados outros dados, tais como, razão isotópica em foraminífero planctônico, fauna, teor de carbonato, razão Ti/Ca e $\mathrm{Fe} / \mathrm{Ca}$ através dos quais pôde-se estimar paleotemperaturas da superfície do mar, aporte de material terrígeno de acordo com as condições de umidade/seca na região de estudo durante o intervalo de interesse.

Por fim, verificou-se que tanto os dados isotópicos de oxigênio $\left(\delta^{18} \mathrm{O}\right)$ do testemunho de gelo da Groenlândia (NGRIP) quanto os da razão de deutério da Antártica variaram de forma semelhante aos $\delta^{18} \mathrm{O}$ de foraminíferos bentônicos do KF-12 e KF-18, confirmando o sincronismo de tais registros.

\section{REFERÊNCIAS BIBLIOGRÁFICAS}

Aaby, B.; Tauber, H. 1995. Eemian climate and pollen. Nature 376, 27-28.

Aurahs, R.; Treis, Y.; Darling, K.; Kucera, M. 2011. A revised taxonomic and phylogenetic concept for the planktonic foraminifer species Globigerinoides ruber based on molecular and morphometric evidence. Marine Micropaleontology, 79, 114.

Bauch, D., Darling, K., Simstich, J., Bauch, H.A., Erlenkeuser, H., Kroon, G. 2003. Palaeoceanographic implications of genetic variation in living North Atlantic Neogloboquadrina pachyderma. Nature 424, 299-302.

Bé, A.W.H. 1967. Foraminifera families: Globigerinidae and Globorotaliidae. Conseil Permanent International pour l'exploration de la mer. Zooplankton, Sheet 108. 9 pp.

Bé, A.W.H. 1977. An ecological, zoogeographic and taxonomic review of recent planktonic foraminifera. In: Oceanic Micropaleontology, Ramsay, A.T.S. (Ed.), Academic Press, London, pp. 1-100. 
Bé, A. W. H.; Tolderlund, D. S. 1971. The Micropaleontology of Oceans, In: Distribution and ecology of living planktonic foraminifera in surface waters of the Atlantic and Indian Oceans. pp. 105-149. Cambridge University Press.

Berger, W. H. 1973. Deep-sea carbonates: Pleistocene dissolution cycles: Journal of Foraminiferal Research, 3, 187-195.

Berger, W. H. \& Vincent, E. 1986. Sporadic shutdown of North Atlantic deep water production during the Glacial-Holocene transition? Nature, 324, 53-55.

Berger, W. H.; Wefer, G. 1996. Expeditions into the past: Paleoceanographic studies in the South Atlantic. In: Wefer, G., Berger, W.H., Siedler, G., Webb, D.J. (Eds.). The South Atlantic: Present and Past Circulation. Springer-Verlag, p. 363-410.

Bolli, H.M.; Saunders, J.B. 1989. Oligocene to Holocene low latitude planktic foraminifera. In: Plankton Stratigraphy, Vol.1. Bolli, H.M.; Saunders, J.B.; PerchNielsen, K. (Eds.). Cambridge Earth Sci. Series. Cambridge Univ. Press, pp: 155262.

Broecker, W.S. (1971) Calcite accumulation rates and glacial to interglacial changes in oceanic mixing. In: Turekian, K.K. (Ed.). The Late Cenozoic Glacial Ages: New Haven (Yale), pp. 239-265.

Broecker, W.S., Turekian, K.K., Heezen, B.C. 1958. The relation of deep sea sedimentation rates to variations in climate. American Journal of Science, 256, 503517.

Butzin, M., Prange, M., Lohmann, G. 2005. Radiocarbon simulations for the glacial ocean: the effects of wind stress, Southern Ocean sea ice and Heinrich events. Earth and Planetary Science Letters, 235, 45-61.

Caley, T., Giraudeau, J., Malaizé, B., Rossignol, L., Pierre, C. 2012. Agulhas leakage as a key process in the modes of Quaternary climate changes. Proceedings of the National Academy of Sciences of the United States of America, 109(18), 6835-9. doi: 10.1073/pnas.1115545109

Ciotti, A. M.; Odebrecht, C.; Fillmann, G.; Moller, O. O. Jr. 1995. Freshwater outflow and Subtropical Convergence Influence on phytoplankton biomass on the southern Brazilian Continental Shelf. Continental Shelf Research, 15, 1737-1756.

CLIMAP (1981) Seasonal Reconstructions of the Earth's Surface at the Last Glacial Maximum. Geological Society of America Map and Chart Series, MC-36, 1-18. 
Cortese, G.; Abelmann, A.; Gersonde, R. 2007. The last five glacial-interglacial transitions: A high-resolution 450,000-year record from the subantartic Atlantic. Paleoceanography, 22, PA4203, 14p.

Costa, K. B.; Toledo, F.A.L.; Pivel, M.A.G; Moura, C.A.V.; Chemale, Jr, F. (2006) Evaluation of two genera of benthic foraminifera for down-core paleotemperature studies in the western South Atlantic. Brazilian Journal of Oceanography, 54(1):7584.

Crowley, T. J. 1985. Late Quaternary carbonate changes in the North Atlantic and Atlantic/Pacific comparisons. In: Sundquist, E.T. \& Broecker, W.S. (Eds.). The Carbon Cycle and Atmospheric CO2: Natural Variations, Archean to Present. Geophysical Monography Series, The American Geophysical Union, 32, 271-284.

Curry, W. B; Lohmann, G. P. 1982. Carbon Isotopic Changes in Benthic Foraminifera from the Western South-Atlantic - Reconstruction of Glacial Abyssal Circulation Patterns. Quaternary Research, 18(2), 218-235.

Darling, K. F., Wade, C. M., Steward, I. A., Kroon, D., Dingle, R., Leigh Brown, A. J. (2000) Molecular evidence for genetic mixing of Arctic and Antarctic subpolar populations of planktonic foraminifers, Nature, 405, $43-47$.

Deuser, W.G. \& Ross, E.H. 1989. Seasonally abundant planktonic foraminifera of the Sargasso Sea: succession, deep-water fluxes, isotopic compositions and paleoceanographic implications. Journal of Foraminiferal Research, 19, 268-293.

Dunn, D. A. 1982. Miocene sediments of the equatorial Pacific Ocean: carbonate stratigraphy and dissolution history [Ph.D. dissert.]. Univ. Rhode Island, Kingston

Emiliani, E. 1954. Depth habitats of some species of pelagic foraminifera as indicated by oxygen isotope ratios. Am. J. Sci., 252: 149-158.

Emilson, I. 1961. The shelf and coastal waters off Southem Brazil. Bol. Inst. Oceanogr., São Paulo, 17(2):101-112.

Ericson, D.B.; Wollin, G. 1968. Pleistocene climates and chronology in deep-sea sediments. Science, 162(3859), 1227-1234.

ERICSON, D.B. \& Wollin, G. (1956) Micropaleontological and isotopic determinations of Pleistocene climates. Micropaleontology, 2, 257-270.

Evans, D.; Signorini, S.R. 1985. Vertical Structure of the Brazil Current. Nature, 315, 48-50.

Fairbanks, R.G., Mortlock, R.A., Chiu, T.-C., Cao, L., Kaplan, A., Guilderson, T.P., Fairbanks, T.W., Bloom, A.L. (2005) Marine Radiocarbon Calibration Curve 
Spanning 10,000 to 50,000 Years B.P. Based on Paired 230Th/234U/238U and 14C Dates on Pristine Corals. Quaternary Science Reviews, 24, 1781-1796.

Fairbridge, R.W. 1972. Climatology of a glacial cycle. Quarternary Research 2, 283302.

Field, M. H., Huntley, B.; Müller, H. 1994. Eemian climate fluctuations observed in European pollen record. Nature 371, 779-783.

Guiot, J., Pons, A., de Beaulieu, J. L., and Reille, M. 1989. A 140,000-year continental climate reconstruction from two European pollen records. Nature 338, 309-313.

Hall, J.M.; Chan, L.H. 2004. Li/Ca in multiple species of benthic and planktonic foraminifera: thermocline, latitudinal, and glacial-interglacial variation. Geochimica et Cosmochimica Acta 68, 529 - 545.

Harper, S. 2000. Thermocline ventilation and pathways of tropical-subtropical water mass exchange. Tellus, 52A, 330-345.

Hemleben, C., Spindler, M. e Eerson, O.R. 1989. Modern planktonic foraminifera. Springer- Verlag, Berlin Heidelberg New York, 363p.

Hilbrecht, H., 1996. Extant planktic foraminifera and the physical environment in the atlantic and indian oceans. Technical Report 300, Mitteilungen aus dem Geologischen Institut der Eidgen. Technischen Hochschule und der Universität Zürich.

Hodell, D.A., Charles, C.D., Sierro, F.J. 2001. Late Pleistocene evolution of the ocean's carbonate system. Earth and Planetary Science Letters, 192, 109-124.

Imbrie, J.; Kipp, N.G. 1971. A new micropaleontological method for quantitative paleoclimatology: Application to a late Pleistocene Caribbean core. In: Turekian, K. K (Ed). The late Cenozoic Glacial Ages. Yale University Press, New Haven, Connecticut, p. 71-179.

Keigwin, L.D.; Curry, B.; Lehman, S.; Johnsen, S. 1994. The role of deep ocean in North Atlantic climate change between 70 and 130kyr ago. Nature, 371, 323-326.

Kemle von Mücke, S.; Hemleben, C. 1999. Foraminifera. In: Boltovskoy, D. (Ed.), South Atlantic Zooplankton. Backhuys Publishers, Leiden, Netherlands, pp. 43-73.

Kiefer, T., McCave, I.N., Elderfield, H. 2006. Antarctic control on tropical Indian Ocean sea surface temperature and hydrography, Geophysical Research Letters, 33, L24612, doi: 10.1029/2006GL027097.

Kohl, B., Fillon, R.H., Roberts, H.H. 2004. Foraminiferal biostratigraphy and paleoenvironments of the Pleistocene Lagniappe delta and related section, 
northeastern Gulf of Mexico. In: Andersen, J.B. \& FILLON, R. (Eds.). Late Quaternary Stratigraphic Evolution of the Gulf of Mexico Basin. SEPM, Special Publication, 79, 189-216.

Kowsmann, R.O, Silva, D.B., Giacomel, R.S., Vicalvi, M.A., Amaral, C.S., Gonçalves, A.J., Silva, M.S.L. (2008) Description and dating of jumbo piston cores from Tupi ring-fence, Santos Basin (Fugro Explorer Campaign 2007). PETROBRAS, Relatório Interno RT GSEP 012/08, 19p.

Kucera, M.; Weinelt, M.; Kiefer, T.; Pflaumann, U.; Hayes, A.; Weinelt, M.; Chen, M.T.; Mix, A.C.; Barrows, T.T.; Cortijo, E.; Duprat, J.; Juggins, S.; Waelbroeck, C. 2005b. Reconstruction of sea-surface temperatures from assemblages of planktonic foraminifera: multi-technique approach based on geographically constrained calibration data sets and its application to glacial Atlantic and Pacific Oceans. Quat. Sci. Rev., 24: 951-998.

Kukla, G.; McManus, J.F.; Rousseau, D.-D.; Chuine, I. .1997. How long and how stable was the last interglacial? Quaternary Science Reviews 16, 605-612.

Kukla, G.J.; Bender, M.L.; Beaulieu, J-L.; Bond, G.; Broecker, W.S.; Cleveringa, P.; Gavin, J.E.; Herbert, T.D.; Imbrie, J.; Jouzel, J.; Keigwin, L.D.; Knudsen, K-L.; McManus, J.F.; Merkt, J.; Muhs, D.R.; Muller, H.; Poore, R.Z.; Porter, S.C.; Seret, G.; Shackleton, N.J.; Turner, C.; Tzedakis, P.C.; Winograd, I.J. (2002a) Last Interglacial Climates. Quaternary Research 58, 2-13.

Kuroyanagi, A., Kawahata, H. 2004. Vertical distribution of living planktonic foraminifera in the seas around Japan. Marine Micropaleontology 53, 173-196.

Kutzbach, J.E. 1987. Model simulations of the climatic patterns during the deglaciation of North America, in: W.F. Ruddiman, H.E. Wright Jr. (Eds.), The Geology of North America and Adjacent Oceans During the Last Deglaciation, The Geological Society of America, Boulder, CO,1987, pp. 425-446.

Levitus, S., Boyer, T.P. 1994. World Ocean Atlas Volume 4: Temperature. NOAA Atlas NESDIS, U.S. Department of Commerce, Washington, D.C., vol. 4.

Lisiecki, L.E.; Raymo, M.E. 2005. A Pliocene-Pleistocene stack of 57 globally distributed benthic $\delta^{18} \mathrm{O}$ records. Paleoceanography, vol. 20, PA1003, 17p.

Malmgren, B.A.; Nordlund, U. 1997. Application of Artificial Neural Networks to Paleoceanographic Data. Palaeogeogr. Palaeoclimatol. Palaeoecol., 136: 359-373.

Malmgren, B.A.; Kucera, M.; Nyberg, J.; Waelbroeck, C. 2001. Comparison of statistical and artificial neural network techniques for estimating past sea surface 
temperatures from planktonic foraminifer census data. Paleoceanography 16(5): 520530.

Manabe, S., Stouffer, R.J., 1994. Multiple-century response of a coupled oceanatmosphere model to an increase of atmospheric carbon dioxide. Journal of Climate $7,5-23$.

Marinov, I., Gnanadesikan, A., Toggweiler, J.R., Sarmiento, J.L. 2006. The Southern Ocean biogeochemical divide. Nature, 441, 964-967

Marins, G.M. Foraminíferos Planctônicos do Quaternário da Bacia de Campos (RJ), poço-GL451: Aspectos bioestratigráficos. 2009. Trabalho de conclusão de curso (Bacharelado em Geologia). Instituto de Agronomia, Univ. Fed. Rural do Rio de Janeiro, Rio de Janeiro, 39p.

Martinez, J.I., Mora, G., Barrows, T.T. 2007. Paleoceanographic conditions in the western Caribbean Sea for the last $560 \mathrm{kyr}$ as inferred from planktonic foraminifera. Marine Micropaleontology 64, 177-188.

Maslin, M.; Sarnthein, M.; Knaack, J.J.; Grootes, P.; Tzedakis, C. 1998. Intrainterglacial cold events: an Eemian-Holocene comparison. In: Cramp, A.; MacLeod, C.J.; Lee, S.V.; Jones, E.J.W. (eds.) Geological evolution of oceans basins: Results from the ocean drilling program. Geological Society, Special Publications, London, 91-99.

McManus, J.F.; Bond, G.C.; Broecker, W.S.; Johnsen, S.; Labeyrie, L.; Higgins, S. 1994. High-resolution climate records from the North Atlantic during the last interglacial. Nature 371, 326-329.

Mix, A. 1987. The oxygen-isotope record of glaciation. In: Ruddiman, W.F. \& Wright, H.E. (Eds.). The Geology of North America, Vol. K-3, North America and adjacent oceans during the last deglaciation, Geological Society of America, Boulder CO p. 111-135.

Moreira, J. L. P.; Nalpas, T.; Joseph, P.; Guillocheau, F. 2001. Stratigraphie sismique de la marge éocène du Nord du bassin de Santos Brésil: relations Plateforme/systèmes turbiditiques; distorsion des sequences de depot. Earth and Planetary Sciences 332, 491-498.

Müller, P.J, Cepek, M., Ruhlan, G., Schneider, R.R. 1997. Alkenone and coccolithophorid species changes in late Quaternary sediments from the Walvis Ridge: Implications for the alkenone paleotemperature method. Palaeogeography, Palaeoclimatology, Palaeoecology, 135, 71-96. 
Neftel, A.; Oeschger, H.; Schwander, J.; Stauffer B.; Zumbrumm R. 1982. Ice core sample measurements give atmospheric $\mathrm{CO} 2$ content during the last 40,000 years. Nature 295, 220-223.

Numberger, L., Hemleben, C., Hoffmann, R., Mackensen, A., Schulz, H., Wunderlich, J.M., Kucera, M. 2009. Habitats, abundance patterns and isotopic signals of morphotypes of the planktonic foraminifer Globigerinoides ruber (d'Orbigny) in the eastern Mediterranean Sea since the Marine Isotopic Stage 12. Marine Micropaleontology, 73, 90-104.

Oppo, D.W.; Keigwin, L.D., McManus, J.F., Cullen, J.L. 2001. Persistent suborbital climate variability in marine isotope stage 5 and Termination II. Paleoceanography $16,280-292$.

Oppo, D.W.; McManus, J.F.; Cullen, J.L. 2006. Evolution and demise of the Last Interglacial warmth in the subpolar North Atlantic. Quaternary Science Reviews, $10 \mathrm{p}$.

Ortiz, J.D., Mix, A.C., Collier, R.W. 1995. Environmental control of living symbiotic and asymbiotic foraminifera of the California Current. Paleoceanography 10 (6), 987-1009.

Ostlund, H.G., Craig, H., Broecker, W.S., Spencer, D. 1987. GEOSECS Atlantic, Pacific and Indian ocean expeditions, shorebased data and graphics, Vol. 7. Technical report, I.D.O.E. National Science Fundation, p. 200.

Pahnke, K ; Zahn, R. 2005. Southern Hemisphere Water Mass Conversion Linked with North Atlantic Climate Variability. Science,307, 1741-1746.

Paillard, D., LABEYRIE, L. YIOU, P. 1996. Macintosh program performs time-series analysis, Eos Transactions AGU 77 (39), p. 379.

Palter, J.B., Sarmiento, J.L., Gnanadesikan, A., Simeon, J., Slater, R.D. 2010. Fueling export production: nutrient return pathways from the deep ocean and their dependence on the Meridional Overturning Circulation. Biogeosciences, 7, 35493568 .

Pena, L.D., Cacho, I., Ferretti, P., Hall, M.A. 2008. El Niño-Southern Oscillation-like variability during glacial terminations and interlatitudinal teleconnections, Paleoceanography, 23: PA3101, doi:10.129/2008PA001620.

Peterson, R. G; Stramma, L. 1991. Upper-Level Circulation in the South-Atlantic Ocean. Progress in Oceanography 26(1):1-73. 
Petit, J. R.; Jouzel, J.; Raynaud, D.; Barkov, N. I.; Barnola, J.-M.; Basile, I.; Bender, M.; Chappellaz, J.; Davis, M.; Delaygue, G.; Delmotte, M.; Kotlyakov, V. M.; Legrand, M.; Lipenkov, V. Y.; Lorius, C.; Pepin, L.; Ritz, C.; Saltzman, E. and Stievenard, M. 1999. Climate and atmospheric history of the past 420,000 years from the Vostok ice core, Antarctica. Nature 399, 429-436.

Pflaumann, U., Duprat, J., Pujol, C., Labeyrie, L. 1996. SIMMAX: A modern analog technique to deduce Atlantic sea surface temperatures from planktonic foraminifera in deep-sea sediments. Paleoceanography, 11, 15-35.

Pisias, N. G.; Martinson, D. G.; Moore, T. C. Jr.; Shackleton, N. J.; Prell, W.; Hays, J., and Boden, G. 1984. High resolution stratigraphic correlation of benthic oxygen isotopic records spanning the last 300,000 years. Marine Geology 56, 119-136.

Pivel, M. A. G. 2010. Reconstrução da hidrografia superficial do Atlântico Sul Ocidental desde o Último Máximo Glacial a partir do estudo de foraminíferos planctônicos. Tese de Doutorado, Inst. Oceanográfico, Univ. de São Paulo, 164 pp.

Rangel, H.D., Martins F.A.L., Esteves F.R., Feijó, F.J. 1994. Bacia de Campos. Boletim de Geociências da Petrobras, 8 (1): 203-217.

Rau, A.J.; Rogers, J.; Lutjeharms, J.R.E. ; Giraudeau J ; Lee-Thorp, J.A.; Chen, M.-T. ; Waelbroeck, C. 2002. A 450-kyr record of hydrological conditions on the western Agulhas Bank Slope, south of Africa. Marine Geology 180,183-201.

Ravelo, A.C., Fairbanks, R.G., Philander, S.G.H. 1990. Reconstructing Tropical Atlantic Hydrography Using Planktonic Foraminifera and an Ocean Model. Paleoceanography, 5 (3), 409-431.

Reid, J. L. 1989. On the total geostrophic circulation of the South Atlantic Ocean: Flow patterns, tracers and transports. Prog. Oceanog., 23:149-244.

Reynolds, L. \& Thunell, R.C. 1985. Seasonal succession of planktonic foraminifera in the subpolar North Pacific. Journal of Foraminiferal Research 15, 282-301.

Ruddiman, W.F. 1971. Pleistocene sedimentation in the Equatorial Atlantic: stratigraphy and faunal paleoclimatology. Geological Society of America Bulletin, 82, 283-302.

Ruddiman, W.F. \& McIntyre, A. 1979. Warmth of the Subpolar North Atlantic Ocean During Northern Hemisphere Ice-Sheet Growth. Science, 204, 173-175.

Santarosa, A.C.A. 2007. Zoneamento Bioestratigráfico e Paleoclimático do Quaternário Superior em um testemunho da Bacia de Campos. Trabalho de conclusão de curso 
(Bacharelado em Oceanografia). Instituto Oceanográfico, Univ. de São Paulo, São Paulo, 25p.

Santarosa, A. C. A. 2010. Caracterização paleoceanográfica de um testemunho da Bacia de Santos com base em foraminíferos planctônicos durante o Holoceno. Dissertação de Mestrado, Inst. Oceanográfico, Univ. de São Paulo. 81 p.

Sarmiento, J.L., Slater, R., Barber, R., Bopp, L., Doney, S.C., Hirst, A.C., Kleypas, J., Matear, R., Mikolajewicz, U., Monfray, P., Soldatov, V., Spall, S.A., Stouffer, R. 2004. Response of ocean ecosystems to climate warming. Global Biogeochemical Cycles, 18, GB3003, doi: 10.1029/2003GB002134.

Schiebel, R., Waniek, J., Bork, M., Hemleben, C. 2001. Planktic foraminiferal production stimulated by chlorophyll redistribution and entrainment of nutrients. Deep-Sea Research I, 48, 721-740.

Shackleton, N. J. 1967. Oxygen isotope analyses and Pleistocene tempearture reassessed. Nature, 215, 15-17.

Shackleton, N. J. 1969. The last interglacial in the marine and terrestrial records, Proc. R. Soc. London, Ser. B, 174, 135- 154.

Shackleton, N. J.; Hall, M. A. 1984. Oxygen and carbon isotope stratigraphy of Deep Sea Drilling Project Hole 552A: Plio-Pleistocene glacial history. In Roberts, D. G., Schnitker, D., et al., (Eds.). Initial Reports DSDP, 81: Washington (U.S. Govt. Printing Office), 599-609.

Signorelli, N. T. 2013. Indirect investigations of the Atlantic Meridional Overturning changes in the South Atlantic Ocean in numerical models for the 20th century. Dissertação de Mestrado, Inst. Oceanográfico, Univ. de São Paulo. 135 p.

Soutelino, R. G. 2008. A origem da corrente do Brasil. Dissertação de Mestrado, Inst. Oceanográfico, Univ. de São Paulo. 101p.

Spero, H. J. e Lea, D. W. 2002. The Cause of Carbon Isotope Minimum Events on Glacial Terminations, Science, 296, 522-525.

Stramma, L; England, M. 1999. On the water masses and mean circulation of the South Atlantic Ocean. Journal of Geophysical Research, 104, C9, 20.863-20.883.

Sverdrup, H. U., Johnson M. W.; Fleming R. H. 1942 The Oceans: their physics, chemistry and general biology. Englewood Cliffs, Prentice- Hall Inc. 1087.

Toggweiler, J. R., Dixon, K. Broecker, W. S. 1991. The Peru upwelling and the ventilation of the south Pacific thermocline. Journal of Geophysical Research, 96: doi: 10.1029/91JC02063. ISSN: 0148-0227. 
Tokutake, L. R. 2005. Bioestratigrafia de Nanofósseis Calcários e Estratigrafia de Isótopos ( $\mathrm{C}$ e $\mathrm{O})$ do Talude médio, Quaternário, porção $\mathrm{N}$ da Bacia de Campos, ES. Dissertação de Mestrado. Universidade Federal do Rio Grande do Sul, Porto Alegre, RS. 96p.

Toledo, F.A.L. 2000. Variações Paleoceanográficas nos últimos 30.000 anos no oeste do Atlântico Sul: isótopos de oxigênio, assembléia de foraminíferos planctônicos e nanofósseis calcários. Tese de doutorado. Universidade federal do Rio Grande do Sul. 245 p.

Toledo, F.A.L.; Costa, K.B.; Pivel, M.A.G. 2007. Salinity changes in the western tropical South Atlantic during the last 30 kyr. Global. Planet. Change, 57: 383-395.

Tu, X.; Zheng, F.; Wang, J.; Cai, H.; Wang, P; Bühring, C.; Sarnthein, M. 2001. An abrupt cooling event early in the last interglacial in the northern South China Sea. Science in China, 44(10), 865-870.

Turley, C. 2002. The importance of "marine snow". Microbiology Today, 29, 177- 179.

Vicalvi, M.A. 1997. Zoneamento Bioestratigráfico e Paleoclimático dos sedimentos do Quaternário Superior do Talude da Bacia de Campos, RJ, Brasil. B. Geoci. PETROBRAS, Rio de Janeiro, 11 (1/2): 132-165.

Vicalvi, M.A. 2009. Distribuição estratigráfica quantitativa de foraminíferos planctônicos no quaternário da margem continental do sudeste brasileiro. PETROBRAS. Relatório Interno RT BPA 004/09, 12p.

Volat, J. L.; Pastouret, L.; Vernaud-Graggini, C. 1980. Dissolution and carbonate fluctuations in Pleistocene deep-sea cores: a review. Marine Geology, 34, 1-28.

Vuille, M., Werner, M. 2005. Stable isotopes in precipitation recording South American summer monsoon and ENSO variability: observations and model results. Climate Dynamics 25, 401-413.

Weatherly, G. L. 1993. On deep-current and hydrographic observations from a mudwave region and elsewhere in the Argentine basin. Deep-Sea Res. II, 40(4/5): 939-961.

Woillard, G. M. 1978. Grande Pile peat bog: A continuous pollen record for the last 140,000 years. Quaternary Research 9, 1-21.

Woillard, G. M. 1979. Abrupt end of the last interglacial s.s. in north-east France. Nature. 281, 558-562. 
Wylie, P. C. 1981. Ecologic Atlas of Benthic Foraminifera of the Gulf of Mexico: Hutchinson Ross Publishing Company. 174 p.

Zembruscki. S.G. 1979. Geomorfologia da margem continental sul Brasileira e das bacias oceânicas adjacentes. In: Projeto Petrobras REMAC. Petrobras,Rio de Janeiro, Série Projeto REMAC, 1979, v.7, p 129-177. 
Dissertação encaminhada à Comissão de Pós-Graduação do Instituto Oceanográfico da Universidade de São Paulo.

São Paulo, 01 de dezembro de 2013.

De acordo com o estabelecido neste documento, subscrevemo-nos:

Carla Nishizaki

Karen Badaraco Costa 